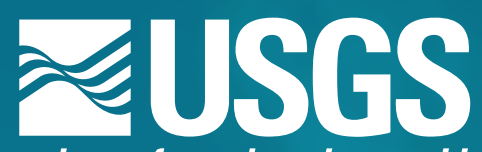

\title{
U.S. Geological Survey Environmental Health Science Strategy- Providing Environmental Health Science for a Changing World
}

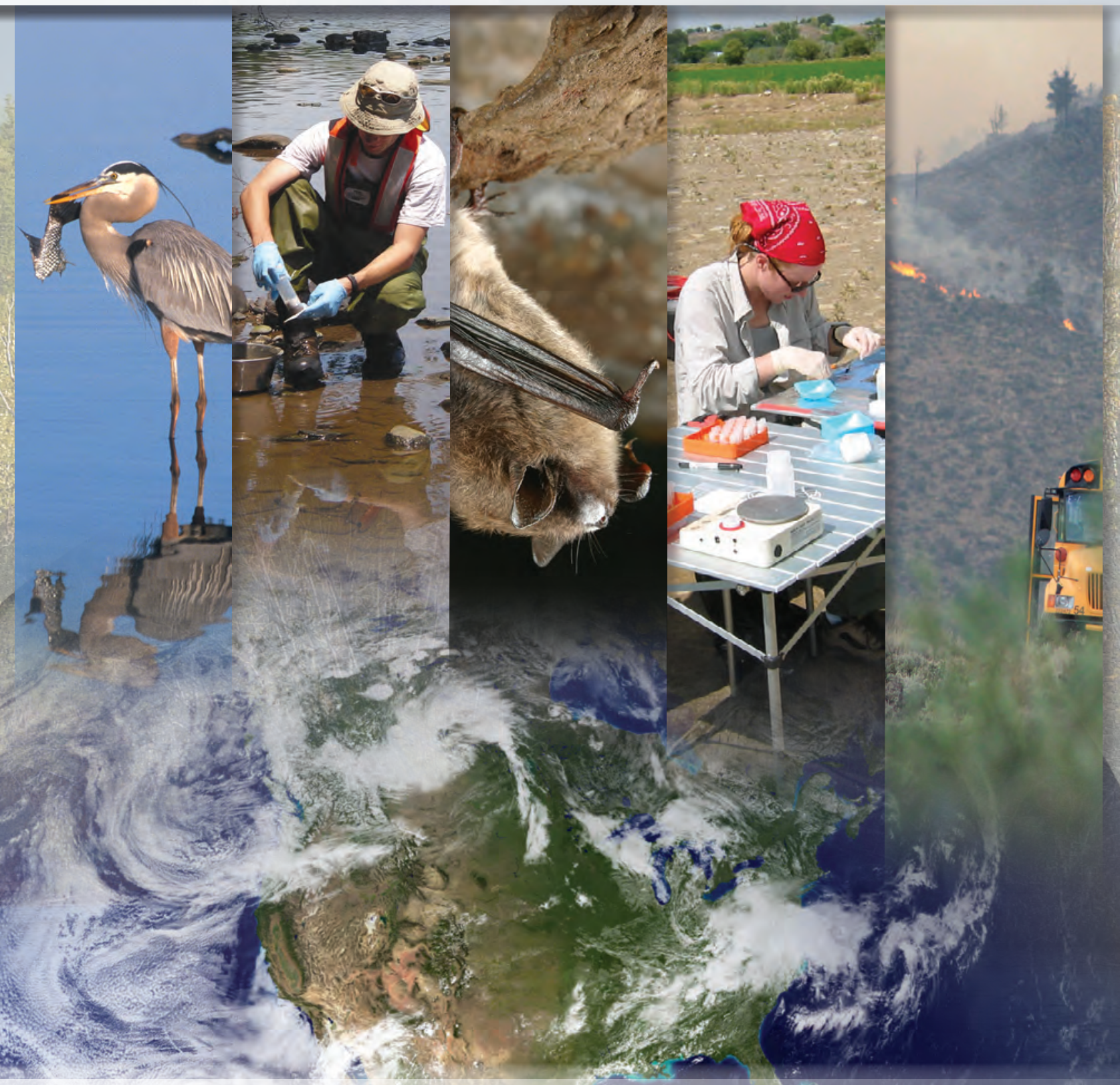

Circular 1383-E

U.S. Department of the Interior U.S. Geological Survey 


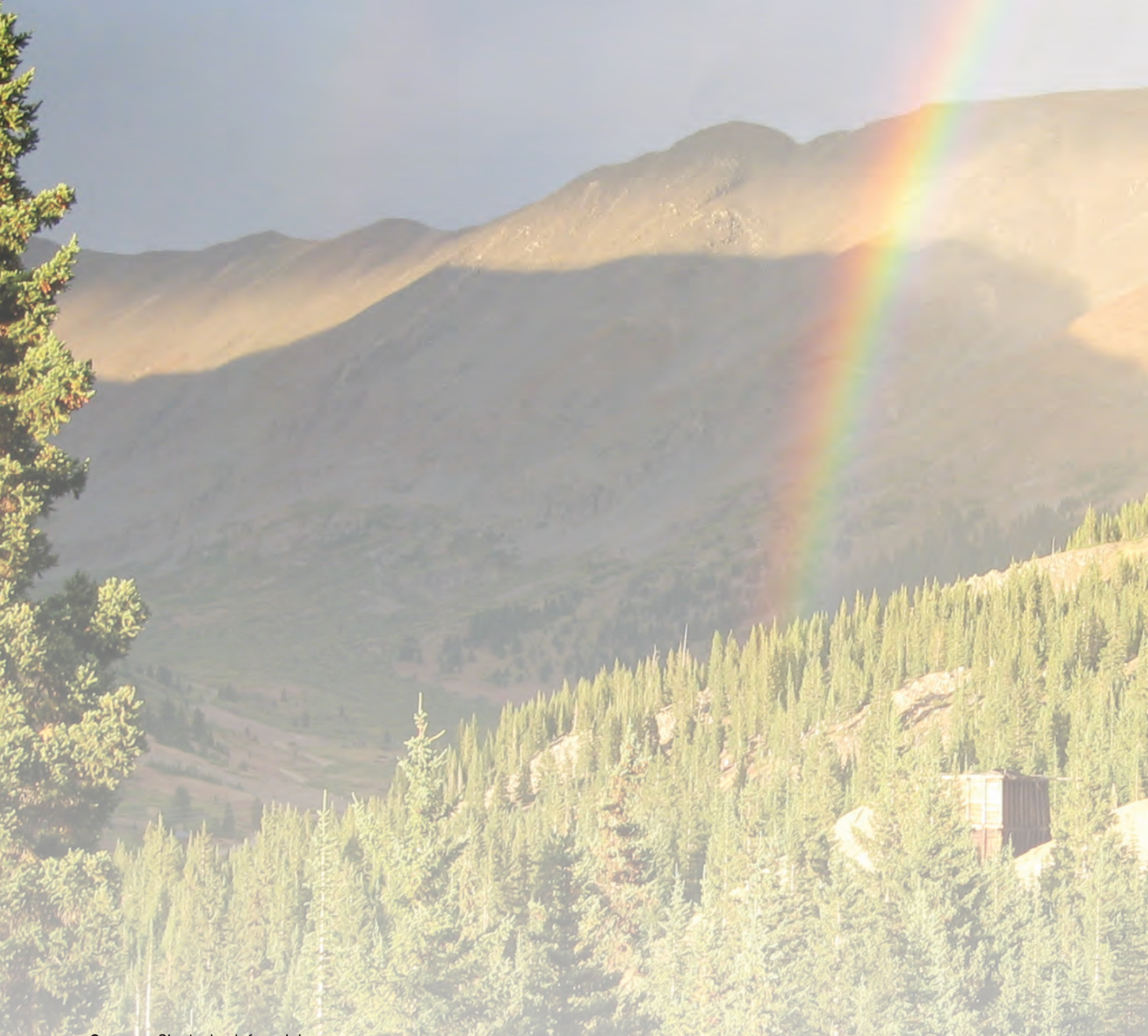

Cover. Clockwise left to right:

Great Blue Heron fishing in the Salton Sea. Photograph by Milton Friend (emeritus), U.S. Geological Survey (USGS). USGS scientist collecting an emerging-contaminants bed-sediment sample at the Susquehanna River at Danville, Pennsylvania. Photograph by Connie Loper, USGS.

Little Brown bat with fungal growth on muzzle. Photograph by Al Hicks, New York Department of Environmental Conservation. USGS researcher examining bass for abnormalities in Colorado. Photograph by USGS.

Squirrel Creek fire near Laramie, Wyoming. Photograph by Laura Hallberg, USGS.

The Blue Marble. Image by NASA Goddard Space Flight Center.

Cover background. Elwah River restoration project, Olympic National Park, Washington. Photograph by John McMillan, National Oceanic and Atmospheric Administration.

Inside cover. Headwaters drainage of Peru Creek, Colorado, and the upper workings of the Pennsylvania Mine. Photograph by Robert L. Runkel, USGS. 


\section{U.S. Geological Survey Environmental Health Science Strategy-Providing Environmental Health Science for a Changing World}

By Patricia R. Bright, Herbert T. Buxton, Laurie S. Balistrieri, Larry B. Barber, Francis H. Chapelle, Paul C. Cross, David P. Krabbenhoft, Geoffrey S. Plumlee, Jonathan M. Sleeman, Donald E. Tillitt, Patricia L. Toccalino, and James R. Winton

Circular 1383-E 


\section{U.S. Department of the Interior \\ KEN SALAZAR, Secretary \\ U.S. Geological Survey \\ Marcia K. McNutt, Director}

U.S. Geological Survey, Reston, Virginia: 2013

For more information on the USGS — the Federal source for science about the Earth, its natural and living resources, natural hazards, and the environment, visit http://www.usgs.gov or call 1-888-ASK-USGS.

For an overview of USGS information products, including maps, imagery, and publications, visit http://www.usgs.gov/pubprod

Any use of trade, product, or firm names is for descriptive purposes only and does not imply endorsement by the U.S. Government.

Although this report is in the public domain, permission must be secured from the individual copyright owners to reproduce any copyrighted materials contained within this report.

Suggested citation:

Bright, P.R., Buxton, H.T., Balistrieri, L.S., Barber, L.B., Chapelle, F.H., Cross, P.C., Krabbenhoft, D.P., Plumlee, G.S., Sleeman, J.M., Tillitt, D.E., Toccalino, P.L., and Winton, J.R., 2013, U.S. Geological Survey environmental health science strategy_-Providing environmental health science for a changing world: U.S. Geological Survey Circular 1383-E, $43 \mathrm{p}$. 


\section{Foreword}

In 2007, the U.S. Geological Survey (USGS) published a Bureau Science Strategy Facing Tomorrow's Challenges - U.S. Geological Survey Science in the Decade 2007-2017. It provided a view of the future, establishing science goals that reflected the USGS's fundamental mission in areas of societal impact such as energy and minerals, climate and land use change, ecosystems, natural hazards, environmental health, and water. Intended to inform long-term program planning, the strategy emphasizes how USGS science can make substantial contributions to the well-being of the Nation and the world.

In 2010, I realigned the USGS management and budget structure, changing it from a structure associated with scientific disciplines — Geography, Geology, Biology and Hydrology — to an issue-based organization along the lines of the Science Strategy. My aim was to align our management structure with our mission, our science priorities, our metrics for success, and our budget. An added benefit was that the USGS immediately appeared relevant to more Americans, and it became easier for those outside the agency to navigate our organizational structure to find where within the USGS they would find the solution to their problem. External partners rarely approached us with a problem in "geology," but they might need help with an issue in climate change or energy research.

The new organization is focused on seven science mission areas:

- Climate and Land Use Change

- Core Science Systems

- Ecosystems

- Energy and Minerals

- Environmental Health

- Natural Hazards

- Water

The scope of each of these new mission areas is broader than the science directions outlined in the USGS Science Strategy and together cover the scope of USGS science activities.

In 2010, I also commissioned seven Science Strategy Planning Teams (SSPTs) to draft science strategies for each USGS mission area. Although the existing Bureau Science Strategy could be a starting point for this exercise, the SSPTs had to go well beyond the scope of the existing document. What is of value and enduring from the work of the programs that existed under the former science disciplines needed to be reframed and reinterpreted under the new organization of the science mission areas. In addition, new opportunities for research directions have emerged in the five years since the Bureau Science Strategy was drafted, and exciting possibilities for cooperating and collaborating in new ways are enabled by the new mission focus of the organization.

Scientists from across the Bureau were selected for these SSPTs for their experience in strategic planning, broad range of experience and expertise, and knowledge of stakeholder needs and relationships. Each SSPT was charged with developing a long-term (10-year) science strategy that encompasses the portfolio of USGS science in the respective mission area. Each science strategy will reinforce others because scientific knowledge inherently has significance to multiple issues. Leadership of the USGS and the Department of the Interior will use the science vision and priorities developed in these strategies for program guidance, implementation planning, accountability reporting, and resource allocation. These strategies will guide science and technology investment and workforce and human capital strategies. They will inform our partners regarding opportunities for communication, collaboration, and coordination.

The USGS has taken a significant step toward demonstrating that we are ready to collaborate on the most pressing natural science issues of our day and the future. I believe a leadership aligned to support these issue-based science directions and equipped with the guidance provided in these new science strategies in the capable hands of our scientists will create a new era for USGS of which we can all be proud.

Marcia McNutt

Director 


\section{Contents}

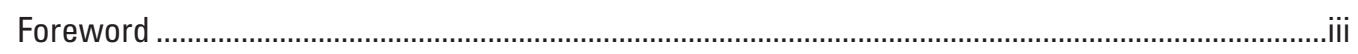

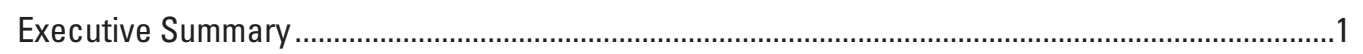

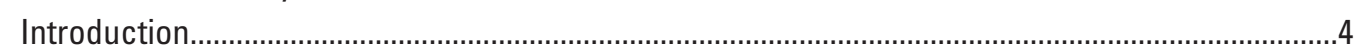

Environmental Health Challenges ...................................................................................

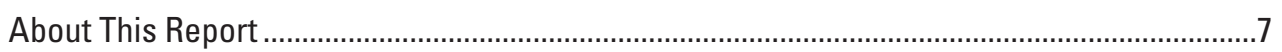

What is Environmental Health Science? …….................................................................

The USGS Role in Environmental Health Science ...............................................................

USGS Partner and Stakeholder Relationships..................................................................11

USGS Core Strengths, Capabilities, and Future Challenges to Core Strengths and

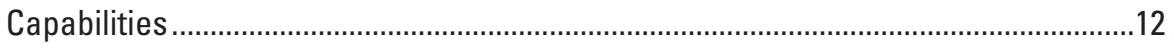

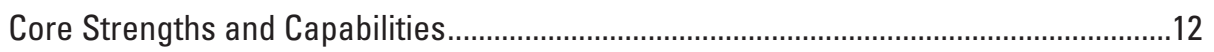

Future Challenges to Core Strengths and Capabilities.................................................13

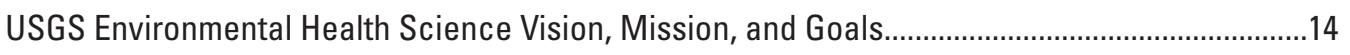

Identifying USGS Environmental Health Science Goals ....................................................14

Goal 1: Identify, Prioritize, and Detect Contaminants and Pathogens of Emerging

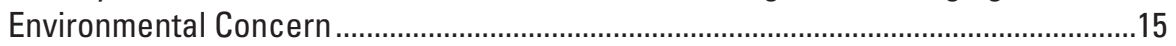

Priority Science Questions........................................................................................... 17

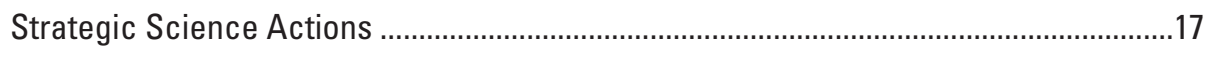

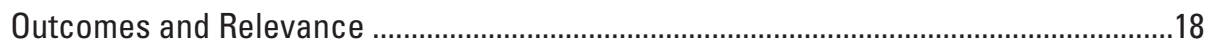

Goal 2: Reduce the Impact of Contaminants on the Environment, Fish and Wildlife, Domesticated Animals, and People ...................................................................19

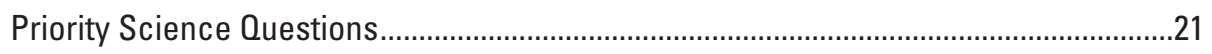

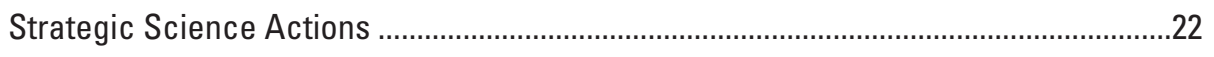

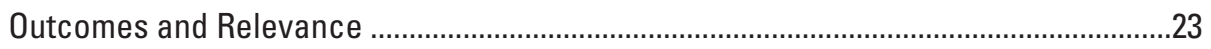

Goal 3: Reduce the Impact of Pathogens on the Environment, Fish and Wildlife, Domesticated Animals, and People ...........................................................................24

Priority Science Questions.............................................................................................24

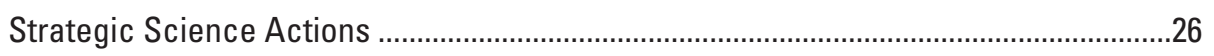

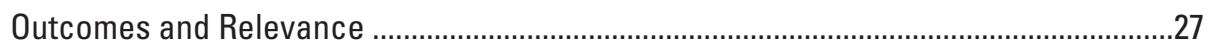

Goal 4: Discover the Complex Interactions Between, and Combined Effects of, Exposure to Contaminants and Pathogens ...............................................................28

Priority Science Questions..........................................................................................29

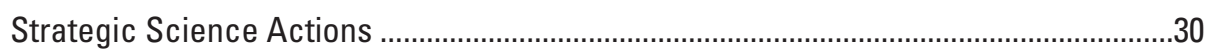

Outcomes and Relevance ......................................................................................... 
Goal 5: Prepare for and Respond to the Environmental Impacts and Related Health Threats of Natural and Anthropogenic Disasters..

Priority Science Questions..............................................................................................31

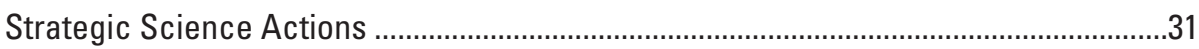

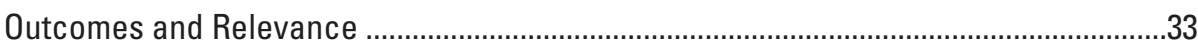

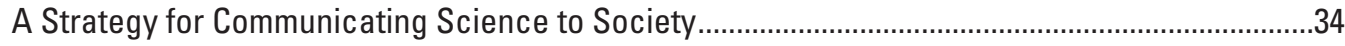

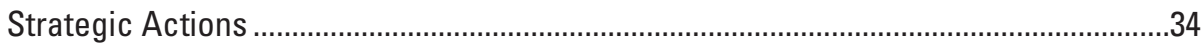

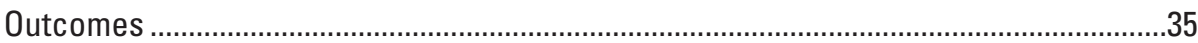

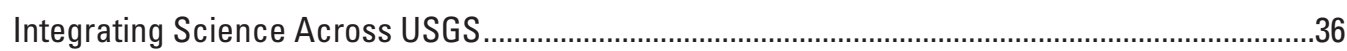

Summary of Intended Outcomes.............................................................................................

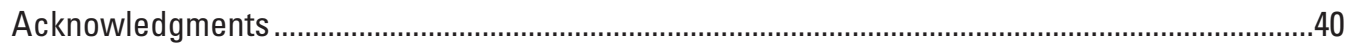

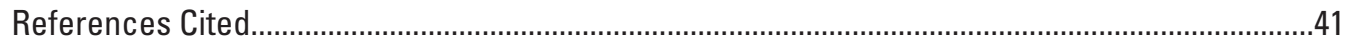

\section{Figures}

1. Diagram describing the relations among environmental drivers, exposure to disease agents (contaminants and pathogens) through various media and exposure pathways, and the complex responses to contaminant and pathogen exposure that result in environmental disease

2. Diagram depicting environmental health science as the study of the interrelations among the quality of the physical environment, the health of the living environment, and human health

3. Illustration showing the role of USGS in environmental health science, to provide scientific information and tools to environmental, natural resource, agricultural, and public health agencies for management and policy decisionmaking....

4. Illustration showing environmental contaminant source and transport pathways.

5. Illustration showing infectious disease transmission pathways

\section{Table}

1. Agents of environmentally driven disease, exposure and transmission pathways, and corresponding examples of diseases. 


\section{Highlights}

Earth Materials, Natural Earth Processes, and Environmental Health

Why USGS?

Native American Communities in Alaska are Inseparably Linked to Their

Surrounding Natural Resources.

Providing Information About Potential Exposures to Chemicals in

Drinking Water...

USGS Laboratories Are OIE Collaborating Centre and Reference

Laboratories

Manufacturing Facilities Found to Release Pharmaceuticals into the

Environment.

Viral Hemorrhagic Septicemia Virus in the Great Lakes...........................................15

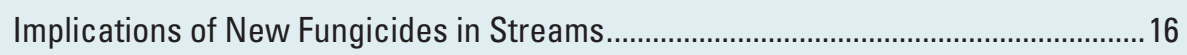

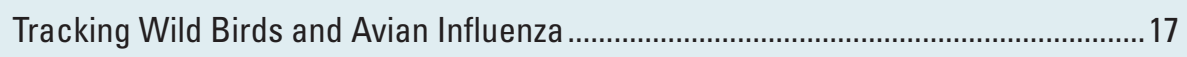

Endocrine Disruption in Fish Populations ...............................................................20

Anthropogenic Sources of Mercury and Methylmercury Identified in the North Pacific Ocean

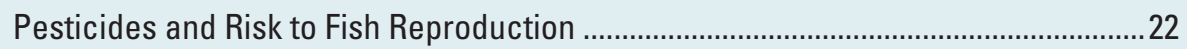

Brucellosis in Wildlife and Livestock........................................................................2 24

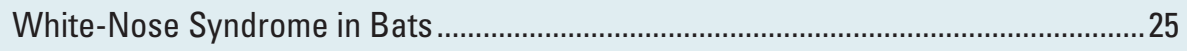

Reduction of Bacterial Kidney Disease (BKD) in Chinook Salmon...............................26

Effects of Plague on Wildlife May Have Been Underestimated ...................................27

Endocrine Disruption of Immune Function in Fish......................................................28

Antimicrobial Resistance in the Natural Environment .................................................29

Responding to Recent Wildfires and Their Potential Environmental

Health Risks.

U.S.-Mexico Border Health Initiative and Environmental Health-Risk

Assessment Along the Upper Santa Cruz River ................................................34

Uranium Production and Environmental Health ..........................................................36

Sensitivity of Freshwater Mussels to Ammonia Results in Lower Water-Quality Criteria.. 


\section{Abbreviations}

$\begin{array}{ll}\text { ARG } & \text { antibiotic resistance genes } \\ \text { AVMA } & \text { American Veterinary Medical Association } \\ \text { BEHI } & \text { Border Environmental Health Initiative } \\ \text { BKD } & \text { bacterial kidney disease } \\ \text { CCD } & \text { colony collapse disorder } \\ \text { DOI } & \text { Department of Interior } \\ \text { EDC } & \text { endocrine disrupting chemicals } \\ \text { GAO } & \text { Government Accountability Office } \\ \text { HIV/AIDS } & \text { human immunodeficiency virus/acquired immunodeficiency syndrome } \\ \text { HPAI } & \text { highly pathogenic avian influenza (H5N1) } \\ \text { IOM } & \text { Institute of Medicine } \\ \text { NIEHS } & \text { National Institute of Environmental Health Sciences } \\ \text { OIE } & \text { World Organisation for Animal Health } \\ \text { ppb } & \text { parts per billion } \\ \text { SARS } & \text { Severe acute respiratory syndrome } \\ \text { SMB } & \text { small mouth bass } \\ \text { SSPT } & \text { Science Strategy Planning Team } \\ \text { Hg/L } & \text { micrograms per liter } \\ \text { USDA } & \text { U.S. Department of Agriculture } \\ \text { U.S. EPA } & \text { U.S. Environmental Protection Agency } \\ \text { USGS } & \text { U.S. Geological Survey } \\ \text { VHSV } & \text { viral hemorrhagic septicemia virus } \\ \text { WHO } & \text { World Health Organization } \\ \text { WNS } & \text { white-nose syndrome } \\ \text { WOC } & \text { National Water Quality Criteria } \\ & \end{array}$


Lake Michigan near Sheboygan, Wisconsin, on a calm morning while USGS scientists sample dead and dying fish for viral hemorrhagic septicemia. Photograph by Gael Kurath, USGS. 


\title{
U.S. Geological Survey Environmental Health Science Strategy-Providing Environmental Health Science for a Changing World
}

\author{
By Patricia R. Bright, Herbert T. Buxton, Laurie S. Balistrieri, Larry B. Barber, Francis H. Chapelle,
} Paul C. Cross, David P. Krabbenhoft, Geoffrey S. Plumlee, Jonathan M. Sleeman, Donald E. Tillitt,

Patricia L. Toccalino, and James R. Winton

\section{Executive Summary}

America has an abundance of natural resources. We have bountiful clean water, fertile soil, and unrivaled national parks, wildlife refuges, and public lands. These resources enrich our lives and preserve our health and wellbeing. These resources have been maintained because of our history of respect for their value and an enduring commitment to their vigilant protection. Awareness of the social, economic, and personal value of the health of our environment is increasing. The emergence of environmentally driven diseases caused by exposure to contaminants and pathogens is a growing concern worldwide. New health threats and patterns of established threats are affected by both natural and anthropogenic changes to the environment. Human activities are key drivers of emerging (new and re-emerging) health threats. Societal demands for land and natural resources, quality of life, and economic prosperity lead to environmental change. Natural earth processes, climate trends, and related climatic events will compound the environmental impact of human activities. These environmental drivers will influence exposure to disease agents, including viral, bacterial, prion, and fungal pathogens, parasites, synthetic chemicals and substances, natural earth materials, toxins, and other biogenic compounds.

The U.S. Geological Survey (USGS) defines environmental health science broadly as the interdisciplinary study of relations among the quality of the physical environment, the health of the living environment, and human health. The interactions among these three spheres are driven by human activities, ecological processes, and natural earth processes; the interactions affect exposure to contaminants and pathogens and the severity of environmentally driven diseases in animals and people. This definition provides USGS with a framework for synthesizing natural science information from across the
Bureau and providing it to environmental, natural resource, agricultural, and public health managers.

USGS specializes in science at the environment-health interface, by characterizing the processes that affect the interaction among the physical environment, the living environment, and people, and the resulting factors that affect ecological and human exposure to disease agents. The USGS is a Federal science agency with a broad range of natural science expertise relevant to environmental health. USGS provides scientific information and tools as a scientific basis for management and policy decisionmaking.

This report describes a 10-year strategy that encompasses the portfolio of USGS environmental health science. It summarizes national environmental health priorities that USGS is best suited to address, and will serve as a strategic framework for USGS environmental health science goals, actions, and outcomes for the next decade. Implementation of this strategy is intended to aid coordination of USGS environmental health activities and to provide a focal point for disseminating information to stakeholders.

The "One Health" paradigm advocated by the World Health Organization (WHO; World Health Organization, 2011), and the American Veterinary Medical Association (AVMA; American Veterinary Medical Association, 2008), among others, is based on a general recognition that the health of humans, animals, and the environment are inextricably linked. Thus, successful efforts to protect that health will require increased interdisciplinary research and increased communication and collaboration among the broader scientific and health community. This strategy is built upon that paradigm. 
The vision, mission, and five cornerstone goals of the USGS Environmental Health Science Strategy were developed with substantial input from a wide range of stakeholders.

Vision-The USGS is a premier source of the environmental health science needed to safeguard the health of the environment, fish and wildlife, domesticated animals, and people.

Mission-The mission of USGS in environmental health science is to contribute scientific information to environmental, natural resource, agricultural, and public health managers, who use that information to support sound decisionmaking. USGS will provide science to achieve the following societal goals:

- Goal 1: Identify, prioritize, and detect contaminants and pathogens of emerging environmental concern.

- Goal 2: Reduce the impact of contaminants on the environment, fish and wildlife, domesticated animals, and people.

- Goal 3: Reduce the impact of pathogens on the environment, fish and wildlife, domesticated animals, and people.

- Goal 4: Discover the complex interactions between, and combined effects of, exposure to contaminants and pathogens.

- Goal 5: Prepare for and respond to the environmental impacts and related health threats of natural and anthropogenic disasters.

Goals 1 through 4 are intended to provide science to address environmental health threats in a logical order, from informing prevention and preparedness, to supporting systematic management response to environmental health issues. Goal 4 addresses the interaction among contaminants and pathogens, an issue of emerging concern in environmental health science. Goal 5 acknowledges the fact that natural and anthropogenic disasters (for example, earthquakes, volcanic eruptions, floods, droughts, fires, industrial accidents, oil spills, acts of terrorism, and pandemics) can cause immediate and prolonged adverse environmental health threats.

This strategy proposes that USGS take the following strategic science actions to achieve each of the five goals of this strategy:

Goal 1: Identify, prioritize, and detect contaminants and pathogens of emerging environmental concern.

- Strategic Science Action 1.-Prioritize contaminants and pathogens of emerging concern to guide research, detection, and management activities.
- Strategic Science Action 2.-Conduct research, surveillance, and monitoring to provide early warning of emerging health threats.

- Strategic Science Action 3.-Develop approaches and tools that identify vulnerable environmental settings, ecosystems, and species.

Goal 2: Reduce the impact of contaminants on the environment, fish and wildlife, domesticated animals, and people.

- Strategic Science Action 1.-Systematically characterize the sources, occurrence, transport and fate of environmental contaminants to guide efforts to manage and mitigate contamination.

- Strategic Science Action 2.-Evaluate the threat of environmental contamination to the health of the environment, fish and wildlife, domesticated animals, and people, and inform the associated management and protection efforts.

- Strategic Science Action 3.-Characterize potential human exposure to support establishment of health standards and contamination-reduction efforts.

Goal 3: Reduce the impact of pathogens on the environment, fish and wildlife, domesticated animals, and people.

- Strategic Science Action 1.-Determine the biotic and abiotic factors that control the ecology of infectious diseases in natural populations of aquatic and terrestrial species and potential transmission to other animals and humans.

- Strategic Science Action 2.-Establish how natural and anthropogenic environmental changes affect the distribution and severity of infectious diseases in natural populations of aquatic and terrestrial species and potential transmission to other animals and humans.

- Strategic Science Action 3.-Develop surveillance systems to identify changing patterns of disease activity in priority geographic areas.

Goal 4: Discover the complex interactions between, and combined effects of, exposure to contaminants and pathogens.

- Strategic Science Action 1.--Identify how exposure to one class of disease agents (contaminants or pathogens) can make an organism more susceptible to adverse effects from exposure to the other class of disease agents.

- Strategic Science Action 2.--Implement interdisciplinary studies that characterize the effects of combined exposure to pathogens and contaminants. 


\section{Introduction}

\section{Environmental Health Challenges}

America has an abundance of natural resources. We have bountiful clean water, fertile soil, and unrivaled national parks, wildlife refuges, and public lands. These resources enrich our lives and preserve our health and wellbeing. These resources have been maintained because of our history of respect for their value and an enduring commitment to their vigilant protection. Awareness of the social, economic, and personal value of the health of our environment is increasing. The emergence of environmentally driven diseases caused by environmental exposure to contaminants and pathogens is a growing concern worldwide. New health threats and patterns of established threats are affected by both natural and anthropogenic changes to the environment. Human activities are key drivers of emerging (new and re-emerging) health threats. Societal demands for land and natural resources, quality of life, and economic prosperity, lead to environmental change.

Natural earth processes (such as erosion and weathering), climate trends, and related climatic events will compound the environmental impact of human activities. These environmental drivers will influence exposure to disease agents including viral, bacterial, prion, and fungal pathogens, parasites, synthetic chemicals and substances, natural earth materials, toxins and other biogenic compounds (fig. 1). Environmental drivers, such as climate change, may also affect an organism's sensitivity to contaminants in the environment (Stahl and others, 2013). Organisms can be exposed to environmental contamination through multiple routes of exposure (consumption, inhalation, contact) and in many forms (drinking water, food, air, soil, sediment, dusts, and other aerosols), which are affected by contaminant occurrence and distribution in the environment (table 1). Similarly, pathogens spread in the environment and via other living organisms, and are transmitted to other organisms or people via host-to-host transmission, vector-borne transmission, or environmental exposure (table 1).
Environmentally driven diseases are referred to herein as diseases that are caused by exposure to contaminants (toxicologic disease) or pathogens (infectious disease) and are significantly influenced by environmental factors.

Changes in the use, handling, and disposal of chemical wastes affects the environment, the health of fish and wildlife, and human health by affecting the quality of the air (and dust) we breathe, the water we drink, the soil we till, and the food we eat. Other human-induced alterations such as changes in land use and increasing urbanization alter fish and wildlife habitats and ultimately species diversity. The increasing spatial interconnections between human communities and natural and disturbed ecosystems enhance the risk of transmission of zoonotic diseases from wildlife to people. Weathering, runoff of natural and disturbed landscapes, windblown particulates, and dissolution of harmful minerals in rocks and aquifers, as well as the environmental disruption from natural hazards increase the potential for exposure to contaminants and pathogens. New approaches to meet the increasing demands for food, water, energy, and other resources can introduce more contamination to the environment and increase exposure to contaminants and pathogens. Furthermore, unprecedented increases in international travel and trade, as well as climate change, further complicate efforts to protect the health of the environment, fish and wildlife, domesticated animals, and people.

An environmental driver is any natural or human induced factor that directly or indirectly causes a change in the environment.

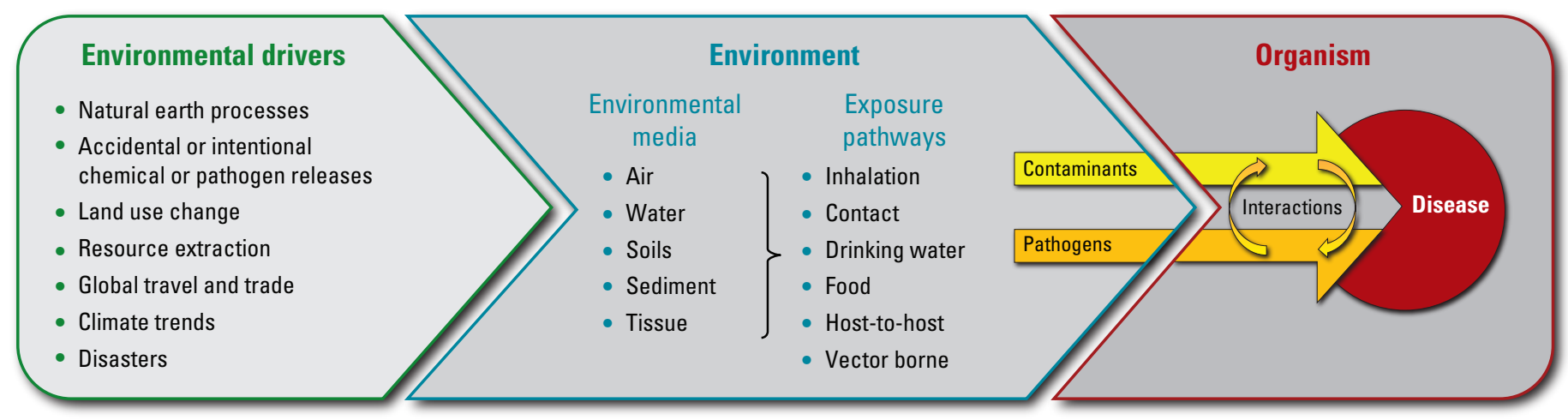

Figure 1. The relations among environmental drivers, exposure to disease agents (contaminants and pathogens) through various media and exposure pathways, and the complex responses to contaminant and pathogen exposure that result in environmental disease. 
A WHO study determined that an estimated 24 percent of the global burden of disease and 23 percent of all global deaths can be attributed to environmental factors (Prüss-Ütün and Corvalán, 2006). The threat of contaminants to the health of the environment and public health is widely acknowledged. The National Institute of Environmental Health Sciences (NIEHS) stated "Experience tells us that virtually all human diseases can be caused, modified, or altered by environmental agents," where they describe environmental agents as pollutants and chemicals, commercial products we use that enter our environment, and naturally occurring toxins (National Institute of Environmental Health Sciences, 2006). Only a small fraction of the 80,000 chemicals in use in the United States today have been tested for safety according to the 2008-2009 Annual Report of the President's Cancer Panel. They said

"A growing body of research documents myriad established and suspected environmental factors linked to genetic, immune, and endocrine dysfunction that can lead to cancer and other diseases. ... the consequences of cumulative lifetime exposures to known carcinogens and the interaction of specific environmental contaminants remain largely unstudied" (President's Cancer Panel, 2010).

Table 1. Agents of environmentally driven disease, exposure and transmission pathways, and corresponding examples of diseases.

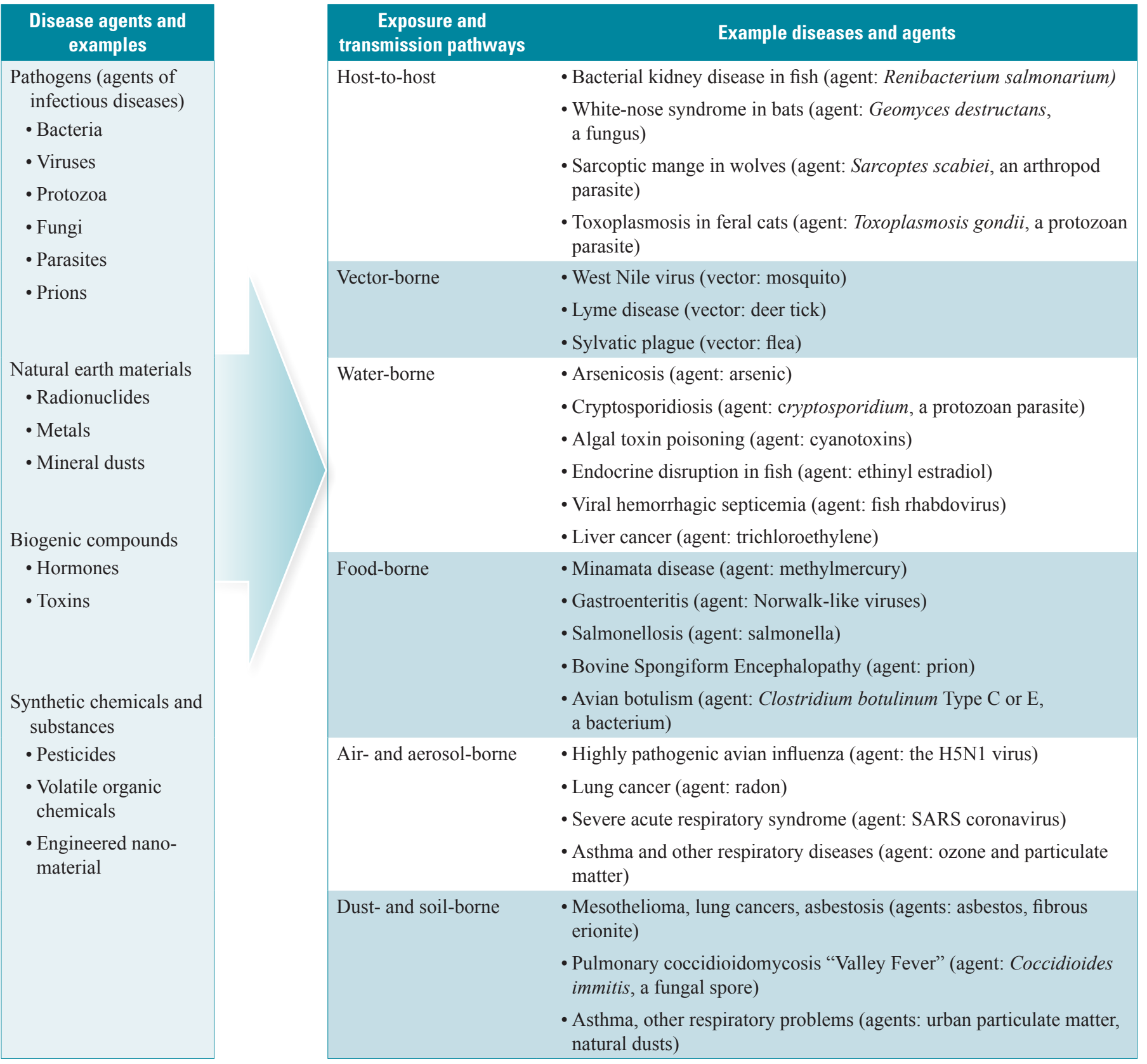


Pathogens are biological agents, including bacteria, viruses, protozoa, fungi, parasites, and prions, that cause harmful effects to humans or other living organisms.

Continued increases in the types and number of contaminants and limited understanding of the mechanisms by which contaminants can cause adverse health effects are challenges to continued efforts to safeguard environmental health. Environmental release of engineered nanomaterial is an example of a new type of contaminant; new approaches and methods are needed to measure their presence in the environment and to assess their potential ecological and human health effects (National Science and Technology Council, 2008). Scientists are reevaluating current approaches for assessing risk and the potential health outcomes associated with exposure to environmental contaminants (Birnbaum, 2012). New challenges include defining the potential health effects of chronic exposures to extremely low (sub part-per-billion) concentrations, potential increased vulnerability of some populations such as the elderly or early life stages, the fact that exposures in early life stages can cause impacts much later in life or in subsequent generations, and exposure to mixtures of environmental contaminants that have unknown combined effects. The effect of endocrine-disrupting chemicals (EDCs) on exposed organisms is an example of the need for improved understanding of the mechanisms by which contaminants affect organisms (Vandenberg and others, 2012). EDCs increasingly are being recognized as serious environmental health threats, and in their first Scientific Statement, the Endocrine Society implicated EDCs as a significant concern to public health (Diamanti-Kandarakis and others, 2009).

Like contaminants, pathogens threaten the health and security of the Nation and its resources. Of particular concern are pathogens that can lead to global pandemics, and they are featured prominently in the National Security Strategy (The White House, 2010), the National Response Framework (Department of Homeland Security, 2008), and the National Health Security Strategy (Department of Health and Human Services, 2009). Most pathogens that infect humans are of animal origin (zoonotic) (Woolhouse and Gowtage-Sequeria, 2005); the Institute of Medicine (IOM) stated "The significance of zoonoses in the emergence of human infections cannot be overstated" (Lederberg and others, 1992). Virtually all of the major pandemics to date have been caused by zoonotic diseases, including the Black Death, Spanish influenza, and HIV/AIDS (Morens and others, 2008). Between 1940 and 2004, more than 60 percent of emerging infectious diseases were zoonotic; more than 70 percent of these originated in wildlife (Jones and others, 2008). Many emerging diseases, such as Ebola, HIV/AIDS, Lyme disease, Severe Acute Respiratory Syndrome (SARS), and highly pathogenic avian
Contaminants are physical or chemical agents, including minerals, chemicals, toxins, and radionuclides, that are present where they do not naturally occur or at concentrations above those that occur naturally, and may cause harmful effects to humans or other living organisms.

influenza (HPAI) had their genetic origins in wildlife (Friend, 2006). Many zoonotic disease outbreaks are evident in wild animal populations before they affect people or domesticated animals. Therefore, wildlife health and disease monitoring serve as early warning indicators of environmental and ecosystem health and are essential to any information system designed to protect human health. Increasing coordination among wildlife, domesticated animal, and human health agencies will improve our ability to understand the potential for cross-species transmission (Jerolmack, 2012).

Diseases can no longer simply be regarded as natural regulators of wild populations; they often pose a serious threat to fish and wildlife conservation, an increasing challenge for natural resource management, and may threaten the health of humans and domesticated animals. Numerous endangered species are threatened by disease. For example, chytridiomycosis, caused by an emerging fungal pathogen, has resulted in global extinction of amphibian species, and continues to jeopardize the persistence of a number of species. In addition, the impacts of disease on populations of common species may result in major losses to ecosystem services on which we depend. White-nose syndrome in bats, for instance, has resulted in dramatic declines of insectivorous species that control important pests. The loss of these natural insect predators may result in damage to crops and forestry products, increased use of insecticides, and negatively impact the economy.

The scientific community increasingly is acknowledging the complex interaction within organisms of exposure to both contaminants and pathogens, and considering implications for the health of an organism, of populations, and of sensitive subpopulations. Figure 1 describes how environmental drivers influence the environment, human and ecological exposure to disease agents, and ultimately the complex responses from exposure to contaminants and pathogens that result in disease.

The "One Health" paradigm, advocated by the WHO (World Health Organization, 2011) and the AVMA (American Veterinary Medical Association, 2008) among others, is based on recognition by the scientific community that the health of humans, the health of animals, and the quality of the environment are inextricably linked. Thus, successful health protection will require increased interdisciplinary research and increased communication and collaborations among the broader scientific community. This strategy is built upon that paradigm. 


\section{Earth Materials, Natural Earth Processes, and Environmental Health}

Many earth materials have been linked definitively to, or blamed (in some cases incorrectly) for adverse environmental health impacts. These include natural earth materials (such as volcanic ash and gases, desert dusts, bedrock sources of arsenic or other contaminants in drinking water), and earth materials extracted for use by society (such as historic mine wastes, fossil fuel combustion byproducts, commercial asbestos). The distribution, exposure pathways, and toxicity of these and many other natural and anthropogenic contaminants can be significantly modified by natural earth processes such as wind transport, water transport, and biogeochemical reactions. USGS earth scientists routinely collaborate with biologists, ecologists, and public health scientists to help characterize ecosystem and human exposures to earth materials and other potential contaminants, understand the influence of earth processes on distributions and toxicity of contaminants, and evaluate whether or not contaminants actually pose a health risk in given situations. Photograph courtesy of Marith Reheis, USGS, shows dusts emanating from Cadiz Dry Lake, California. More information is available online at $h$ ttp://health.usgs.gov.

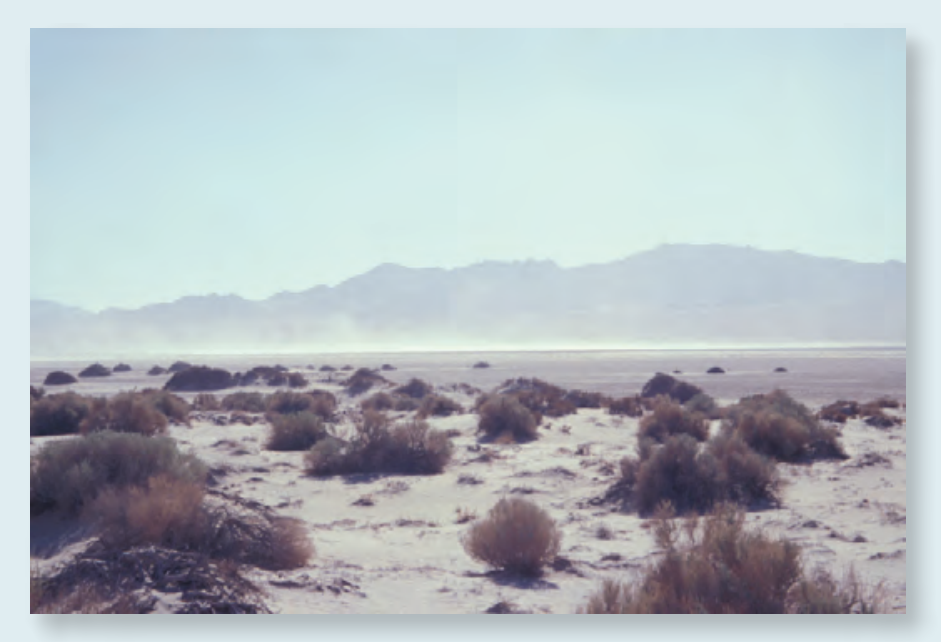

\section{About This Report}

This report describes a 10-year strategy that encompasses USGS environmental health science activities. It summarizes national environmental health priorities that the USGS is best suited to address, and will serve as a strategic framework for USGS environmental health goals, actions, and outcomes for the next decade. The strategy is intended to improve coordination of environmental health science activities across the USGS, and facilitate the dissemination of information to stakeholders. It identifies internal and external partnerships that are critical to advancing environmental health science. It will be used by USGS leadership in science planning and execution, and as a basis for budget initiatives, national guidance, and regional implementation strategies.

In 2010, the USGS realigned its organizational structure by establishing seven issue-based mission areas around which USGS science activities are organized:

- Climate and Land Use Change

- Core Science Systems

- Ecosystems

- Energy and Mineral Resources

- Environmental Health

- Natural Hazards

- Water
These mission areas build on the broad science themes outlined in the USGS 10-year Bureau-wide science strategy: Facing Tomorrow's Challenges-U.S. Geological Survey Science in the Decade 2007-2017 (U.S. Geological Survey, 2007). This Environmental Health strategy is based specifically on the chapter titled The Role of the Environment and Wildlife in Human Health. This strategy also provides a foundation for USGS support of the Department of the Interior (DOI) Strategic Plan (U.S. Department of the Interior, 2010).

With the establishment of the Environmental Health Mission Area, for the first time, the USGS has a focal point that helps integrate diverse environmental health science activities from across the USGS. This new mission area builds upon USGS core responsibilities related to environmental contamination and infectious diseases in fish, wildlife, and people.

In November 2010, the Director of the USGS commissioned a Science Strategy Planning Team to develop an Environmental Health Science Strategy that encompasses the portfolio of USGS environmental health science activities for the next decade (McNutt, 2010). The Team included scientists from across USGS with expertise in a wide range of environmental health fields, from infectious diseases of fish and wildlife, to environmental sources, occurrence, and adverse impacts of natural and anthropogenic contaminants. The Team defined a broad range of USGS contributions to environmental health science, and incorporated input from numerous USGS scientists and managers, partners, and the public. 


\section{What is Environmental Health Science?}

The USGS defines environmental health science as the interdisciplinary study of relations among the quality of the physical environment, the health of the living environment, and human health (fig. 2).

- The quality of the physical environment includes the physical, chemical, and aesthetic characteristics of both natural environments (including those affected by human activities) and built environments (such as homes and workplaces).

- The health of the living environment reflects the health of all organisms from microbes to fish, wildlife, and plants.

- People's health and wellbeing are affected by both the quality of the physical environments and the health of the other living organisms with which they interact.

The quality of our physical environment, the health of our living environment, and human health are inextricably linked. The interactions among these three spheres are driven by human activities, ecological processes, and natural earth processes. These interactions affect exposure to contaminants and pathogens and the severity of environmentally driven diseases in animals and people. Changes in the environment affect the health of people and wild and domesticated animals. Changes in the health and abundance of wild and domesticated animals affect human health and wellbeing. The significance of these interactions to environmental health along with the need for increased collaboration across disciplines increasingly is being acknowledged by public- and animal-health professionals, conservationists, and environmental scientists. USGS specializes in science at the environment-health interface, by characterizing the processes that affect the interaction among the physical environment, the living environment, and people, and the resulting factors that affect ecological and human exposure to disease agents (fig. 2).

There are many definitions of environmental health; the definitions vary based on the perspectives and responsibilities of the authors. A value of the broad definition of environmental health science presented herein is that it provides USGS with a framework for synthesizing natural science information from across the Bureau and providing it to environmental, natural resource, agricultural, and public health managers, regulators, and scientists.

A major implication of this definition is the integration of the study of infectious and toxicologic disease. The definition acknowledges the need to consider how contaminants and pathogens interact to affect an organism's health (fig. 1). The need for such integration is recognized in the environmental health science community (Feingold and others, 2010).

\section{The USGS Role in Environmental Health Science}

The USGS is a non-management, non-regulatory science agency within the DOI. The Bureau provides impartial and reliable scientific information on the conditions and health of ecosystems and the environment, on our natural resources, and on potential hazards that affect people. The role of USGS in environmental health science is providing scientific information and tools to environmental, natural resource, agricultural, and public health managers. The information and tools are used as a scientific basis for management and policy decisionmaking (fig. 3). In its current strategic plan, DOI states:

"Science is a key component of the Department of the Interior mission. The U.S. Geological Survey serves as the Department's primary science organization ... Science is an essential, cross-cutting element that assists bureaus in land and resource management and regulation. Department science also reaches beyond the boundaries of Interior lands and the United States. ... products are available worldwide to provide credible, applicable, unbiased information to inform decisionmaking related to ecosystems, climate change, land use change, energy and mineral assessments, environmental health, natural hazards, and water resources." (U.S. Department of the Interior, 2010).

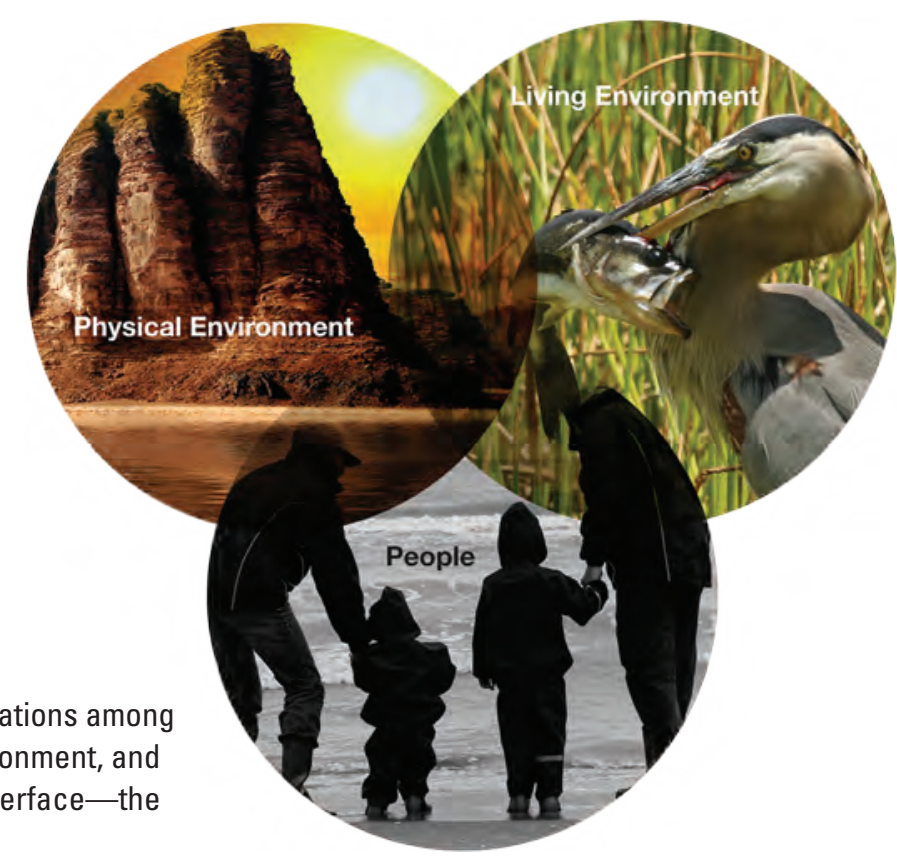

Figure 2. Environmental health science as the study of the interrelations among the quality of the physical environment, the health of the living environment, and human health. USGS science focuses on the environment-health interface-the interactions among these three spheres. 
The role of USGS in environmental health science is to provide scientific information and tools to environmental, natural resource, agricultural, and public health managers. The information and tools are used as a scientific basis for management and policy decisionmaking.
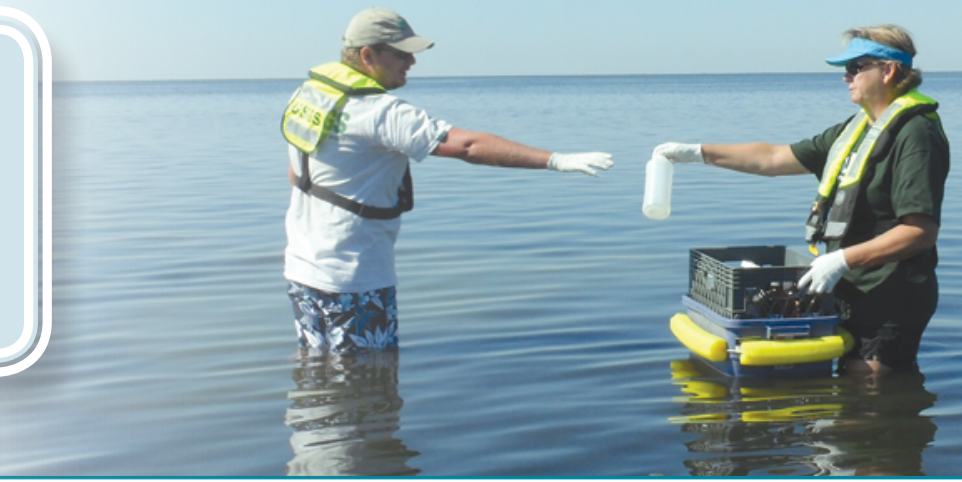

USGS environmental health science activities (1) are at the forefront of identifying wild animal disease reservoirs and the sources of emerging contaminants; (2) monitor the quality of the environment and the health wildlife at local, regional, and national scales; (3) synthesize critical knowledge about wild animal disease transmission (including to domesticated animals and humans); (4) identify the environmental properties and ecological effects of natural and anthropogenic contaminants; (5) characterize potential human exposure to contaminants via drinking and recreational water, air, dust, soil, and sediment; (6) evaluate bioaccumulation and toxicity of contaminants to fish and wildlife; and (7) provide capabilities for geographic analysis and interpretation of environmental data. These agency activities are the foundation of USGS environmental health science.
USGS scientists collected environmental data and samples in coastal areas affected by the 2010 Deepwater Horizon oil spill in the Gulf of Mexico. Photograph by Lori Lewis, USGS.
Although the USGS does not have a direct public health mission, information from these activities contributes directly to the work of partner agencies responsible for safeguarding public health, as well as the health of domesticated animals. USGS science is useful for defining human exposure to zoonotic and vector-borne diseases, parasites, harmful earth materials, synthetic chemicals and substances, and biogenic contaminants. Fish and wildlife can act as sentinels that provide valuable insight into threats to human and domesticated animal health.

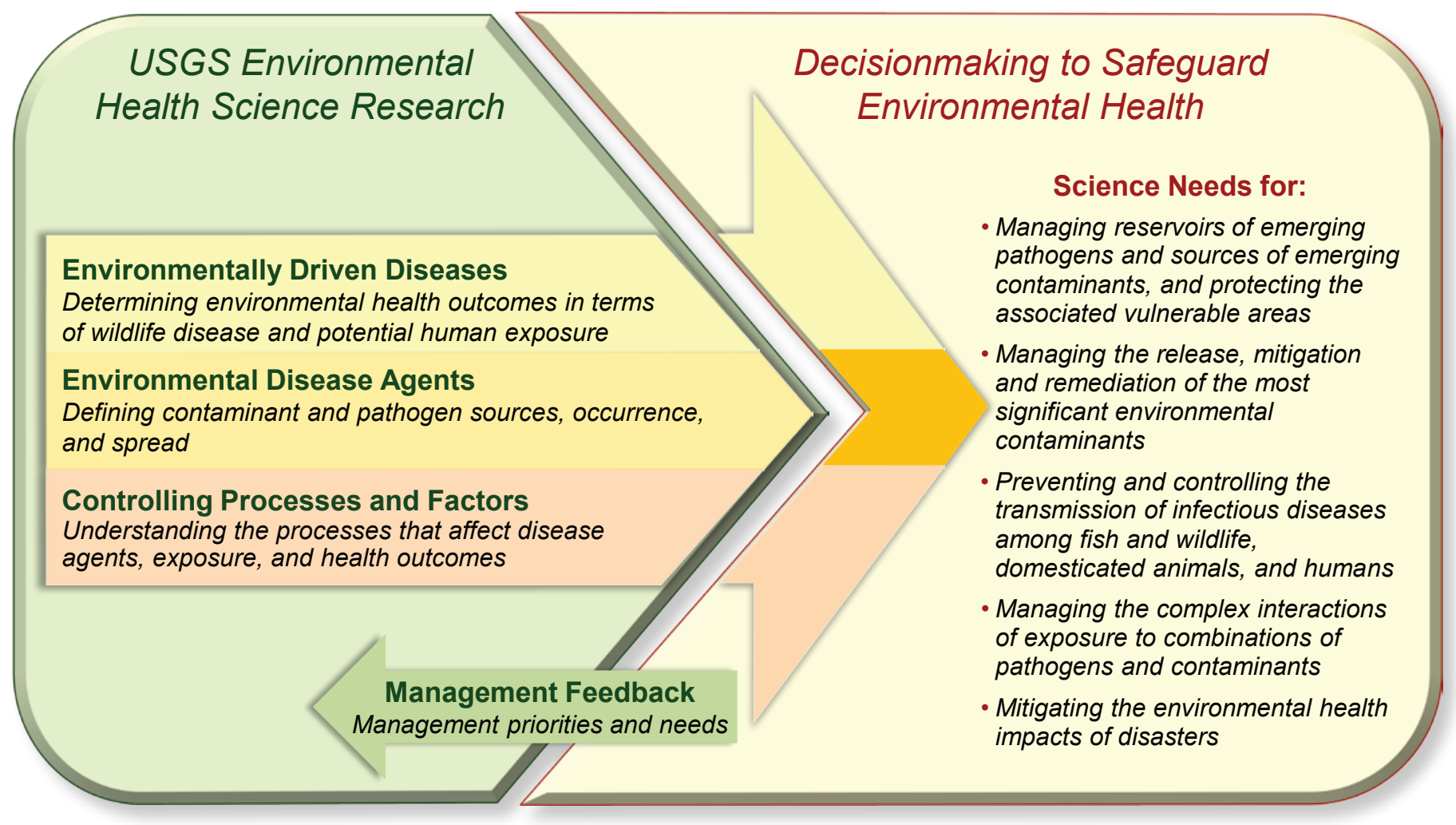

Figure 3. The role of USGS in environmental health science, is to provide scientific information and tools to environmental, natural resource, agricultural, and public health agencies for management and policy decisionmaking. 


\section{USGS Partner and Stakeholder Relationships}

USGS provides science to managers and other decisionmakers at all levels of government (Federal, State, Tribal, and local). These include agencies within DOI, the U.S. Environmental Protection Agency (U.S. EPA), the U.S. Department of Agriculture, the National Oceanic and Atmospheric Administration, the Department of Defense, the Department of Energy, the Department of Health and Human Services, the Department of Homeland Security, and the Department of State. Additionally, it is critical for USGS to improve coordination and collaboration with other science agencies that provide science to decisionmakers, particularly in areas outside of the usual scope of USGS activities, such as the health of people and domesticated animals.
The USGS Environmental Health Mission Area is committed to strengthening relationships with established partners and exploring new partnership opportunities. Fostering strong alliances with environmental, natural resource, agricultural, and public health agencies is essential to ensure that (1) capabilities for identifying emerging environmental health threats are enhanced; (2) resources are leveraged among partners; (3) data gaps are identified and filled; and (4) information is made available in a useful and timely manner. Coordination among government partners, academia, and nongovernmental organizations also will be essential in enabling efficient linkages between science needs and resource investments. These alliances will require cooperation and regular communication to set priorities, plan and conduct joint research, and disseminate information.

\section{Native American Communities in Alaska are Inseparably Linked to Their Surrounding Natural} Resources

The Alaska Climate, Ecosystems and Human Health Work Group is providing scientific information that explains the relations among ecosystem impacts, human health, and changing climate. The Work Group intends to improve the quality of information, services and technical assistance available to Alaskans, and elevate awareness about climate-health connections. USGS participates in the Work Group, which is co-chaired by the Alaska Department of Health and Social Services, the US Environmental Protection Agency, and the Alaska Native Tribal Health Consortium. The Work Group meets to facilitate the exchange of ideas, data, and research opportunities, and communicates key priorities and needs to the Alaska Climate Change Executive Roundtable and the Governor's Sub-Cabinet on Climate Change. Activities of the Work Group have included assessing the hydrology, water quality, and trace elements associated with placermining in the Birch Creek Watershed of central, Alaska; evaluating contaminants in salmon and pike; assessing the relationship between northern pike consumption and human mercury exposure as indicated by concentrations in human hair; promoting environment-friendly methods for disposal of medications; studying zoonotic and animal arboviruses; testing Black Brant for Avian Influenza viruses; monitoring marine mammals for fecal pathogens known to cause illness in humans; and West Nile Virus and St. Louis Encephalitis surveillance in horses. Photograph courtesy of Carol Ann Woody, USGS. More information is available online at http://www.climatechange.alaska.gov/chh.htm.

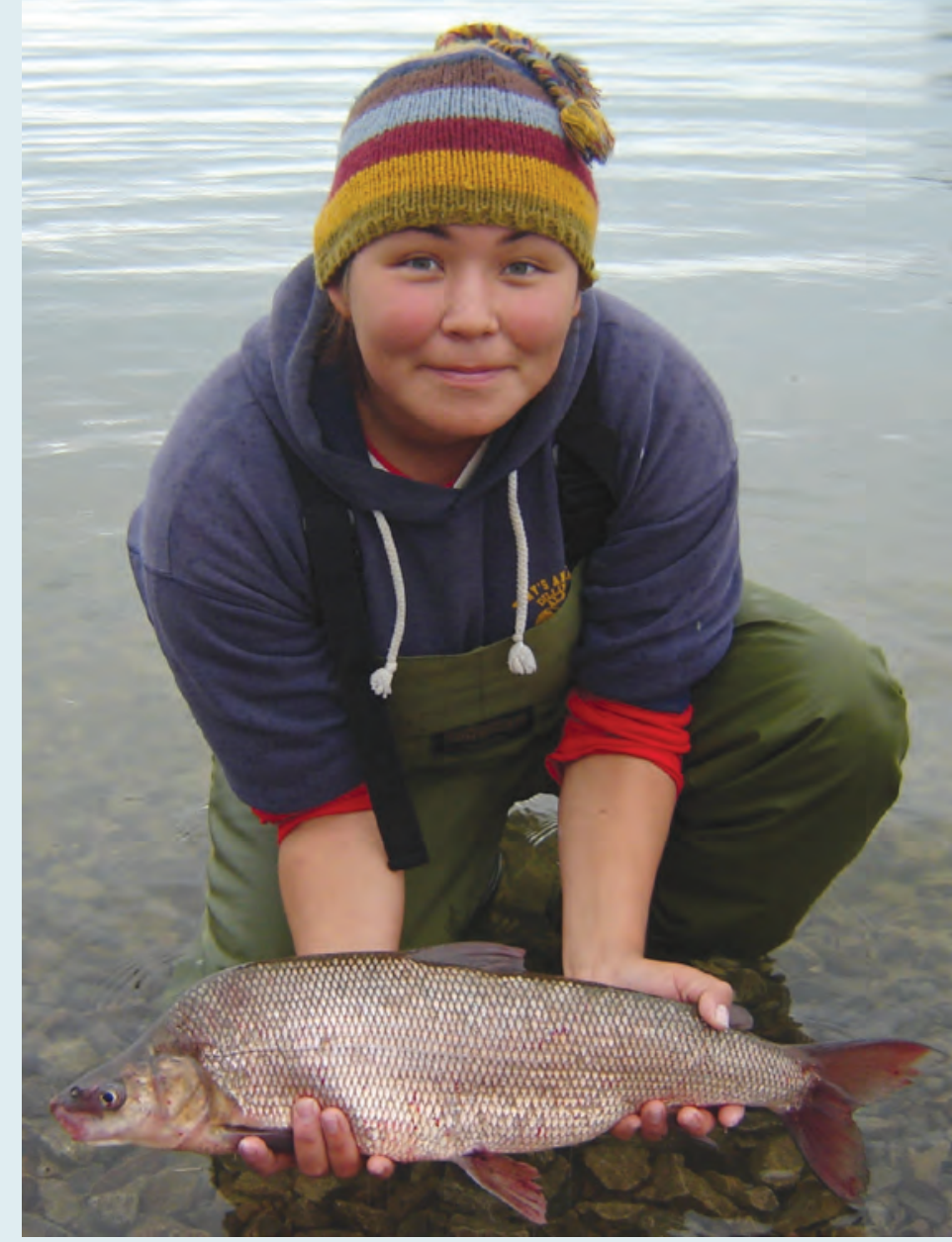




\section{USGS Core Strengths, Capabilities, and Future Challenges to Core Strengths and Capabilities}

\section{Core Strengths and Capabilities}

The ability of USGS to address a wide range of environmental health science issues is enhanced by (1) an interdisciplinary workforce with diverse expertise; (2) a distributed national presence and infrastructure; and (3) significant capabilities for data collection, analysis, and synthesis.

1. Interdisciplinary workforce with diverse expertise:

- Expertise in characterizing the sources, occurrence, behavior, toxicological characteristics, and ecological impacts of natural and anthropogenic contaminants in the environment.

- Expertise in developing indicators (benchmarks) of environmental health.

- Expertise in the diagnosis, pathology, epidemiology, and ecology of infectious diseases, including the development of animal models relevant to both aquatic and terrestrial organisms.

- Knowledge of the influence of environmental and earth processes on the spread and distribution of disease agents.

- Expertise in characterizing the environmental and related health effects of a wide range of human activities, natural processes (weathering, erosion, landslides, and climatic variability), and disasters (earthquakes, volcanic eruptions, hurricanes, wildfires, floods, droughts, pandemics, and biological threats).

- Expertise related to the economic valuation of ecosystem services.
- Expertise in developing techniques and models to characterize novel and emerging pathogens and contaminants.

- Project teams with a broad range of scientific expertise that use interdisciplinary approaches.

2. National presence and infrastructure:

- A nationally distributed staff of scientists who collect environmental data with spatially and temporally consistent protocols.

- Databases that provide real-time and long-term environmental information and data ranging from local to national spatial scales.

- Internationally recognized research laboratories that develop and provide state-of-the-art methods to measure new and understudied disease agents.

- The ability to conduct landscape-scale assessments across state and international boundaries.

3. Capabilities for data integration:

- Ability to synthesize spatially diverse environmental data with information on ecosystem characteristics, human demographics, and landscape changes.

- Ability to integrate and model environmental data on the causes and effects of environmental stressors, and compare outcomes of alternative management strategies.

- Ability to integrate research, data, and knowledge across a wide range of scales from investigation and monitoring at a site to development of approaches to apply remotely sensed data and mapping tools to environmental health threats across the Nation.

\section{Providing Information About Potential} Exposures to Chemicals in Drinking Water

USGS provides data at national and regional scales on unregulated contaminants in sources of drinking water. The U.S. Environmental Protection Agency uses USGS data on the occurrence of these contaminants in water resources to fulfill part of the Safe Drinking Water Act requirements for determining whether specific contaminants should be regulated in drinking water from public water supplies. Local health officials and the public also use USGS data to make decisions about the use of drinking water from untreated domestic wells. Photograph courtesy of iStock Photographs. More information is available online at $h t t p: / / h e a l t h . u s g s . g o v / d w \_$contaminants/.

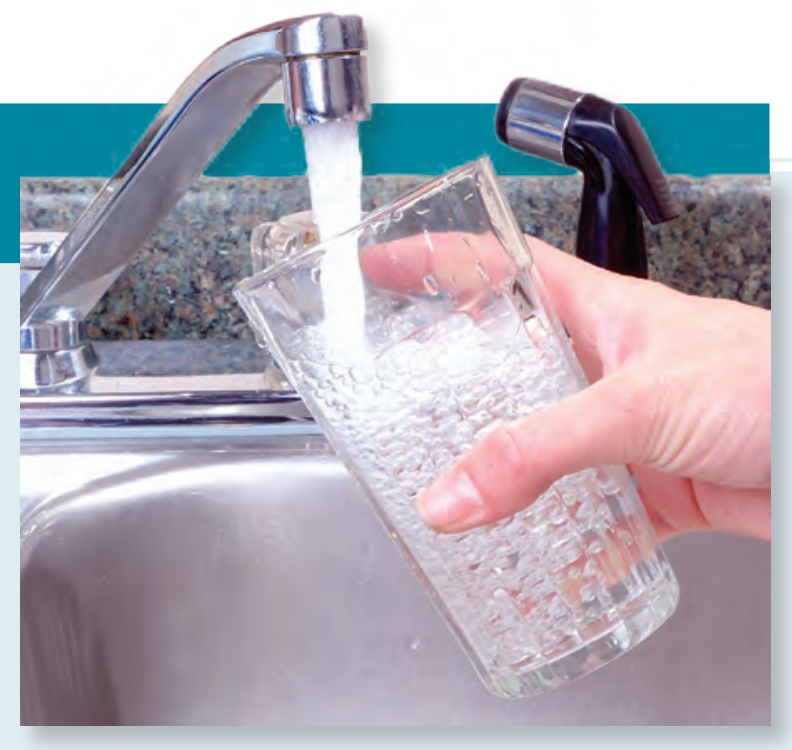




\section{Future Challenges to Core Strengths and Capabilities}

USGS will be challenged by rapid advances in scientific technologies, fundamental scientific understanding, and evolving interdisciplinary approaches to environmental health problems. The next decade will require close attention to maintaining a technically proficient workforce with skills in integrating interdisciplinary science. It will also require wise investments of resources in technologies that enable innovative approaches to the highest priority problems. Ultimately, it will require building capacity and mechanisms for delivering resource science that is timely, relevant, and adds value to decisionmaking.

USGS will need increased capabilities and methodologies related to, genetics and genomics, modeling and risk analysis to understand the epidemiology of environmentally driven diseases. Understanding the factors that influence pathogens and contaminants of emerging concern will require increased expertise in atmospheric/meteorological processes, disease ecology, pathology, and bioinformatics. Taking full advantage of the newest capabilities in remote sensing will be essential. A complete understanding of the effects of contaminants and the interactions of multiple contaminants will require mechanistic understanding of the mode of action at the cellular, organismal, and population levels. Chemical and pharmacological modeling of fate and effects of biologically active contaminants will need to be integrated with models of physical processes that affect environmental transport. USGS also will be challenged with maintaining specialized laboratories to investigate emerging biohazardous agents that threaten environmental health and national security.

It will be essential for USGS to achieve the capabilities to anticipate and measure environmental contaminants at concentrations necessary to assess potential ecological and human health effects and guide pollution prevention, management, and mitigation actions. Perhaps the best example of this is the ability to analyze the impact of environmental contaminants measured at sub part-per-trillion levels - measurements that were not possible a decade ago. Measuring new substances that could potentially contaminate the environment, such as engineered nanomaterial, likely will require completely new technologies. Highthroughput tools for genetic characterizations will enable assessment of the wide combinations of disease agents that are potential environmental health threats. Similarly, use of in vitro bioassays to screen environmental samples for biological activity will be essential in identifying vulnerable environmental settings and priority contaminants. Broad application of such tools can indicate the biological mechanisms of action and potential adverse biological outcomes of specific chemicals or mixtures of chemicals found in the environment, and contaminated environmental media (water, sediment, or soil).

\section{USGS Laboratories Are OIE Collaborating Centre and Reference Laboratories}

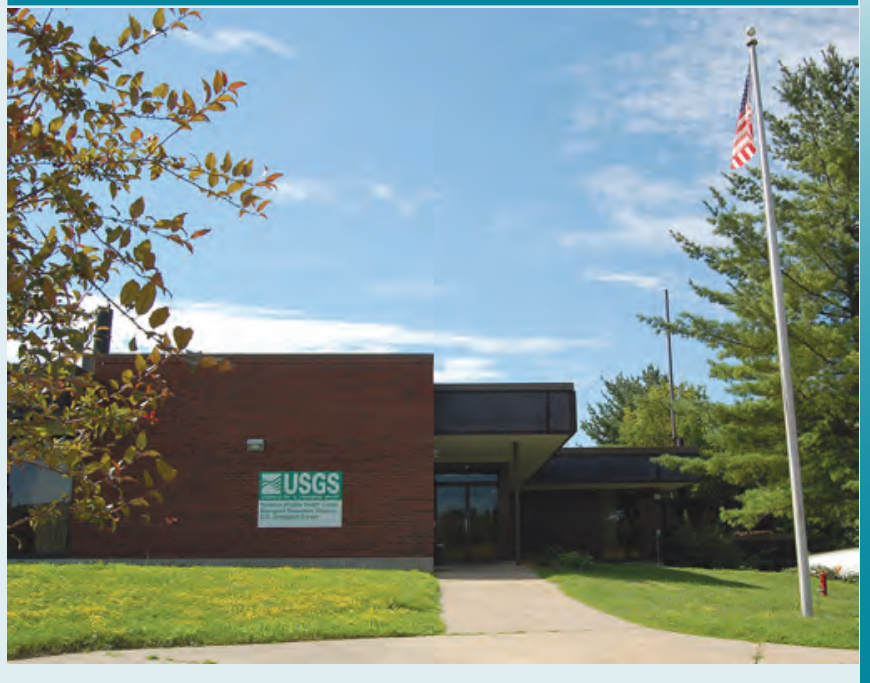

USGS laboratories provide specialized expertise to the international animal health community through collaboration with the World Organisation for Animal Health (OIE), an international organization that enhances intergovernmental coordination on global disease incidents and facilitates safe trade of animals and animal products. A critical component of the OIE is its network of Collaborating Centres and Reference Laboratories-an elite group of institutions with specific animal health expertise. The USGS National Wildlife Health Center serves as an OIE Collaborating Centre for research and diagnosis of pathogens in wildlife. The USGS Western Fisheries Research Center is an OIE Reference Laboratory that provides international expertise on infectious haematopoietic necrosis (a viral disease) and bacterial kidney disease of fish. Photograph courtesy of Gail MoedeRogall, USGS. More information is available online at http://www.nwhc.usgs.gov/and http://wfrc.usgs.gov/.

Research into the infectious diseases of fish and wildlife requires specialized instrumentation and equipment in highly specialized laboratory settings. For USGS to continue to be a global leader in the field of environmental science, we must maintain our capabilities and stay abreast of new and innovative techniques and technologies. This means leveraging resources with government and university partners and making investments wisely to avoid duplication while targeting the highest priority science needs for the future. 


\section{USGS Environmental Health Science Vision, Mission, and Goals}

\section{Identifying USGS Environmental Health Science Goals}

This section describes five USGS environmental health science goals. These goals were identified by using the following criteria.

- Achieving the goal will address critical environmental health science knowledge gaps.

- The USGS has a well-defined role and the necessary interdisciplinary expertise to make a significant contribution to achieving the goal.

- Achieving the goal is realistic in terms of the state-ofscience, and will contribute substantially to safeguarding the health and prosperity of the Nation.

- Each goal optimizes USGS opportunities to leverage robust partnerships with, and provide critical technical assistance to environmental, natural resource, agricultural, and public health managers.

- The combined goals must focus USGS science on the highest priority environmental health issues facing the Nation.

The vision, mission, and five cornerstone goals of the USGS Environmental Health Science Strategy were developed with significant input from a broad range of stakeholders as well as from scientists and managers across USGS.
Vision-USGS is a premier source of the environmental health science needed to safeguard the health of the environment, fish and wildlife, domesticated animals, and people.

Mission - The mission of USGS in environmental health science is to contribute scientific information to environmental, natural resource, agricultural, and public health managers, who use that information to support sound decisionmaking. USGS will provide science to achieve the following societal goals:

- Goal 1: Identify, prioritize, and detect contaminants and pathogens of emerging environmental concern.

- Goal 2: Reduce the impact of contaminants on the environment, fish and wildlife, domesticated animals, and people.

- Goal 3: Reduce the impact of pathogens on the environment, fish and wildlife, domesticated animals, and people.

- Goal 4: Discover the complex interactions between, and combined effects of, exposure to contaminants and pathogens.

- Goal 5: Prepare for and respond to the environmental impacts and related health threats of natural and anthropogenic disasters.

\section{Manufacturing Facilities Found to Release Pharmaceuticals into the Environment}

USGS discovered that pharmaceutical manufacturing facilities can be a significant source of pharmaceuticals to aquatic environments. Effluents from two wastewater treatment plants that receive discharge from pharmaceutical manufacturing facilities had 10 to 1,000 times higher concentrations of pharmaceuticals than effluents from wastewater treatment plants across the Nation that do not receive pharmaceutical manufacturing facility discharge (Phillips and others, 2010). The drugs included a muscle relaxant, an opioid prescribed for pain relief and drug withdrawal, a stimulant prescribed for obesity, and a barbiturate. USGS has been investigating the sources, distribution, and effects of pharmaceuticals and other emerging contaminants since the late 1990's. Photograph shows USGS hydrologic technicians sampling Hallocks Mill Brook, New York, downstream of the outfall of a wastewater treatment plant receiving discharge from a pharmaceutical manufacturing plant. Photograph courtesy of Patrick Phillips, USGS. Additional information is available online at $h t t p: / / t o x i c s . u s g s . g o v / h i g h l i g h t s /$ PMFs.html.

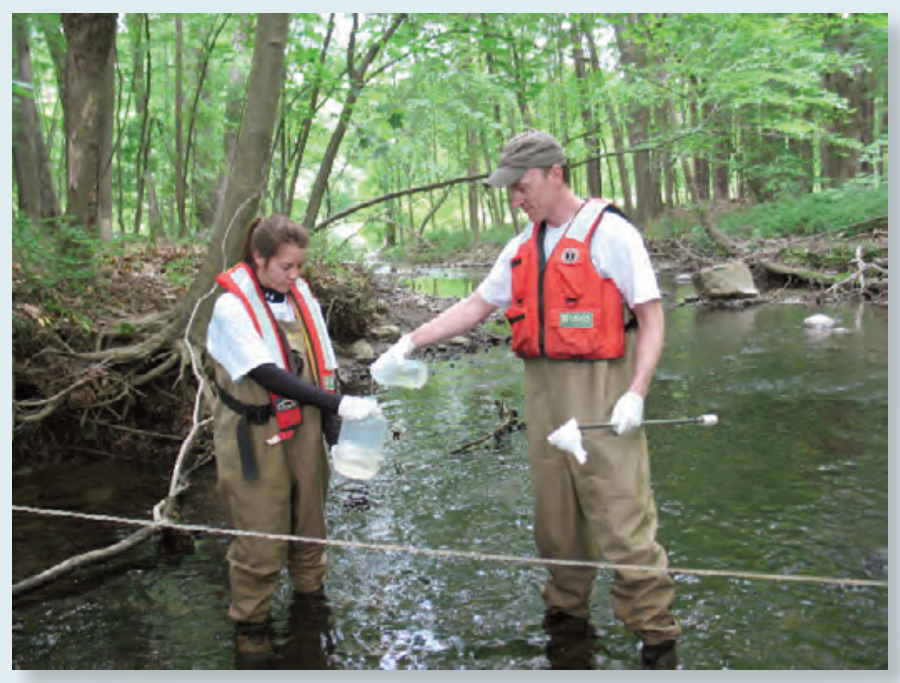


Goals 1 through 4 are intended to provide science to address environmental health threats in a logical order from informing prevention and preparedness to supporting systematic management response to environmental health issues. The results from Goal 1 will be used to prioritize research conducted to address goals 2 and 3. Goals 2 and 3 are intended to provide the systematic research, national assessment activities, and fundamental knowledge to determine effective, long-term management strategies. Goal 4 acknowledges the increasing biological complexity surrounding the understanding of the combined effects of exposure to contaminants and pathogens. Goal 5 acknowledges the fact that natural and anthropogenic disasters can cause immediate and prolonged adverse health threats and add a significant additional complication in efforts to protect the health of the environment, fish and wildlife, domesticated animals, and people. The knowledge and understanding gained in achieving Goals 1 through 4 will be essential in preparing for and mitigating the adverse environmental impacts of disasters (Goal 5). The goals are not intended to be equal in terms of the level of resources invested; however, they each identify critical environmental health science needs. Goals 1 and 5 are rapid response preparatory goals. Goals 2, 3, and 4 are foundational goals and by nature larger in scope and level of resource investment.

\section{Goal 1: Identify, Prioritize, and Detect Contaminants and Pathogens of Emerging Environmental Concern}

Emergence of environmentally driven diseases constitute a critical and growing threat to environmental healthincluding the health of fish, wildlife, and people. There is a growing consensus among the scientific and health communities that threats from emerging disease agents will continue to increase and that the health risks and economic vulnerability of our increasingly interconnected planet will grow.

Historically, scientists have relied on established monitoring programs to assess changes in the environmental conditions that affect environmentally driven disease - an approach that allows us to react to past changes, but leaves a significant scientific gap in the Nation's ability to identify and anticipate emerging health threats. As the number of environmental health threats continues to grow and become increasingly complex, informed decisionmaking and early action will be critical for timely and cost-effective prevention and mitigation.

Emerging infectious diseases can have devastating effects on wildlife conservation, such as white-nose syndrome (WNS) in bat populations in the United States. Other factors that reduce population resilience (such as the sub-lethal effects of contaminants and reductions in genetic diversity) further increase the vulnerability of free-ranging aquatic and terrestrial species to infectious pathogens.

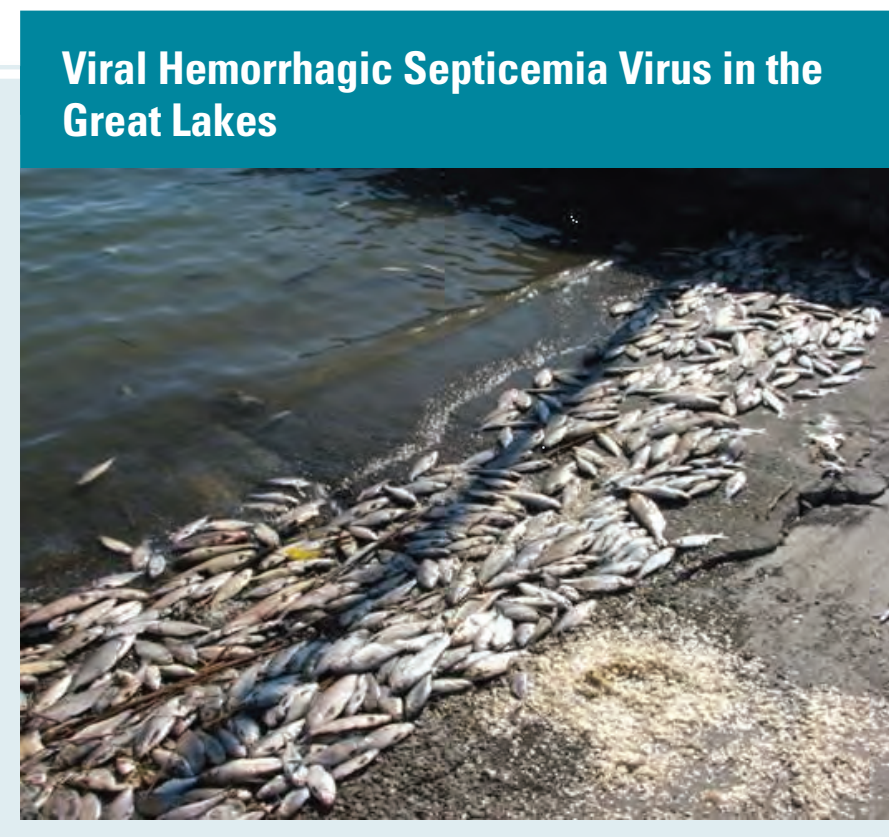

Viral hemorrhagic septicemia virus (VHSV) is among the most important viral pathogens of finfish-causing losses in both freshwater and marine species. In 2005-06, VHSV emerged in the Great Lakes Basin, causing a series of large fish kills. As of June 2011, the virus has been found in 31 species of fish from Lake Superior, Lake Huron, Lake Michigan, Lake St. Clair, Lake Erie, Lake Ontario, the Niagara, and St. Lawrence Rivers, and inland lakes in New York, Michigan, Wisconsin, and Ohio. Significant outbreaks affected muskellunge (Esox masquinongy), freshwater drum (Aplodinotus grunniens), goby (Neogobius melanostomus), burbot (Lota lota), yellow perch (Perca flavescens), gizzard shad (Dorosoma cepedianum) and smallmouth bass (Micropterus dolomieu). Work by USGS scientists in collaboration with State, Federal and Canadian partners focuses on: developing improved diagnostic methods, determining methods for disinfection of eggs, testing for vertical (intra ovum) transmission, and using molecular tools to identify and track strains of the virus. Genetic sequence analysis of more than 100 VHSV isolates from 37 locations in the Great Lakes Basin revealed a very low level of genetic diversity consistent with a recent, single introduction of the virus to a naïve population of fish. Photograph courtesy of Andrew Noyes, New York Department of Environmental Conservation, shows gizzard shad mortality event, Lake Erie. Additional information is available online at $h$ ttp://wfrc.usgs.gov/fieldstations/hq/vhs.html.

Consequently, diseases can no longer simply be regarded as natural regulators of wild populations; they now pose a serious threat to fish and wildlife conservation and an increasing challenge for natural resource management. The availability 
of effective wildlife disease management tools is limited. The few options that do exist (such as population reduction, use of vaccines or other biologics, and environmental modification) are expensive, often lack any assurance of success, and can be environmentally unsound, as well as unpalatable to the general public.

Most (60.3 percent) emerging diseases identified in the last century were zoonotic - caused by pathogens originating from animals or animal products. Furthermore 71.8 percent of these zoonotic events originated in wildlife species (Jones and others, 2008). In the 21 st century, approaches to evaluate health risks will have to consider increasing human populations; expanding urban centers; increasing interaction among people, wildlife, and livestock; global change; and movement of humans, animals, and food products.

\section{Implications of New Fungicides in Streams}

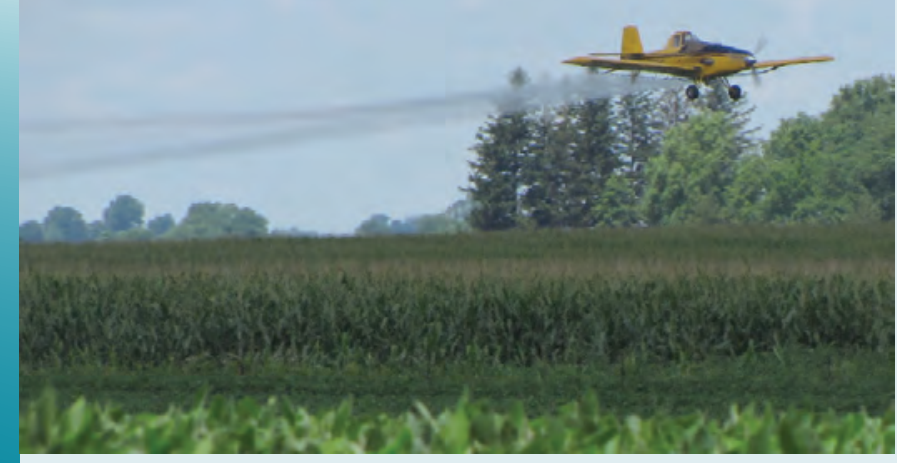

In a 5-year period (2004 to 2009), the application of fungicides increased from less than 2 percent to 25-30 percent of the 89 million hectares of corn, soybean, and wheat planted in the United States. Fungicides are also used on turf and a variety of fruit and vegetable crops, such as almonds, apples, grapes, lettuce, peanuts, potatoes, and tomatoes. The number of fungicides used has increased significantly since 2002. In a recent study, USGS scientists detected one or more fungicides, including azoxystrobin, metalaxyl, propiconazole, myclobutanil, and tebuconazole, in 20 of 29 U.S. streams sampled during 2005 and 2006 in areas where soybeans are grown. This was the first time that some of these fungicides were detected in the environment. Mixtures of fungicides were common. The potential impact of these fungicides on non-target organisms, such as the gut fungi of insects, is being investigated. This information is relied on to guide pesticide use practices and registrations. Photograph courtesy of Dana Kolpin, USGS, shows aerial spraying of fungicides in lowa. More information is available online at http://toxics.usgs.gov/highlights/ fungicides_streams.html.
Emerging threats from non-native and novel infectious diseases are of particular concern because animal and human populations are less likely to have developed immunity to the pathogen. As illustrated by West Nile virus, the introduction of a non-native invasive pathogen into the United States can be difficult to control and can have severe ecological and economic impacts. Similarly, the H5N1 Asian strain of highly pathogenic avian influenza and Severe Acute Respiratory Syndrome (SARS) are examples of diseases that can spread rapidly across the globe, emphasizing the need for prediction, early detection, and rapid response when new diseases arise.

The identification of the emerging environmental contaminants that constitute significant ecological and human health concern requires determining (1) the levels at which exposure poses a health concern, and (2) whether there is risk of exposure at or above the levels of concern. Gathering knowledge on potential contaminants that are newly developed and have limited or no available data is extremely challenging. Our past experience with legacy contaminants, such as persistent organic pollutants, contaminants that associate with sediment, contaminants that enter large groundwater systems, and contaminants that do not exhibit predictable environmental behavior, has shown that once released into the environment, management, removal or remediation can be expensive and difficult, if not impossible. In many cases, however, the need for information is only recognized after a contaminant is observed in the environment or an adverse toxicologic effect is suspected. Therefore, a management approach that emphasizes recognition of potential environmental health concerns before use of a chemical, pollution prevention, and rapid response to discovery of emerging environmental contaminants is essential. The need for scientific information to support this management approach will only continue to grow in magnitude and complexity.

Our experience with pharmaceuticals and endocrine-disrupting chemicals in the environment has demonstrated the need for scientific vigilance regarding emerging environmental issues. The discovery of widespread occurrence of pharmaceuticals in the Nation's streams (Kolpin and others, 2002) demonstrated that even chemicals that we use in very small amounts in our homes can enter the environment and warrant serious evaluation as a potential health concern. Furthermore, models that predict the occurrence of environmental contaminants are challenged by the complexities of source pathways and transport processes. For example, models of pharmaceuticals in the environment have not adequately addressed potential pharmaceutical losses from manufacturing facilities, land-applied biosolids, and use of pharmaceuticals in animal agriculture, and generally suffer from a lack of knowledge of transport behavior and degradation byproducts. 
Society is continually developing diverse new technologies and materials to enhance our way of life. These can include new forms of energy production, new methods of mineral and energy resource extraction, use of new materials in telecommunications and electronics, new approaches to food production, and the increasingly widespread development and use of nanomaterial. Many of these technologies may require increased consumption of new synthetic chemicals or exotic metals such as tellurium, gallium, and rare earth elements. The environmental behavior of many of these technologically important chemicals and metals are poorly understood, and little is known about their potential toxicologic effects on humans and other organisms.

\section{Priority Science Questions}

- How do we identify emerging contaminants and pathogens that are likely to become environmental, ecological, and human health threats?

- What are the major sources of emerging contaminants or reservoirs of emerging pathogens, and how will they change in the future?

- What new classes of contaminants and (or) pathways of contamination to the environment will occur in the next decade?

- What is the risk of exposure to emerging contaminants and do we anticipate adverse biological outcomes?

- What factors promote the movement and establishment of new pathogens?

- Which host species and (or) regions are most at-risk of introduction of high-consequence diseases?

- Can sentinel organisms be used to provide an early warning of emerging environmentally driven diseases?

\section{Strategic Science Actions}

USGS will (1) prioritize contaminants and pathogens of emerging concern to guide research and management activities, (2) conduct surveillance and monitoring to provide early warning of emerging health threats, and (3) develop approaches and tools that identify vulnerable environmental settings, ecosystems, and species. Information from these efforts will help focus the attention of the scientific community on the Nation's highest priority emerging environmental health threats, and enable timely, proactive management action.

\section{Tracking Wild Birds and Avian Influenza}

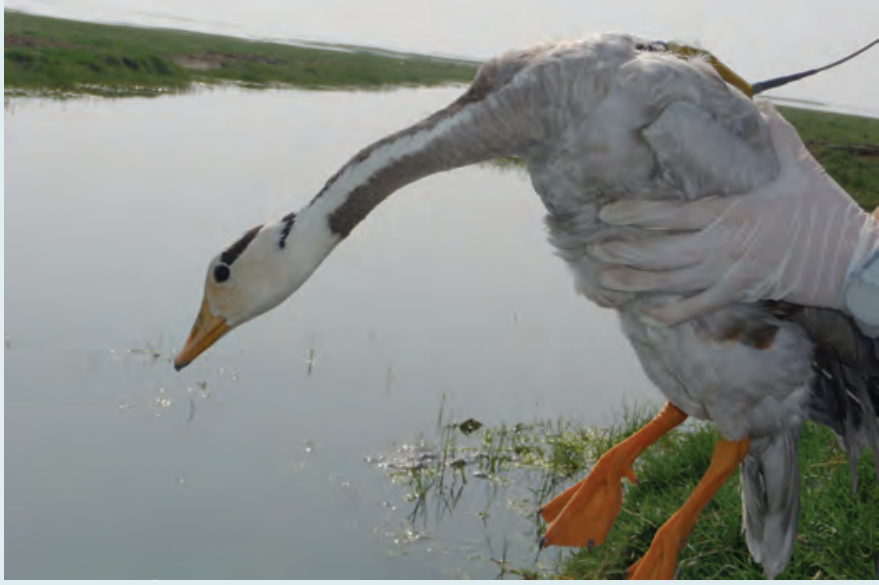

Highly pathogenic avian influenza (HPAI H5N1) can devastate wild bird populations and infect poultry and humans. The H5N1 virus continues to reemerge across much of Eurasia and Africa. Since 2003, HPAI H5N1 has killed more than 340 people, including 18 in 2010, and has led to the culling of more than 250 million domestic poultry. Although the disease is not efficiently transmitted between humans, public health officials worry that the H5N1 could mutate into a more transmissible form, possibly leading to a pandemic. The USGS and its partners have been using satellite telemetry to track movements of waterfowl and shorebirds within Asia (the likely source of HPAI H5N1), and conducting surveillance for the virus along migratory routes to the United States and within Alaska. This surveillance work improves our ability to assess the risk of HPAI H5N1 entering the United States and our chances of early detection. Photograph courtesy of John Takekawa, USGS, shows a bar-headed goose (Anser indicus) equipped with a miniaturized global positioning system (GPS) satellite transmitter being released in Koonthankulum Sanctuary, India.
Strategic Science Action 1.-Prioritize contaminants and pathogens of emerging concern to guide research, detection, and management activities.

- Coordinate with other Federal agencies to develop methods for prioritizing pathogens and contaminants of emerging concern. Ensure information essential for prioritization is distributed widely among multiple Federal agencies. USGS will encourage, and where appropriate, lead efforts to integrate such information and apply it to effective prioritization based on the most likely potential health concerns. USGS will use this prioritization to develop measurement methods and field efforts to identify 
and monitor contaminants and pathogens of emerging concern.

- Utilize knowledge of the chemical life cycles and other substances to identify point-source and nonpointsource pathways of release to the environment. Use this knowledge to inform the design of monitoring efforts intended to identify which contaminants enter the environment, the pathways to the environment that may be of significant concern, and the complex contaminant mixtures that may enter the environment via these pathways.

- Enhance USGS disease diagnostic capabilities to provide early detection of emerging environmentally driven diseases in aquatic and terrestrial organisms that will be used for systematic disease surveillance.

- Improve capabilities to conduct forensic studies to identify unknown contaminants and contaminant mixtures in various environmental samples to aid in the identification of contaminants that enter and persist in environmental media.

- Develop screening tools to test for the biological activity of contaminated environmental media, and work with other Federal agencies, including NIEHS and U.S. EPA, which are developing and applying high-throughput screening techniques to evaluate the biological activity of individual chemicals.

Strategic Science Action 2.-Conduct research, surveillance, and monitoring to provide early warning of emerging health threats.

- Conduct surveillance and monitoring to establish baseline conditions of environmentally driven disease and disease agents, and measure trends; develop the needed measurement methods and field approaches; and rely on indicators to identify multiple sources and the associated mixtures of contaminants and pathogens in the environment.

- Develop and implement real-time monitoring and surveillance techniques that employ indicators of potential health threats and can be used specifically to provide early warning of rapid-onset threats, such as to drinking water or biosecurity.

- Utilize risk analysis, statistical, and epidemiological techniques to target surveillance and mitigation activities to the geographic areas and populations with the highest likelihood of disease emergence.
- Identify environmental contaminants of emerging concern by combining (1) environmental monitoring data, which define the concentrations and mixtures of contaminants to which ecosystems and people are exposed, and (2) the results of screening tools, which estimate biological activity of contaminants and contaminant mixtures.

Strategic Science Action 3.-Develop approaches and tools that identify vulnerable environmental settings, ecosystems, and species.

- Develop models and other forecasting tools that identify emerging environmental health threats, vulnerable ecosystems, susceptible species, and pathways for human exposure. Models of contaminants will build upon existing knowledge of contaminant sources and the hydrologic, atmospheric, and geologic processes that affect the transport and fate of contaminants in the environment. Models of pathogens should build upon existing knowledge of disease reservoirs and the environmental factors that affect disease epidemiology and etiology.

- Provide decisionmakers and other stakeholders with access to the latest USGS information on emerging environmental health threats within the decision framework that the information is used and using bioinformatics to increase availability and usability.

\section{Outcomes and Relevance}

Prevention of environmentally driven disease (resulting from exposure to environmental contaminants and pathogens) is the ultimate desired outcome of the aforementioned USGS strategic science actions. However, agents of environmentally driven disease are often released into the environment before management actions can prevent that from happening. Therefore, the information and tools resulting from these actions also are intended to identify high-risk environmental settings and populations, to guide response activities, and to minimize environmentally driven disease. Environmental data on new or emerging environmental health threats, risk-analysis and disease-management tools, information on potential exposure pathways, and improved knowledge of pathogen reservoirs and contaminant sources are all essential to effective, proactive, preventive management strategies and will enable managers to prevent or minimize environmental contamination and respond rapidly to emerging diseases. 


\section{Goal 2: Reduce the Impact of Contaminants on the Environment, Fish and Wildlife, Domesticated Animals, and People}

Modern human societies produce large amounts of a diverse array of chemicals and other substances that are used in manufacturing, agriculture, medical treatment, transportation, construction, and other applications. There are many pathways by which contaminants can enter the environment (fig. 4). Some of these substances, such as fertilizers and pesticides, are intentionally released into the environment and can become problematic if improperly used or handled. Other chemicals or substances are released into the environment as byproducts of human activities and can be problematic, such as wastes from fossil fuel combustion, and numerous chemicals found in household products associated with treated wastewaters (for example detergents, fire retardants, and pharmaceuticals). Additional contaminants, such as metals, minerals, petroleum products, solvents, and other commercial or industrial substances, are not intended for release but nevertheless find their way into the environment because of unintended, accidental, or malicious releases. Finally, naturally occurring earth processes such as volcanic eruptions, earthquakes, erosion by wind and water, and chemical weathering of rocks also deliver mineral, chemical, and radionuclide contamination to the environment.
Many natural and anthropogenic contaminants can have toxic effects on individual organisms and adversely affect populations, ecosystems, and thus environmental health. Whether a particular contaminant is harmful to wildlife or human health depends on the contaminant's chemical form, concentration, and toxicity in the environmental media (such as soils, water, or air) through which organisms are exposed. Other factors that influence the adverse effects of these contaminants include the susceptibility of individuals and the frequency and (or) duration of exposure to contaminated media (U.S. Environmental Protection Agency, 2008). Furthermore, the sensitivity of an organism to a contaminant can be significantly different at different life stages. Often, embryonic, prenatal, perinatal, or juvenile life stages are the most sensitive to contaminant exposures, which can affect development of individuals later in life as well as future generations. However, all life stages can include critical biological processes that can be disrupted by contaminant exposure. Thus, exposure histories of aquatic and terrestrial organisms as well as humans are an important part of identifying mechanisms of biological activity, susceptible life stages, and thresholds for adverse impacts.

The manner in which organisms are exposed to natural or anthropogenic contaminants depends on a spectrum of factors and processes. These factors include sources and loads of contaminants to the environment; the physical and biogeochemical mechanisms that transport the contaminants from the point

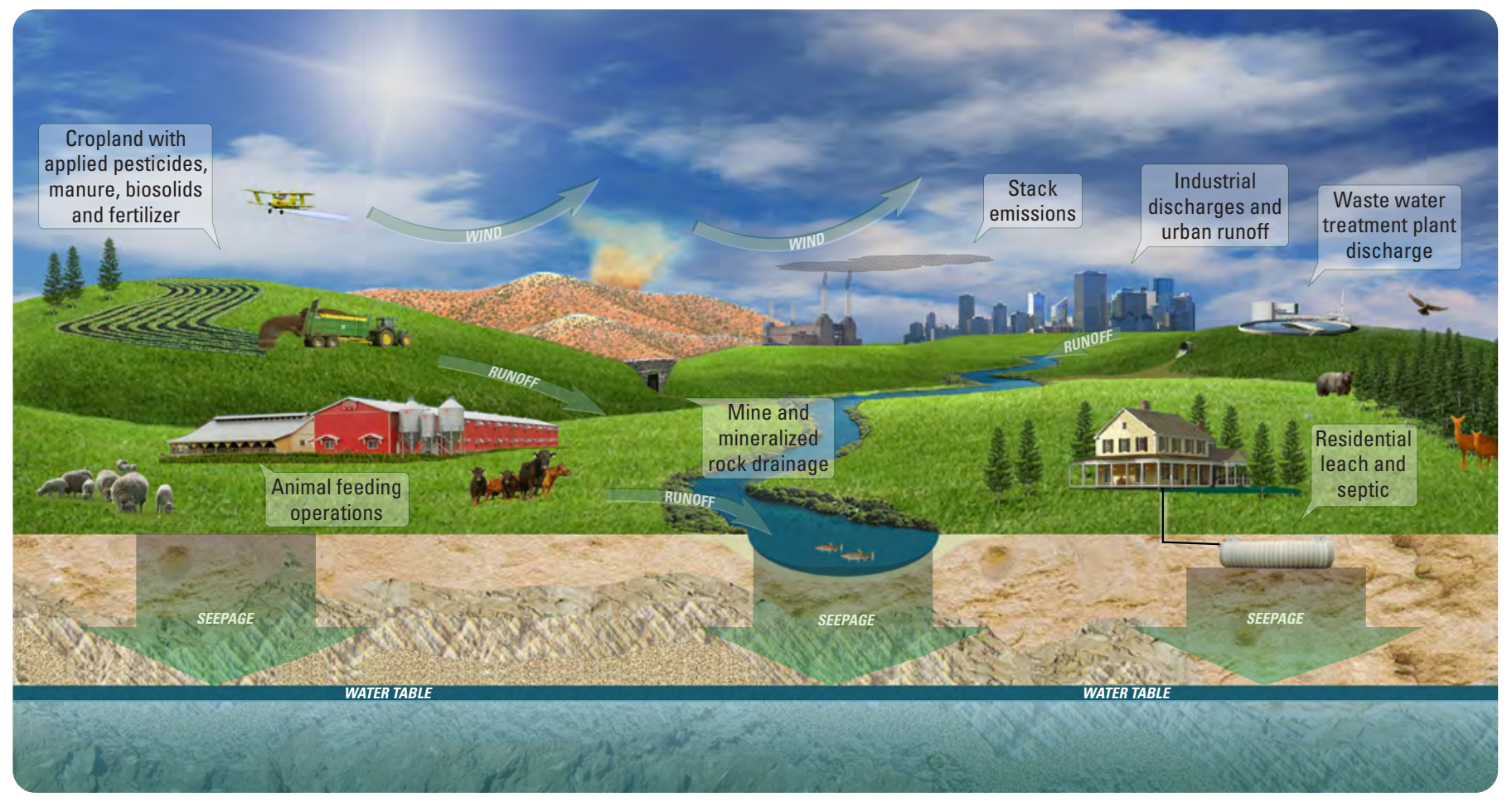

Figure 4. Environmental contaminant source and transport pathways. 
of release to the point of exposure; the chemical speciation of the contaminant and resulting byproducts; and the contaminant mixtures found in the environment to which organisms are exposed.

Our experience with endocrine-disrupting chemicals (EDCs) has demonstrated several new and important considerations for environmental contaminants; it has shown that very low (sub part-per billion, ppb) concentrations of some chemicals can cause significant adverse effects. While common knowledge indicated that adverse health effects occurred largely at concentrations above a ppb, exposure to potent EDCs at concentrations that are 1,000 times lower can have adverse ecological health effects (Kidd and others, 2007). Our experience with EDCs also has reinforced the importance of the timing of exposure, especially in terms of sensitive, early life stages, when disruption of chemical signaling related to development can have significant impacts later in life (Diamanti-Kandarakis and others, 2009). Additionally, it has been demonstrated that the effects of exposure to contaminant mixtures can be significantly different, and sometimes greater than, the effects of exposure to individual contaminants (Brian and others, 2005), even when the level of each individual contaminant is low. The U.S. EPA has adopted a new drinkingwater strategy that addresses contaminants as groups rather than one at a time to enhance drinking-water protection. The new strategy focuses on contaminants in groups that have similar health endpoints, and can be measured and treated using the same methods and approaches (U.S. Environmental Protection Agency, 2010).

\section{Endocrine Disruption in Fish Populations}

Endocrine-disrupting chemicals (EDCs) are important environmental contaminants because they have the ability to interfere with normal function of the endocrine system, thus altering reproduction, development, and immune system integrity. EDCs include naturally occurring chemicals produced by animals (hormones) and plants (phytoestrogens), as well as synthetic hormones and other chemicals used in commercial products, household products, and in agriculture, which can mimic or block the function of natural hormones within an organism. USGS scientists have identified sources and occurrence of some EDCs in ground and surface waters across the Nation. USGS has also been investigating reproductive anomalies, such as intersex, in fish populations believed to be associated with EDCs. The graphic shows the occurrence of intersex in smallmouth bass (SMB), largemouth bass (LMB) and other fish across the Nation (Hinck and others, 2009). Targeted field investigations of endocrine disruption in fish continue in the Potomac River, Boulder Creek, Rio Grande, and other locations in the U.S. These field investigations document fish kills, reproductive anomalies (intersex), the cause-and-effect linkages between exposure to EDCs and endocrine disruption, and threshold concentrations of EDCs that affect fish populations. This science is being used by resource managers to minimize release of EDCs to the environment and to protect wildlife and human health. More information is available online at $h t t p: / / w w w$. cerc.usgs.gov/Assets/ UploadedFiles/ExternalDocs/bass_intersex-09-rev. pdf.

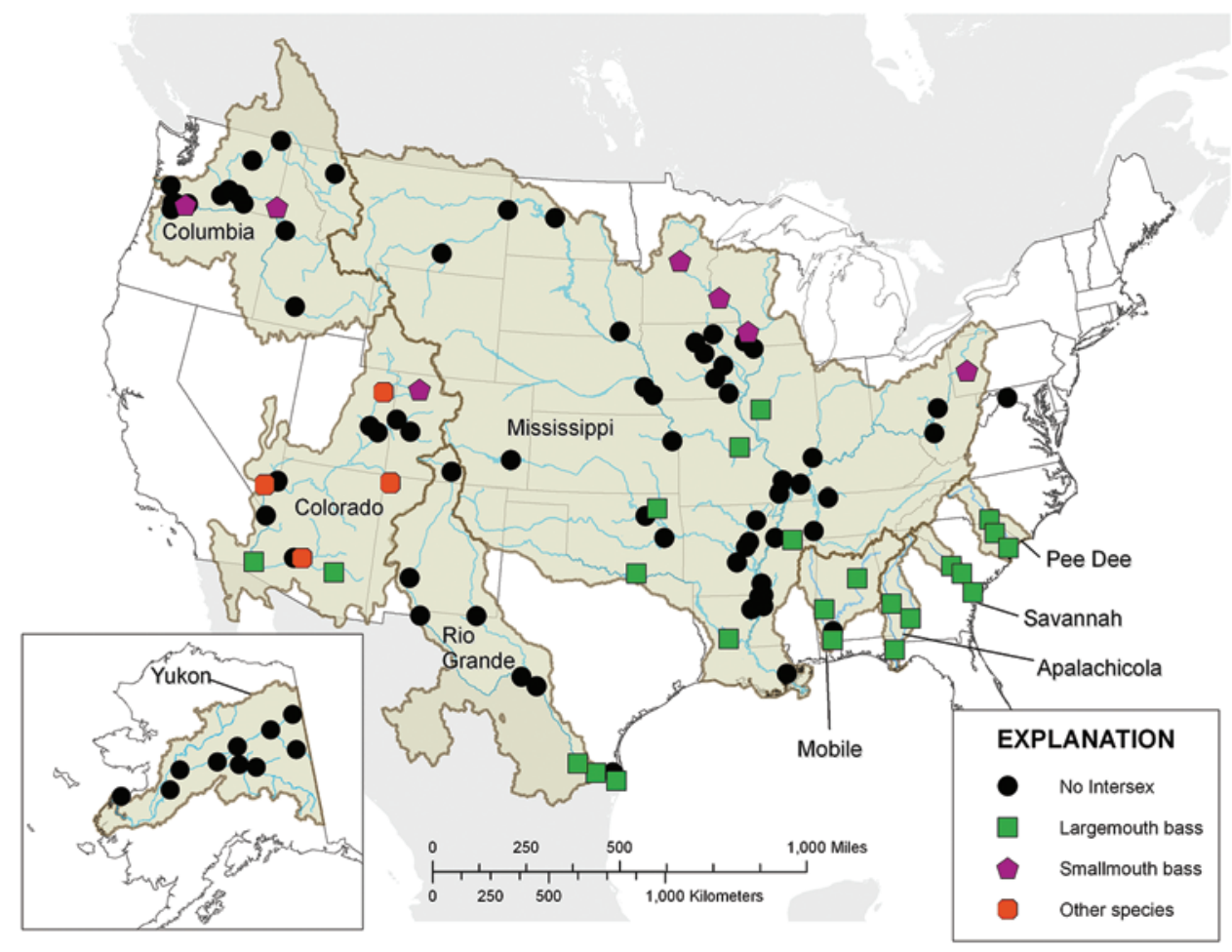


The USGS has a well-established role in characterizing the causes and mechanisms of environmental contamination, contaminant transport and fate, the effects of contaminants on aquatic and terrestrial organisms, and human exposure through various environmental media. The USGS frequently is asked to help public health scientists understand the nature and toxicologic implications of human exposures to environmental contaminants. As a result, the USGS is well positioned to address a variety of priority science questions that focus on the need to understand the linkages between sources of natural and anthropogenic contaminants, their physical, chemical, and toxicologic characteristics, exposure routes to organisms, and the susceptibility and sensitivity of organisms at different life stages.

\section{Priority Science Questions}

- What classes of natural and anthropogenic contaminants have the greatest long-term impact on environmental quality and the health of aquatic and terrestrial organisms and humans?

- What are the most important sources of contaminants to the environment, and what actions can be taken to mitigate environmental contamination? What contaminant mixtures are observed in common environmental settings, reflecting an integration of numerous disparate contaminant sources?
- How does the chemical species or form of a contaminant and the associated properties influence its distribution and persistence in the environment, and its adverse health effects on exposed organisms?

- What environmental processes and factors influence the transport and fate of contaminants in the environment and the vulnerability of organisms to contaminant exposure?

- What are the modes of action of contaminants on vulnerable organisms, which contaminants have similar modes of action, and how will contaminants interact biologically?

- What are the acute and chronic thresholds for adverse health effects (both lethal and sublethal) in aquatic and terrestrial organisms for both individual contaminants and contaminant mixtures - including at sensitive life stages? How do we assess the potential impact of longterm low-level exposures?

- What biological outcomes (for example, behavioral, reproductive, and developmental) result from exposure of aquatic and terrestrial organisms to environmental contamination?

- What biological outcomes have population-level effects?

\section{Anthropogenic Sources of Mercury and Methylmercury Identified in the North Pacific Ocean}

About 40 percent of all mercury exposure experienced by U.S. citizens results from the consumption of fish from the Pacific Ocean. Until recently, it was believed that the primary mercury source was geologic, such as from deep-sea vents. A paradigm-changing study conducted by the USGS and its partners revealed the causal source is recent atmospheric mercury emissions. Mercury deposited to oceans settles to depths where it is converted to methylmercury, a highly toxic form of mercury that accumulates in food webs. These findings link contemporaneous sources to human exposure (consumable fish) and document how large water bodies can be far more responsive to changes in mercury loading than previously thought. The authors showed that mercury concentrations in the Pacific Ocean have increased by 30 percent in the past 20 years, and estimated an additional 50 percent increase by 2050 if mercury emission

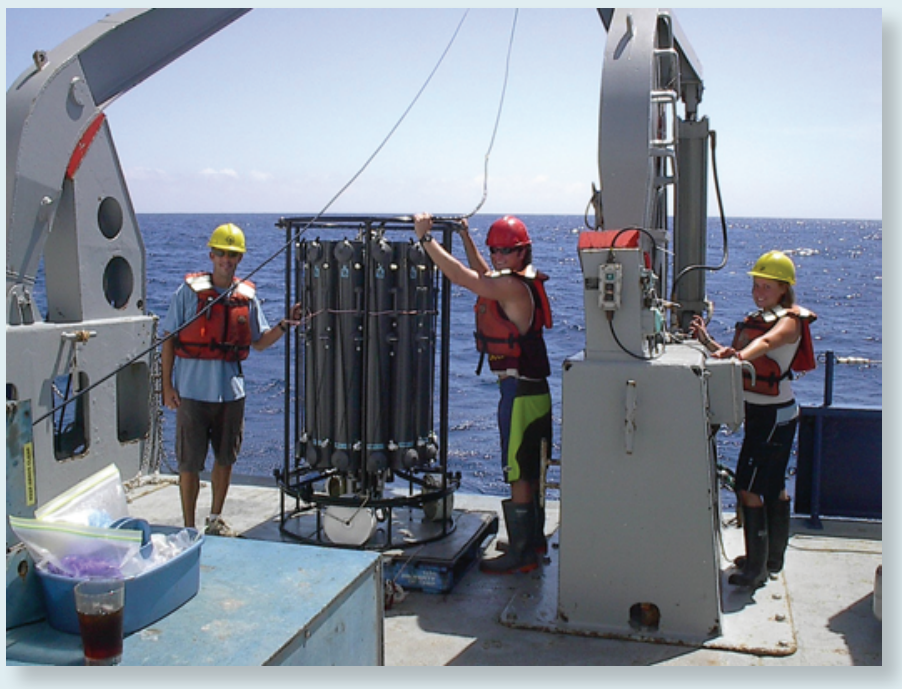
rates continue as projected. Understanding the linkage between sources and exposure helps decisionmakers evaluate the trade-offs between human exposure and future emissions. The photograph, courtesy of William Landing, Florida State University, shows scientists on the vessel R/V Thomas G. Thompson (Office of Naval Research) lowering a "rosette" of 12 Niskin bottles to sample water at various ocean depths. Additional Information is available online at http://toxics.usgs.gov/highlights/pacific_mercury.html. 


\section{Strategic Science Actions}

A strength of USGS environmental health activities is a basis in field studies that characterize the range of actual environmental conditions across numerous settings. USGS field-based studies are intended to identify both common and unusual circumstances. Often the most important environmental circumstances are not common or typical; however, they pose the most significant environmental health threat. USGS field-based studies provide a foundation upon which laboratory and modeling studies are designed and implemented to support and generalize results to other similar settings across the Nation. USGS will (1) systematically characterize the sources, occurrence, transport, and fate of environmental contaminants, (2) evaluate the threat of environmental contamination to the health of the environment, fish and wildlife, domesticated animals, and people, and (3) characterize potential human exposure.

Strategic Science Action 1.-Systematically characterize the sources, occurrence, transport, and fate of environmental contaminants to guide efforts to manage and mitigate contamination.

- Characterize the national occurrence and distribution of priority natural and anthropogenic contaminants in environmental settings that integrate numerous contaminant sources and a range of exposure pathways, including the quantification of contaminant mixtures in various environmental media (air, soil, dust, rock, surface water, sediment, and tissue) and in vulnerable species and at-risk human populations.
- Provide a national assessment of point, nonpoint, and natural contamination sources to the environment, which documents the contaminant mixtures and loads from various sources, and relates that information to environmental occurrence data.

- Identify and quantify the physical and biogeochemical processes that affect the transport, transformation, and fate of environmental contaminants within aquatic environments, terrestrial environments, and the atmosphere.

- Develop contaminant occurrence and distribution models that integrate knowledge of contaminant sources, occurrence, properties, and transport processes to identify important environmental contaminants, quantify exposure pathways, determine how to mitigate contaminant releases to the environment, and determine how to manage existing contamination.

- Identify environmental settings and geographic areas that are particularly vulnerable to environmental contamination and identify vulnerable species and at-risk human populations associated with these settings.

Strategic Science Action 2.-Evaluate the threat of environmental contamination to the health of the environment, fish and wildlife, domesticated animals, and people, and inform the associated management and protection efforts.

- Conduct coordinated field and laboratory studies that (1) define exposure routes through various environmental media, (2) define toxicity thresholds for individual contaminants and mixtures, and (3) identify

\section{Pesticides and Risk to Fish Reproduction}

USGS scientists found that atrazine, one of the most widely used pesticides in the Nation, reduced reproduction in fathead minnows by disrupting egg production (Tillitt and others, 2010). To estimate the risk that atrazine poses to native fish, USGS modeled annual maximum 21-day average concentrations of atrazine in surface water (Stone and others, 2008) to compare to fish toxicity thresholds. The resulting map identifies large regions of the country where the concentrations of atrazine in surface water are above the thresholds for reproductive effects in fish [less than 0.5 micrograms per liter $(\mu \mathrm{g} / \mathrm{L})$ in blue; 0.5 to $5.0 \mu \mathrm{g} / \mathrm{L}$ in yellow; more than $5.0 \mu \mathrm{g} / \mathrm{L}$ in orange; gray is not modeled].

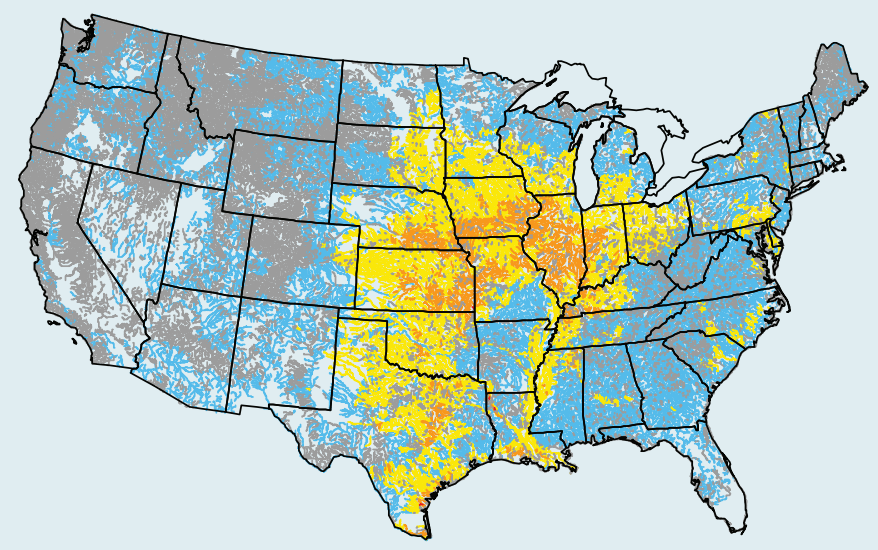

\section{EXPLANATION}

Estimated maximum 21-day moving-average concentration of atrazine, in micrograms per liter Not modeled $<0.5$ $0.5-5.0$ $>5.0-50.0$ $>50.0$ 
critical life stages of contaminant exposure in vulnerable aquatic and terrestrial species.

- Characterize the potential additive, synergistic, antagonistic, and potentiating effects of contaminants commonly found to co-occur in the environment, and integrate this knowledge into assessments and models of susceptibility, vulnerability, and the range of anticipated biological outcomes for aquatic and terrestrial organisms.

- Identify frequently detected contaminants for which toxicity benchmarks are not available, and collaborate with partner agencies to prioritize the development of benchmarks for targeted contaminants.

- Construct models designed to predict the effects of contaminant exposure on populations of aquatic and terrestrial organisms.

Strategic Science Action 3. - Characterize potential human exposure to support establishment of health standards and contamination-reduction efforts.

- Define potential human exposures to contaminants for a range of exposure pathways, including drinking water, recreational water, inhalation and dermal contact with contaminated air, aerosols, dusts, soils and sediments, and selected foods. Support assessments of total exposure, and to prioritize efforts that will have the most significant impact on reducing total human exposure.
- Quantify the performance of selected treatment technologies designed to reduce human exposure to contaminants, particularly drinking-water treatment technologies.

\section{Outcomes and Relevance}

These strategic science actions will provide new tools and fundamental knowledge for managing the release, mitigation, and remediation of the most significant environmental contamination problems facing the Nation in the next decade. An integrated understanding of contaminant sources, mobility, bioavailability, and physiological impacts will enable effective management actions that minimize contaminant releases and their adverse health effects. Specifically, these actions will (1) enable research to focus on the highest priority environmental contaminants, (2) inform management and regulatory actions that prevent or mitigate contaminant releases, (3) enable research and development to focus on the most needed improvements in treatment technologies and best management practices, (4) provide information that enables effective definition of water-quality criteria and other environmental health criteria, (5) enable wildlife conservation and ecosystem restoration activities to target the most vulnerable environmental settings and species, (6) enable wildlife scientists to better characterize and mitigate adverse health effects, and (7) provide public health managers with improved knowledge of human exposure to environmental contaminants. Providing this scientific information to government agencies, industry, and the public will be essential to overall efforts to safeguard the health of the environment.

\section{USGS scientists prepare to collect environmental samples at Orange Beach, Alabama following the 2010 Deepwater Horizon oil spill in the Gulf of Mexico. Photograph by Lori Lewis, USGS.}




\section{Goal 3: Reduce the Impact of Pathogens on the Environment, Fish and Wildlife, Domesticated Animals, and People}

Environmentally driven diseases caused by pathogens are an important cause of morbidity and mortality for all organisms. Understanding the factors that affect the distribution, transmission, and severity of these diseases is critical for mitigating population-level impacts on aquatic and terrestrial organisms. Changes in the distribution, patterns, or severity

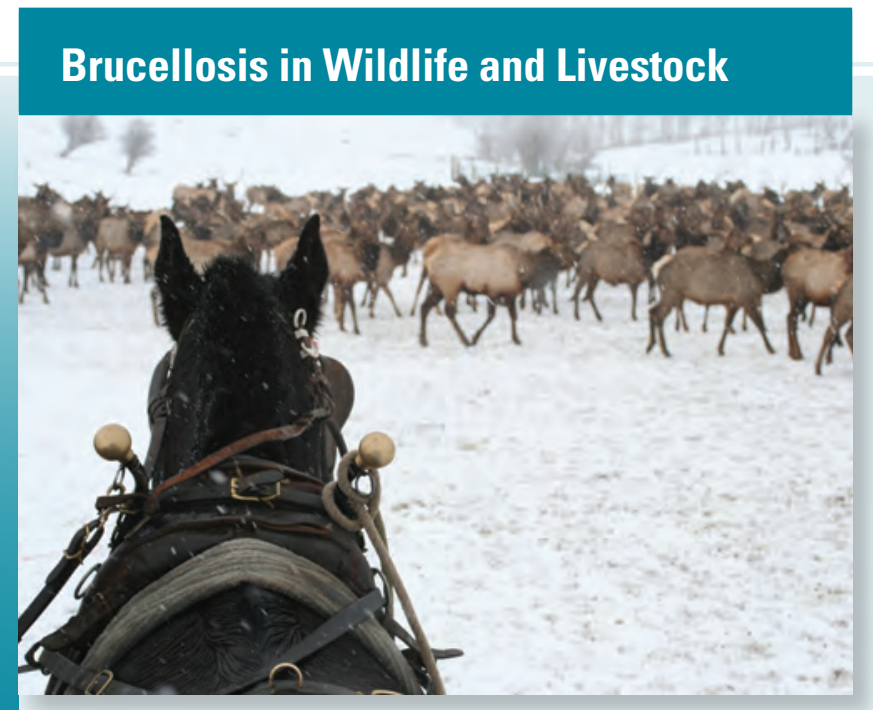

Brucellosis is a chronic bacterial disease in livestock and wild life and is among the most common zoonotic infections worldwide. In the Greater Yellowstone Region, brucellosis was probably introduced from cattle to bison (Bison bison) prior to 1917. Yellowstone bison are one of the few genetically unaltered bison populations; however, since they are also infected by brucellosis, they cannot be used to establish new bison populations elsewhere. After over 70 years of control efforts, brucellosis is almost eradicated in cattle, and the Greater Yellowstone Region is the last reservoir of Brucella abortus in the United States. USGS researchers and partners in state agencies have found that brucellosis is increasing in prevalence in elk (Cervus elaphus) and expanding into new regions, increasing the potential for wildlife-livestock conflict. Reducing artificial feeding by 30 days may reduce brucellosis by around two-thirds. USGS researchers are working with managers on this strategy and alternative methods to reduce the prevalence of brucellosis in elk and bison. Photograph, courtesy of Paul Cross, USGS, shows elk congregating on the Camp Creek Feed Ground in northwestern Wyoming. More information is available online at $h t t p: / / w w w$. esajournals.org/doi/full/10.1890/06-1603. of established diseases can result from a variety of factors such as increased global trade and travel, agricultural and aquacultural practices, habitat loss, climate change, changes in host density, and the introduction of non-native species. Microbial and parasitic adaptation and evolution and changes in common environmental reservoirs (soil, dust, groundwater, and surface water) also affect disease spread and transmission.

In the new paradigm of "One Health," the United States and world health agencies have acknowledged that the health of humans, animals, and the environment are inextricably linked (American Veterinary Medical Association, 2008; World Health Organization, 2011). Perturbations in one can adversely affect the others, but there is a significant gap in our understanding of how changes in earth and environmental processes affect the health of animals and people. A variety of transmission pathways influence the occurrence and distribution of diseases among wildlife, domesticated animals, and people (fig. 5). Novel infectious diseases frequently occur first in wild populations; native fish and wildlife can act as reservoirs for pathogens in the environment that can then "spill over" into domesticated animals (for example, brucellosis or viral hemorrhagic septicemia) or humans (for example, bubonic plague). Alternatively, other diseases can "spill back" into wild populations from humans or domesticated animals (for example, tuberculosis). Infectious diseases are also important from a conservation perspective. They can impede ecosystem function (for example, WNS in bats, chytridiomycosis in amphibians, and aspergillus in corals) as well as the survival or recovery of threatened and endangered species (for example, canine distemper and sylvatic plague in black-footed ferrets).

This goal builds upon USGS expertise in ecologic, geologic, hydrologic, and anthropogenic factors influencing disease occurrence in terrestrial and aquatic ecosystems. USGS has ongoing research and valuable stores of data on key fish, wildlife, human, and ecological health issues including vector-borne and zoonotic diseases, water and airborne contaminants, and bioaccumulation of contaminants. USGS has specialized laboratory facilities and internationally recognized expertise in infectious diseases of fish and wildlife, as well as expertise in the occurrence and transport of pathogens by water and atmospheric particulates. Research is being done collaboratively with Federal, State, Tribal and non-profit organizations with interests in the health of native fish and wildlife, zoonotic diseases, and infectious diseases affecting domestic agriculture or aquaculture.

\section{Priority Science Questions}

- What environmental factors influence the occurrence and control the distribution, severity, and dynamics of wildlife diseases affecting free-ranging 


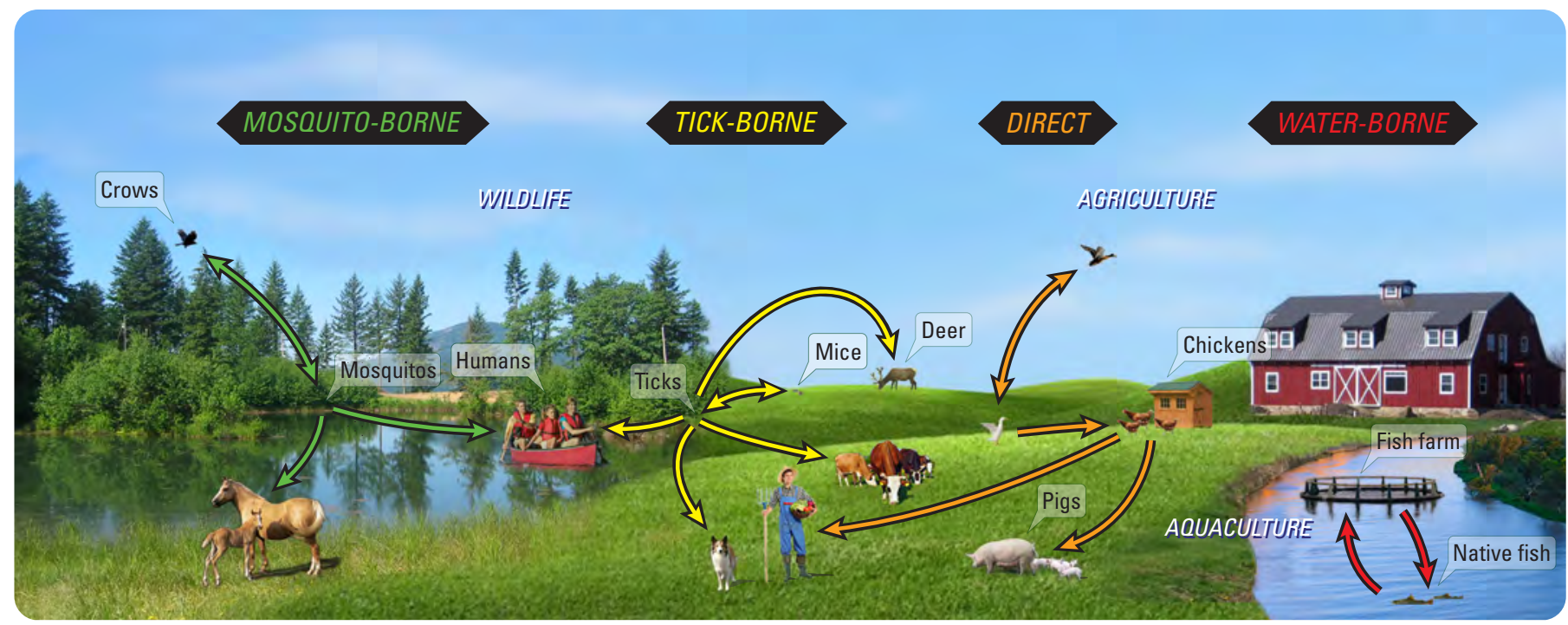

Figure 5. Infectious disease transmission pathways.

populations, and consequently, people and domesticated animals?

- What environmental factors drive the evolution of pathogens affecting aquatic and terrestrial species?

- In what ways are infectious diseases impacting the health or recovery of threatened and endangered species, as well as the natural functioning of ecosystems?
- What are the pathways, risk factors, and potential control strategies that affect transmission of diseases from aquatic and terrestrial wildlife reservoirs to agriculture and aquaculture, and vice versa?

- What are the exposure pathways, risk factors, and potential control strategies that affect transmission of infectious agents between wildlife and humans?

\section{White-Nose Syndrome in Bats}

During 2006-2007, a disease of unknown origin, subsequently named "white-nose syndrome" (WNS) began devastating colonies of hibernating bats near Albany, New York. USGS and collaborators later determined that WNS is caused by a novel fungus (Geomyces destructans). This new disease spread rapidly throughout the Northeast and continues to move into the Midwest, Southeast, and provinces of Canada, often resulting in 100 percent mortality. Although WNS does not pose a direct threat to human health, bats are primary insect predators and can eat up to 1,200 mosquitoes in 1 hour. Many insects, such as mosquitoes, transmit diseases, such as West Nile virus, to humans and animals. Insect populations also affect agriculture and forestry. As a result, declining bat populations

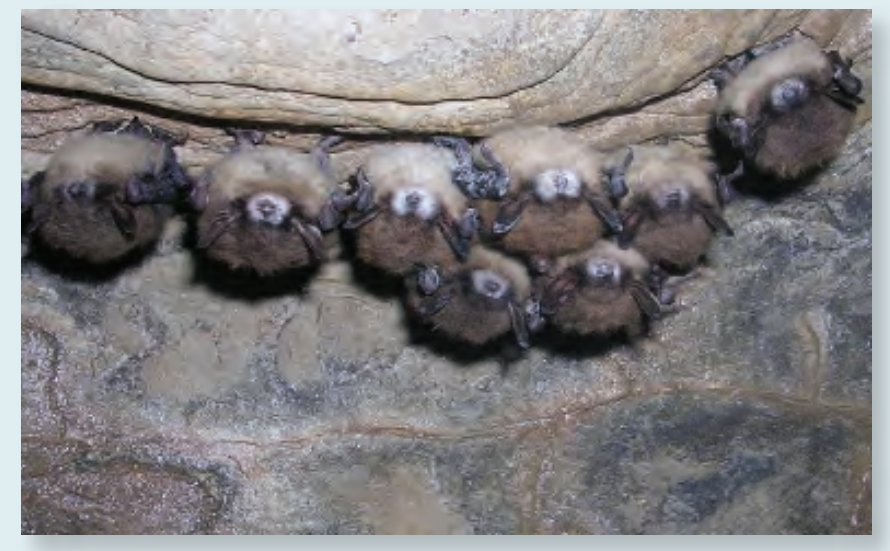
are likely to have significant economic impacts in terms of crop losses and increased pesticide use. Insectivorous bats in North America were estimated to be worth $\$ 22.9$ billion per year to the agricultural industry due their diet of insect crop pests (Boyles and others, 2011). Why did WNS emerge in New York, and why is it so lethal to bats? Answers to these questions will be critical in controlling this disease as well as preventing the next emerging disease. The photograph, courtesy of Nancy Heaslip, New York Department of Environmental Conservation, shows little brown bats (Myotis lucifugus) hibernating in a cave in New York State. Most have the white fungal growth typical of WNS on their muzzles. More information is available online at http://www.nwhc.usgs.gov/disease_information/white-nose_syndrome/index.jsp. 


\section{Strategic Science Actions}

A major focus of the activities conducted to achieve this goal will depend upon development of interdisciplinary teams capable of assessing the complexity of environmental and ecological factors that affect disease epidemiology and etiology. USGS will (1) determine the biotic and abiotic factors that control the ecology of infectious diseases in natural populations of aquatic and terrestrial species and potential transmission to other animals and humans, (2) establish how natural and anthropogenic environmental changes affect the distribution and severity of infectious diseases in aquatic and terrestrial species and potential transmission to other animals and humans, and (3) develop surveillance systems to identify

\section{Reduction of Bacterial Kidney Disease (BKD) in Chinook Salmon}

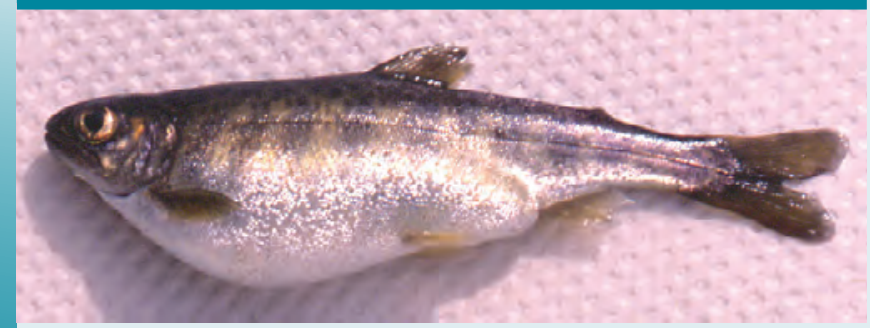

$\mathrm{BKD}$, caused by Renibacterium salmoninarum, is a chronic, systemic disease of Pacific salmon transmitted both to progeny and through the water to nearby fish. BKD causes major losses in Federal, State and tribal hatcheries, and evidence indicates that juvenile anadromous salmonids may die of BKD upon their entry into seawater. The disease is especially detrimental to populations of Chinook salmon (Oncorhynchus tshawytscha). It is difficult to control in hatcheries because effective vaccines do not exist and antibiotic therapy is only partially effective. The photograph, courtesy of Diane Elliott, USGS, shows a salmon with clinical signs of BKD. Most hatcheries rearing Pacific salmon have adopted aggressive programs for monitoring and controlling BKD. A standard hatchery practice for Chinook salmon is to screen female parents for the bacteria using an enzymelinked immunosorbent assay (ELISA) developed by USGS scientists, and to segregate or destroy progeny from female parents with high infection levels. This approach has proven to be a powerful tool for reducing BKD in the western United States, the Great Lakes, and elsewhere, resulting in increased survival of hatchery smolts before and after release, and a reduction in the potential impacts of BKD on wild salmonids in the same watersheds. More information is available online at http://www.tandfonline.com/doi/abs/10.1577/M09-044.1. changing patterns of disease activity in priority geographic areas.

Strategic Science Action 1.-Determine the biotic and abiotic factors that control the ecology of infectious diseases in natural populations of aquatic and terrestrial species and potential transmission to other animals and humans.

- Establish how geologic, climatic, hydrologic, and atmospheric factors influence the distribution of hosts, reservoirs, and vectors.

- Characterize the role of vectors, predators, invasive species, and biodiversity in disease transmission. Determine the biotic factors that influence host response to infection and the associated epidemiological implications.

- Determine the abiotic factors that affect the distribution, viability, transmission, and pathogenicity of infectious agents in soil, water, dust, and other aerosols.

- Determine the influence on disease of genetic drift due to host or geographic isolation, evolution of virulence in multihost and multipathogen systems, and barriers to host shifts.

Strategic Science Action 2.-Establish how natural and anthropogenic environmental changes affect the distribution and severity of infectious diseases in natural populations of aquatic and terrestrial species and potential transmission to other animals and humans.

- Conduct coordinated field and laboratory research on microbial diversity and the role of fish and wildlife as long-term carriers and reservoirs for disease, and investigate the impact of diseases on wildlife populations.

- Characterize the pathways, risk factors, and potential control strategies that affect the transmission of diseases among free-ranging fish and wildlife populations and domesticated animals, including contact patterns within and among species, nature of the reservoirs of infection, vector ecology, and developing methods of estimating transmission rates among different host species.

- Establish how natural and anthropogenic environmental changes influence the distribution, viability, transmission, and replication rate of pathogens and the host immune response.

- Characterize multihost and multipathogen systems, including research to understand the factors that drive the evolution of pathogens and their virulence, and develop models for estimating contact patterns among host species. 


\section{Effects of Plague on Wildlife May Have Been Underestimated}

Sylvatic plague, a flea-borne bacterial disease, poses risks to both wildlife and human health. It is a major obstacle to recovery of the black-footed ferret (Mustela nigripes), one of the most critically endangered mammals in North America. Prairie dogs, which the ferret depends on for food, are highly susceptible to the disease and transmit it to the ferrets. Currently plague is controlled by annual large-scale insecticide application. USGS scientists and colleagues are testing the feasibility of vaccinating prairie dogs against plague. The vaccine, which is mixed with bait and placed in areas where the ferrets live, will provide better protection against plague with less labor, lower costs, and less risk of nontarget ecological impacts than insecticide application. The vaccine has great potential to improve recovery efforts for the blackfooted ferret and may assist in protecting public health by reducing the prevalence of the disease in parks and urban areas where the potential for human exposure is high. Photograph courtesy of R. Haggerty, U.S. Fish and Wildlife Service. Additional information is available online at $h t t p: / / w w w . n w h c . u s g s . g o v / d i s e a s e \_i n f o r m a-$ tion/sylvatic_plague/index.jsp.

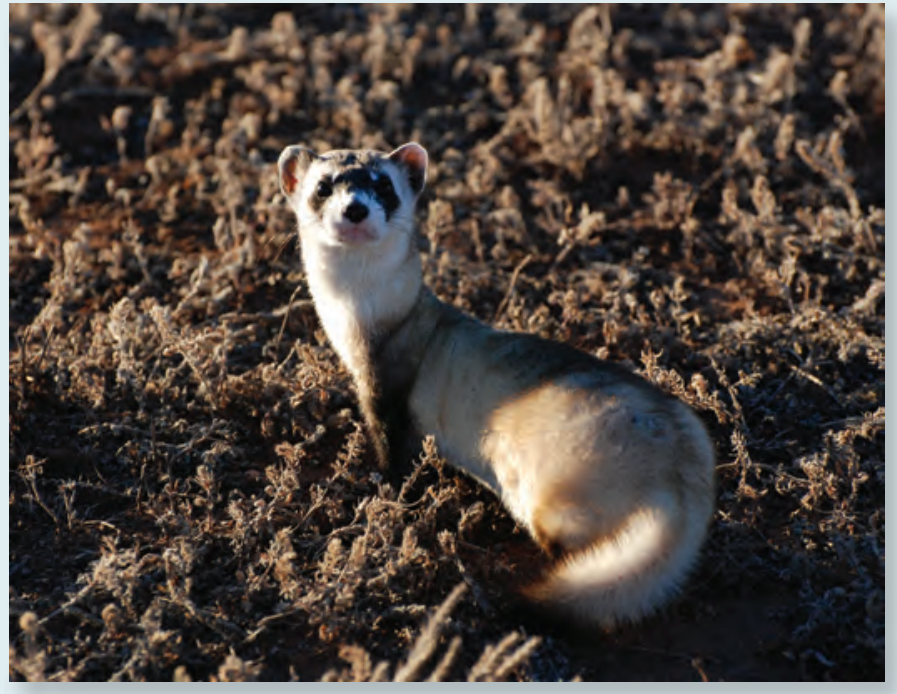

Strategic Science Action 3.-Develop surveillance systems to identify changing patterns of disease activity in priority geographic areas.

- Develop methods to identify geographic areas, ecosystems, and species that are increasingly vulnerable to wildlife disease.

- Develop methods to identify likely points of cross transmission of disease from wildlife population to domesticated animals, and humans.

- Utilize these tools to design and improve disease surveillance systems that provide early warning of wildlife disease outbreaks and are capable of identifying risks associated with cross transmission of disease.

Black-tailed prairie dog. Photograph by Dean Biggins, USGS.

\section{Outcomes and Relevance}

Wildlife and zoonotic diseases constitute a critical and growing threat to all species. Although the efforts of the aforementioned actions are based on a primary focus and expertise in wildlife disease, emphasis will be placed on the factors that affect transmission of diseases among free-ranging populations of aquatic and terrestrial animals, domesticated animals, and humans. Increasing direct interaction and collaboration with resource managers and health professionals responsible for protecting the health of wildlife, domesticated animals, and humans will improve our ability to provide needed expertise, knowledge, and tools. Interagency collaboration will increase efficiency and promote integration of efforts to better understand and prevent the risks of infectious diseases to natural populations of aquatic and terrestrial wildlife, domesticated animals, and humans. 


\section{Goal 4: Discover the Complex Interactions Between, and Combined Effects of, Exposure to Contaminants and Pathogens}

Animals and people can be exposed to multiple classes of disease agents (contaminants and pathogens) from a variety of pathways. Scientists traditionally have studied the effects of individual disease agents or classes of disease agents - for example, the effects of a pathogen or the effects of exposure to a contaminant. We have begun to understand that concurrent exposure to different classes of disease agents can have significant interactions, thereby contributing to an overall adverse biological outcome. This complexity poses a unique challenge for the natural science and public health communities.

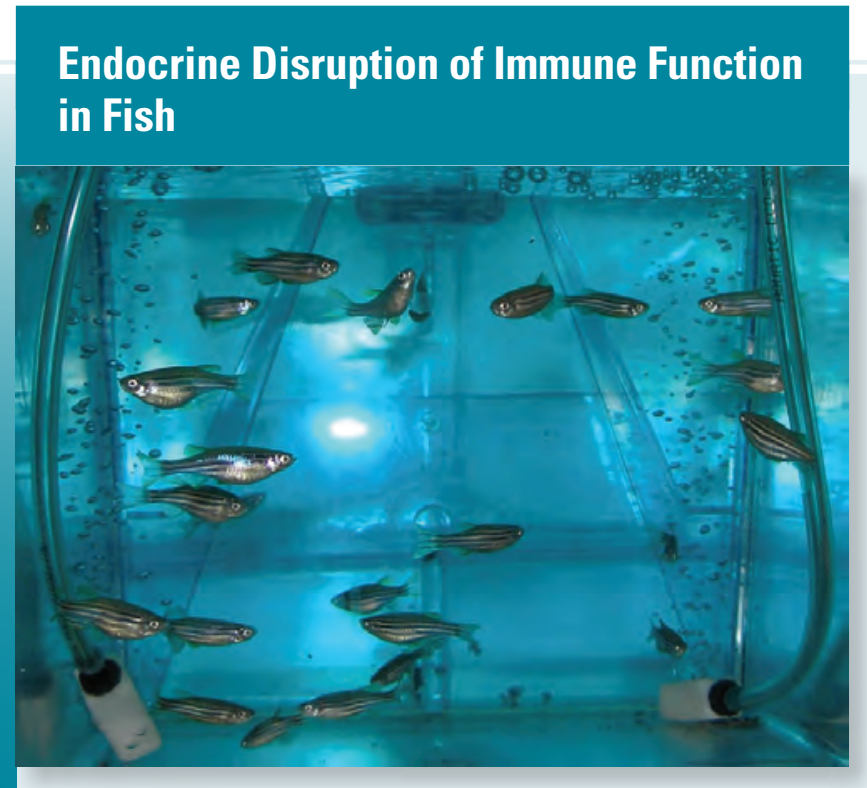

The growing prevalence of endocrine-disrupting chemicals (EDCs) in the environment is a global issue and may affect fish, wildlife, and humans. The dysfunction that can result from exposure to EDCs may manifest as reduced reproduction, modified sexual characteristics, immunosuppression, altered development, or a host of other maladies that subsequently can affect the health of native species. USGS scientists are conducting research into the immune dysfunction in fish caused by EDCs that may be responsible for a number of fish kills and disease outbreaks. USGS laboratory investigations use both native and model species of fish to understand mechanisms leading to compromised immune function. In addition, USGS scientists are developing diagnostic physiological, biochemical, and molecular indicators of EDC-induced immune dysfunction. Photograph, courtesy George Sanders, USGS, shows zebrafish (Danio rerio) used by USGS scientists to study the effects of EDCs on the fish immune system.
Understanding the impacts of combined toxicologic and infectious disease agents will require assessing biological outcomes mechanistically to determine the relative contributions of each agent.

Exposure to environmental contaminants may play a contributing role in significant wildlife declines, such as bee colony collapse disorder (CCD) and amphibian malformations. Although it is unlikely that chemical contaminants are solely responsible, it is possible that the adverse effects of contaminants could make organisms more susceptible to infectious disease or other stressors. A report by the U.S. Department of Agriculture (USDA) Colony Collapse Disease Steering Committee (U.S. Department of Agriculture, 2010) stated,

"Colonies with poor health, including colonies with CCD symptoms, exhibited increased pathogen levels and evidence of pesticide residues ... Findings currently suggest an association of sub-lethal effects of pesticides with CCD. ... The emerging evidence of pesticide exposure to pollinators and potential interactive effects indicates the need to further study pesticides for their potential interactions with CCD."

Contaminants can impact the immune systems of organisms, making them vulnerable to pathogens. Immunosuppression caused at least in part by chemical exposures in the environment has been suggested as a potential contributing cause of massive fish die-offs in the Potomac River drainage (Blazer and others, 2010). The authors stated,
"stressors include high helminth and myxozoan parasite loads, possibly as a consequence of high nutrient loads and/or immunosuppression; contaminant exposure, particularly to estro- genic compounds and complex mixtures; and other water quality factors, such as high $\mathrm{pH}$ and increased mean temperature."

The release of antimicrobial compounds to the environment raises significant implications for the interaction of contaminants and pathogens. Antimicrobials are designed to kill bacteria; when they are released into the environment, antimicrobials can adversely affect indigenous microbes and ultimately can contribute to the development of antimicrobial resistance. The release of antibiotics or antibiotic-resistant microorganisms to the natural environment can increase the development of, and exposure to, antimicrobial resistant pathogens. The Government Accountability Office (Government Accountability Office, 2011) stated,

"Scientific evidence gathered in our literature review shows that, at certain concentration levels, antibiotics present in the environment - in water and soil — can increase the population of resistant bacteria, due to selective pressure." 
The development and (or) spread of antimicrobial resistance through the natural environment raises significant implications for the management of human antibiotics released via household, commercial, and industrial wastes, and the use of veterinary antibiotics in livestock production.

This goal focuses primarily on understanding the dynamics between the effects of exposure to environmental contaminants and pathogens. However, many other environmental stressors (for example, habitat loss, changes in water quality, temperature and climate, run-off from resource extraction, flooding, and presence of non-native invasive species) must also be considered when managing the effects of stressors on fish and wildlife populations, as well as on local human populations. There is increasing awareness that environmental stressors, which may have little direct effect on the health of fish and wildlife populations, are capable of causing substantial indirect effects. These indirect effects may be hard to predict - resulting in what Paine and others (1998) called "ecological surprises." For example, as in the case of amphibian deformities, where nutrient runoff into waterways can result in changes to water quality and eutrophication (Johnson and others, 2007), which may not directly affect the health of organisms, but can serve as catalysts for other processes that do.

\section{Priority Science Questions}

- What are the biological outcomes in aquatic and terrestrial organisms resulting from exposure to a combination of contaminants and pathogens?

- What are the mechanisms of interaction among combinations of contaminants and pathogens?

- What are the highest priority combinations of contaminants and pathogens with the greatest potential to impact aquatic and terrestrial organisms and people, and the geographic areas and environmental settings where they are most likely to occur?

- How do we identify the relative contributions of combinations of contaminants and pathogens to adverse health outcomes?

- How do exposures to combinations of contaminants and pathogens affect the susceptibility of aquatic and terrestrial organisms to other environmental stressors?

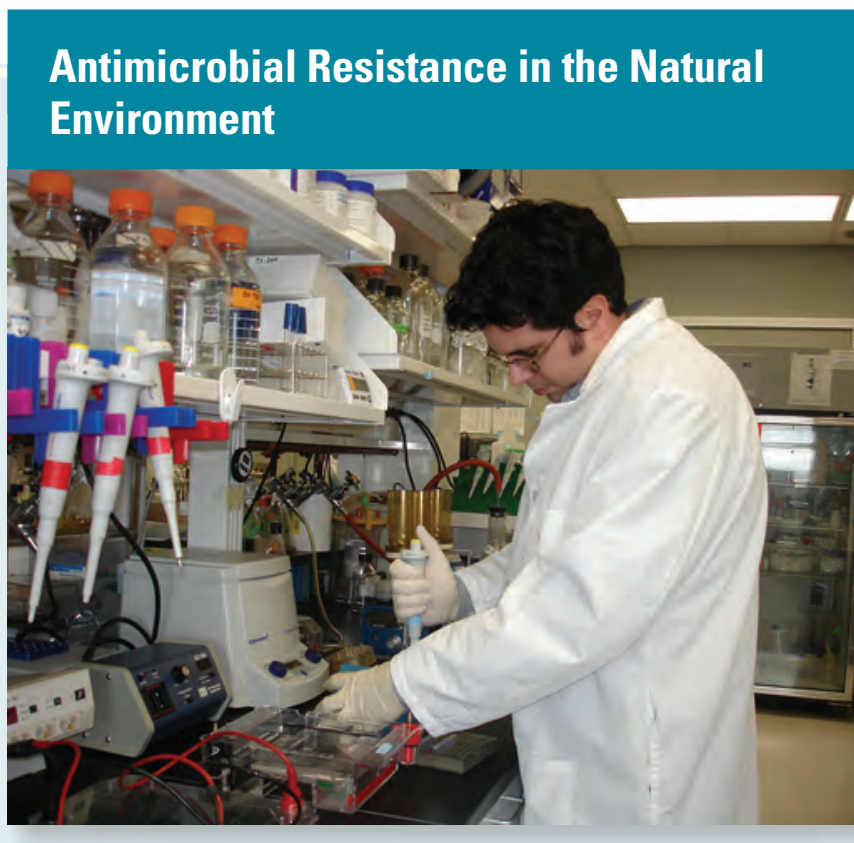

Antimicrobials, such as antibiotics used for human and animal health, have been detected in aquatic and terrestrial environments, largely as a result of release via wastewater discharges, and use in animal agriculture and aquaculture. To explore the potential spread of antimicrobial resistance from veterinary use of antibiotics, USGS surveyed tetracycline and sulfonamide antibiotic resistance genes (ARGs) in waste lagoons in varied livestock operations (McKinney and others, 2010). In all lagoons, sulfonamide ARGs were observed to be generally more recalcitrant than tetracycline ARGs. It was found that layer chicken farms had the lowest concentrations of both tetracycline and sulfonamide ARGs and low total antibiotic concentrations. Sulfonamide ARGs were highest in swine lagoons, which generally corresponded to the highest total antibiotic concentrations. This study provides insight into potential options for managing antimicrobials and antibiotic resistance emanating from agricultural activities, and for evaluating potential threats to the continued effectiveness of animal and human drug therapies. Photograph courtesy of Lisa Fogarty, USGS, shows USGS scientist analyzing bacterial DNA extracted from water samples.

- What metrics should be used to document and assess the impacts of combinations of contaminants and pathogens? 


\section{Strategic Science Actions}

Strategic science actions to address Goal 4 will require integration of expertise that is not traditionally brought together in environmental studies. In order to achieve the objectives, the USGS will (1) identify how exposure to one class of disease agents (contaminants or pathogens) can make an organism more susceptible to adverse effects from exposure to the other class of disease agents, and (2) implement interdisciplinary studies that characterize the effects of the combined exposure to pathogens and contaminants.

Strategic Science Action 1.-Identify how exposure to one class of disease agents (contaminants or pathogens) can make an organism more susceptible to exposure to the other class of disease agents.

- Identify environmentally driven diseases and disease agents that have biological outcomes that result in increased susceptibility to the other class of disease agents.

- Focus toxicological studies on determining the thresholds of effects of one disease that may affect susceptibility to another disease and define the exposure and life history scenarios needed to predict and mitigate impacts.

- Identify the disease agents with the greatest potential to increase susceptibility of disease in aquatic and terrestrial organisms.

- Identify and characterize the biological mechanisms by which organisms that are affected by one class of disease agents become more susceptible to the other class of disease agents. Determine how interactions among diseases can be modulated by immune or other biological system functions, and whether such interactions rise to a level of having population-level consequences.

\section{Demonstration wetland at Henderson, Nevada, where vegetated hummocks were built into the wastewater treatment wetland to improve its effectiveness and sustainability, as well as provide quality wildlife habitat. Photograph by Joan S. Daniels, USGS.}

Strategic Science Action 2.-Implement interdisciplinary studies that characterize the effects of combined exposure to pathogens and contaminants.

- Establish interdisciplinary teams of scientists with crosscutting expertise that can integrate analytical, experimental, and modeling approaches from different disciplines to provide scientific tools and fundamental information essential for use in a comprehensive approach to protecting wildlife health from the combined effects of multiple classes of disease agents.

- Integrate the occurrence of environmentally driven diseases into an assessment of vulnerability to other classes of disease to which they could contribute.

- Develop models that identify environmental settings and species that are vulnerable to combinations of contaminants and pathogens. Anticipate and forecast risk from novel combinations of contaminants and pathogens.

- Utilize knowledge gained about the impacts of multiple classes of disease agents on wildlife to identify potential human-health issues associated with interaction of multiple classes of disease agents. For example, because of the similarity of the endocrine system across vertebrate animals, aquatic and terrestrial wildlife can provide a means to identify potential contaminant-induced vulnerabilities to pathogenic disease agents in humans, such as suppressed immune function.

\section{Outcomes and Relevance}

The aforementioned strategic science actions will enhance the understanding of the effects of exposure to complex combinations of disease agents, help explain heretofore incompletely explained disease, and help to more accurately quantify the individual impacts of different disease agents on the health of aquatic and terrestrial organisms. Resource managers will use this knowledge to identify vulnerable populations and diagnose and respond to disease outbreaks that may not be fully explained by our understanding of the effects of single classes of disease agents.

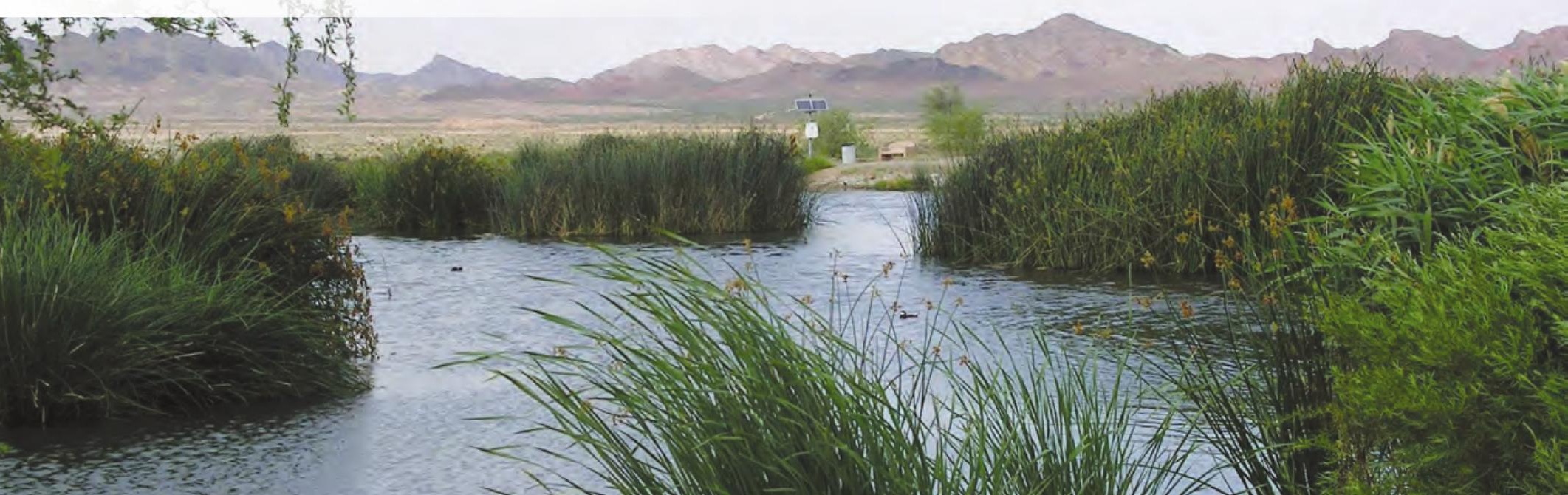




\section{Goal 5: Prepare for and Respond to the Environmental Impacts and Related Health Threats of Natural and Anthropogenic Disasters}

The environmental and related health impacts of disasters have long been recognized, but are understandably overshadowed by the more visible physical impacts of the disasters and the resulting casualties. However, natural and anthropogenic disasters (for example, earthquakes, volcanic eruptions, floods, droughts, fires, industrial accidents, oil spills, acts of terrorism, and pandemics) pose significant immediate and long-term threats to the environment, and as a result, to the health of humans and other organisms. Increasingly, the public and the media are recognizing the environmental health implications of disasters, particularly their potential to affect public health, animal health, quality of life, the economy, and national security. Helping communities and natural resource managers prepare for, respond to, and recover from environmental health impacts of disasters is, therefore, an increasingly important component of disaster resilience. Achieving this goal requires preparedness by using lessons learned from previous disasters and the capability for rapid and immediate response to disaster in order to prevent catastrophic losses, including economic losses.

A disaster event can be a catalyst that leads to release of potentially hazardous materials containing contaminants or pathogens into the environment. Some examples include mobilization and dispersal of contaminants as a result of hurricane wave action, leaking of radiation after earthquake damage to a nuclear reactor, or release of contaminants or pathogens from a wastewater treatment plant due to flooding. Environmental health threats also can occur when the disaster event results in environmental conditions that can promote infectious disease outbreaks such as cholera or dengue fever. USGS has made significant contributions toward understanding the immediate and long-term environmental and humanhealth effects of disasters, including the World Trade Center catastrophe, Hurricane Katrina, and wildfires (Plumlee, 2009). Similarly, USGS has made significant contributions to understanding the impacts of disasters on the environment and fish and wildlife health, including the Deepwater Horizon Oil Spill, and the impacts of strategies for managing the spill (U.S. Geological Survey, 2012a). USGS also provides critical information needed for developing restoration strategies after a disaster.

There is a clear and expanding role for the USGS in responding to emerging disease threats related to bioterrorism, as well as naturally occurring pandemic disease outbreaks. Wildlife morbidity and mortality events can serve as early warning systems for detecting human-health threats associated with bioterrorism and natural pandemics. Most of the disease agents that could be used for bioterrorism listed in the National Select Agent Registry (Animal and Plant Health Inspection Service and Centers for Disease Control and Prevention, 2011) can affect and (or) be transmitted by wildlife species. Engagement and collaboration with other DOI agencies, the Department of Homeland Security, the Federal Bureau of Investigation, the Department of Health and Human Services, the U.S. Department of Agriculture, and others is critical to effectively prepare for and respond to these types of threats.

The USGS role in environmental health disaster response and preparedness is to provide impartial interdisciplinary research, data, and interpretations on disaster-related health issues including the sources, distribution, fate, and impacts of contaminants and pathogens. The USGS contributes specialized expertise in wildlife pathology, toxicology, epidemiology, environmental monitoring, and wildlife disease surveillance. In addition, USGS has specialized diagnostic and experimental research laboratories, including those that are certified for working with selected disease agents. USGS has an extensive mix of expertise, data, and technologies across its mission areas that can be brought together to improve understanding of the implications of disasters on ecological, human, and animal health. To fully leverage its environmental health science capability, USGS must collaborate with external experts in emergency response, public health and safety, homeland security, law enforcement, and ecosystem and animal health (both agriculture and aquaculture).

\section{Priority Science Questions}

- What types of hazardous materials can be released to, or mobilized in, the environment from various types of disasters? What are the associated ecological and human health threats?

- How does the environmental disruption associated with disasters influence the emergence, incidence, and distribution of infectious diseases?

- How can we prepare and monitor for, and rapidly respond to, pandemic outbreaks or acts of bioterrorism?

- How can the environmental and health impacts of past disasters be measured and interpreted to help anticipate plausible environmental health impacts of future disasters?

- What are the economic costs associated with the environmental health impacts of disasters? What are the costs as compared to benefits of alternative management strategies?

\section{Strategic Science Actions}

Natural and anthropogenic disasters are dynamic events that can cause significant environmental disruption and health risk. They require prompt investigation in order to define their immediate and enduring environmental health 


\section{Responding to Recent Wildfires and Their Potential Environmental Health Risks}

wildlife, and human health. These assessments will characterize changes in the environmental distribution of hazardous materials and pathogens produced by disasters, assess the potential for increased exposure, and explore the use of remote sensing to map the characteristics of disease agents within and away from disaster areas.

- Work with other Federal agencies to conduct interdisciplinary investigations of environmentally driven diseases that result from disasters, including changes in wildlife zoonotic diseases and the adverse impacts of hazardous materials. Assist resource managers in utilizing this information to develop management strategies.

- Promptly gather and release preliminary data and interpretations to emergency responders, disaster planners, and other decisionmakers in a timely and useful context to aid in disaster recovery.

- Improve and expand capabilities to measure and anticipate the economic and social implications of environmental disasters.

Strategic Science Action 2.-Enhance methods to anticipate, prepare for, and identify environmental and related health impacts of future disasters.

- Enhance real-time capabilities to warn of associated environmental health risks as disasters are happening.

- Gather new baseline data in areas identified as high risk for types of disasters and the associated environmental health concerns, and develop methods to reconstruct pre-disaster environmental baseline conditions, by using knowledge of current environmental conditions and lessons learned from previous disasters.

risks. The USGS will (1) establish a formal interdisciplinary science capability to rapidly assess the environmental health risks associated with disasters, and (2) enhance methods to anticipate, prepare for, and identify environmental health impacts of future disasters.

Strategic Science Action 1.-Establish a formal interdisciplinary science capability to rapidly assess the environmental health risks associated with disasters.

- Establish a capability for rapid assessment of shortand long-term impacts of disasters on the environment,
- Enhance methods, including predictive models and scenario development exercises, to anticipate and prepare for environmental, ecological, and related health impacts of future disasters. Work with USGS natural hazards experts to contribute environmental and ecological hazards components to multihazards disaster scenarios, such as the ARkStorm, New Madrid earthquake, and Great Southern California ShakeOut earthquake scenarios (U.S. Geological Survey, 2012b). 


\section{A Strategy for Communicating Science to Society}

This strategy is built upon the premise that USGS activities are integrated within an adaptive management framework; the role of USGS within this framework is to provide continual improvements in scientific knowledge and tools that are used directly to guide recurring and incremental improvements in environmental health management and protection (fig. 3). Communication with partners and stakeholders regarding science needs is essential for successful implementation of this strategy. USGS is widely acknowledged as a source of highquality, objective, and unbiased scientific information; however, the best science has limited utility unless it is effectively disseminated and used to inform the highest priority decisions.

Keys to successful communication include: (1) increasing awareness of USGS as a source of environmental health science; (2) engaging stakeholders from the onset in identifying priorities and goals; (3) coordinating with partners to increase synergies and make the best use of available resources; (4) delivering a synthesis of environmental health science information and tools from across the USGS in effective, useful, and useable formats; and (5) continuing to work with stakeholders through the decisionmaking process to explain the implications of the available science. Maintaining a lasting, iterative exchange of priorities and knowledge with stakeholders will require formal and committed communication.

USGS must promote communication among those who develop the scientific information, (including both USGS scientists and partners), and managers, policy makers, industry, and the public. This is particularly important in improving communication among scientists involved in earth sciences, wildlife and animal health, and public health. The National Research Council on Research Priorities for Earth Science and Public Health stated,
"Although valuable linkages do currently exist between the earth science and public health commu- nities, the limited extent of interdisciplinary coop- eration has restricted the ability of scientists and public health workers to solve a range of complex environmental health problems, with the result that the considerable knowledge at the interface of earth science and public health has been only partially realized" (National Research Council, 2007).

The need for effective and broad-ranging internal communication within USGS will only increase as national and international environmental health challenges require a wider range of scientific expertise. This communication strategy requires that scientists from across the USGS coordinate their activities, broadly advance the state of environmental health science, and develop technologies and tools that integrate science of varied disciplines to assist management actions.

\section{Strategic Actions}

Access to, and awareness of, USGS environmental health science contributions will be increased by actions that consolidate and deliver health-related information to stakeholders in a timely manner. A USGS environmental health science web page will provide a portal to all USGS environmental health

\section{United States-Mexico Border Health Initiative and Environmental Health-Risk Assessment Along the Upper Santa Cruz River}

The primary objective of the USGS Border Environmental Health Initiative (BEHI) is to provide data in support of environmental health decisionmaking by public health officials, resource managers, and concerned citizens. One focus is the study of inadequate water quantity and quality caused in large part by extreme human population growth in the dry regions of the United States-Mexico border. The Upper Santa Cruz River, located on the Arizona-Sonora border, is important for its cultural, historical, and ecological value. The river supports a high diversity of plants and animals, but it also sustains human communities by replenishing groundwater, a primary regional water source. Researchers involved in the USGS $\mathrm{BEHI}$ are developing a water quantity and quality model for the Santa Cruz watershed and investigating potential bioaccumulation of contaminants in the food web. The model can be used to analyze various land use and wastewater management

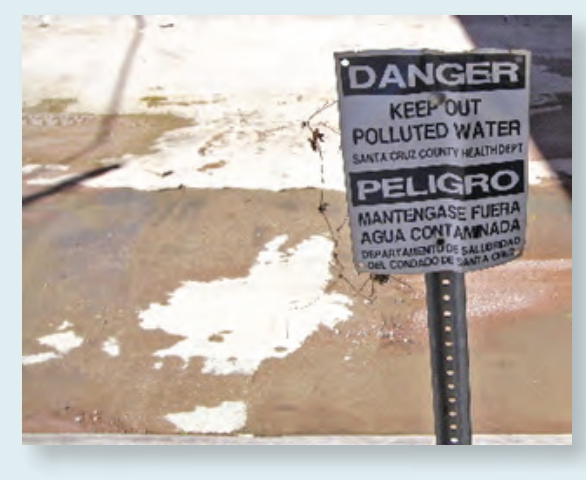
scenarios. The photograph, courtesy of Hans Huth, Arizona Department of Environmental Quality, Office of Border Environmental Protection, was taken Nov. 1, 2010, at the point of discharge of Nogales Wash to the Santa Cruz River, Arizona, and shows a public warning of water pollution. More information on the United States-Mexico BEHI is available online at $h t t p: / /$ borderhealth.cr.usgs.gov/projectindex.html. 
science information. Developing clear and objective messages about environmental and health threats will be aided by consultation with risk communication specialists, especially regarding communicating peer-reviewed findings in the face of scientific uncertainty. The USGS GeoHealth Newsletter (U.S. Geological Survey, 2012c) will widely disseminate USGS environmental health science findings. USGS podcasts - available on the USGS CoreCast web site (U.S. Geological Survey, 2011) - will help communicate new findings and activities to stakeholders. In addition to traditional communication tools, new social media tools will be particularly useful for delivering time-sensitive and high-visibility findings, and communicating with a generation that relies heavily on social media for information. Social media and other emerging technologies can promote environmental awareness among the general public and enable the infusion of new ideas into our cultural fabric. Together, these measures will be especially useful for raising public awareness regarding actions that the public can take to safeguard the environment. Increasing our youths' awareness of the importance of environmental health science to societal goals will enhance enthusiasm in the next generation for protecting the environment and improving our future. USGS will use social media and other emerging technologies to engage students in these issues and recruit the next generation of passionate young scientists.

Effective coordination with managers and policy makers to identify science priorities will be aided by a USGS Environmental Health Liaison Committee. This committee will enhance the flow of information from stakeholders to USGS science planning. It also will improve collaboration with partners to achieve synergies and make the most of existing resources. It will supplement active participation in Federal interagency committees on the environment, such as the National Science and Technology Council's Committees on Environment, Natural Resources and Sustainability, and Homeland and National Security (Office of Science and Technology Policy, 2011), and the Institute of Medicine's Roundtable on Environment, Health Sciences, Research, and Medicine (Institute of Medicine, 2011). The Environmental Health Liaison Committee will facilitate dialogue between scientists and managers that brings together their expertise,

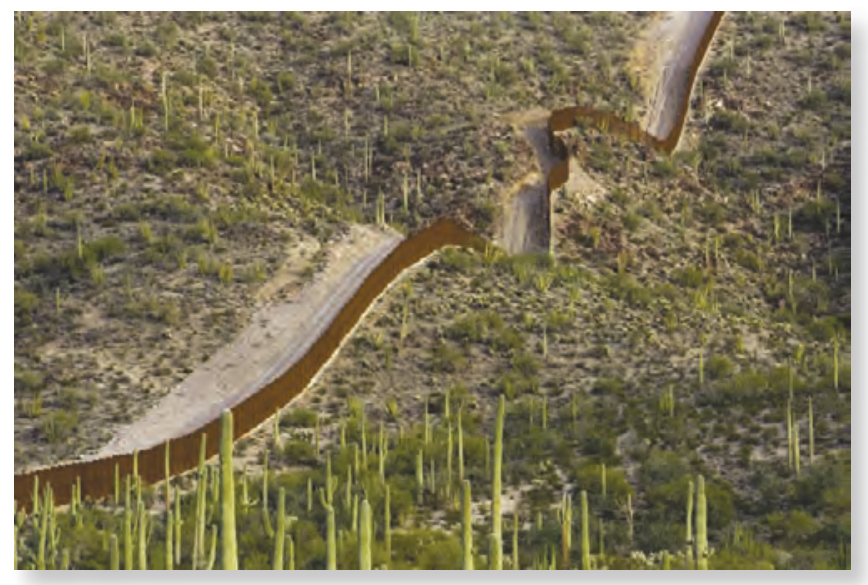

strengths, and perspectives. This dialogue will help to identify priorities, relate scientific information to manage decisions, and map next steps. Similarly, periodic environmental health conferences, such as recent USGS conferences targeting linkages with the public health community (Buxton and others, 2008), will foster collaboration with our partners and communication with stakeholders. Steps will be taken to increase USGS participation in conferences of the environmental and public health communities to increase awareness of USGS as a resource.

Coordination of science activities within USGS will be aided by a framework for synthesizing USGS environmental health science information from across the Bureau. The framework will link databases that have relevance to environmental health decisionmaking and facilitate consideration of all relevant data regardless of source. The framework will include networking among scientists from diverse programs and organizational entities across the Bureau. The framework will be enhanced by use of modern informatics, geographic, and mapping technologies to improve USGS data and information integration, accessibility, and dissemination.

\section{Outcomes}

The causes of newly discovered environmental health threats are often uncertain. The environmental data required to address the problem are frequently incomplete or unavailable. There is also a lack of available information necessary to anticipate and respond to emerging environmental health threats. As a result, decisionmakers often are left to integrate disparate threads of scientific evidence into a coherent understanding upon which scientifically and socially defensible decisions can be based. Through implementation of this strategy, the USGS will create, analyze, interpret, and manage environmental health data. The USGS will provide knowledge and information to decisionmakers in a manner that is easy to access, easy to use, and where appropriate, in real time. The USGS will aid in the application of science to management decisionmaking. Delivery of such information enhances the Nation's ability to prevent and mitigate future threats and take effective management actions to manage and minimize documented threats.

\footnotetext{
The United States-Mexico border fence cuts through a forest of saguaro cactus on the Sonora Mexico and Arizona border, 2012. Photograph courtesy of Jack William Dykinga, @Dykinga Photography.
} 


\section{Integrating Science Across USGS}

The Environmental Health Science Strategy presents plans for research and development activities intended to identify emerging and other priority environmental health issues and provide information and tools to improve management responses to those issues. The USGS will synthesize and interpret a wide range of environmental information from across the Bureau and focus it on a broad spectrum of environmental health issues. One priority in implementing this strategy is to provide a point of access to all environmental health science within the Bureau. Overlap and coordination among this

\section{Uranium Production and Environmental Health}

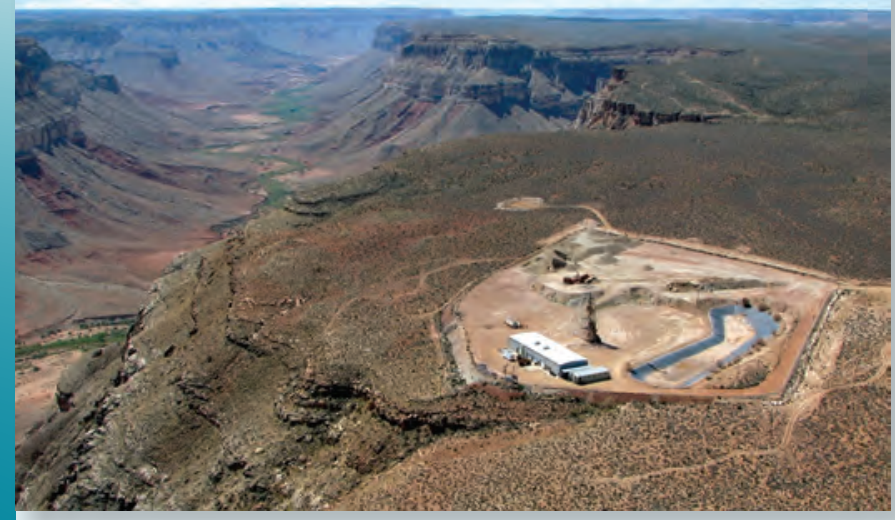

Re-evaluation of nuclear energy as a viable alternative energy source may have a significant impact on uranium production in the United States. Nuclear energy provides about 20 percent of U.S. electricity from 104 nuclear power plants; the U.S. is the largest producer of nuclear-sourced electricity in the world. Approximately 3.9 million pounds of uranium were mined in the U.S. in 2008; however, about 51 million pounds were consumed. Foreign sources and U.S. utility inventories supplied the difference. Informed decisions regarding future sources of nuclear resources in the U.S., as well as an effective means of resource extraction will be aided by an understanding of the potential environmental impacts of domestic production. USGS scientists with knowledge of extraction practices, the geochemistry of uranium deposits, the processes that affect environmental transport, and the pathways of exposure and ecotoxicity for uranium and its radionuclides, are working together to provide information to resource managers and industry that will minimize the environmental impacts of increased uranium extraction. Photograph, courtesy of Don Bills, USGS, shows the Kanab North Mines, northern Arizona. science strategy and the other six USGS science strategies is inevitable and essential. Scientific information collected to meet the goals of one strategy is inherently applicable to the goals of other science strategies.

The research and development activities outlined in this strategy rely on broad national characterizations of background or baseline (pre-impact) environmental conditions and environmental stressors provided by companion USGS science strategies. The Water, Ecosystems, Energy and Mineral Resources, and Core Science Systems Science Strategies will provide information from significant environmental monitoring and assessment studies. The Climate and Land Use Change, Natural Hazards, and Energy and Mineral Resources Science Strategies will provide information on the nature of other environmental stressors.

The Environmental Health Science Strategy will support the activities of the other six science strategies by providing new and innovative tools, as well as broad fundamental understanding of disease outbreaks, environmental life cycle of anthropogenic and natural contaminants, ecology of pathogens that cause infectious diseases, and potential measures for preventing or mitigating exposure pathways and disease. Collectively, implementation of the seven USGS science strategies will allow the coordination of research activities, the sharing of expertise and information, and the coordination of efforts to put scientific information and tools into the hands of decisionmakers. The following sections describe examples of complementary activities with other USGS mission areas.

Climate and Land Use Change-Global change affects environmental conditions that determine the distribution of contaminants and pathogens, ecological and human exposures, the severity with which they might cause disease, and their ultimate fate. These environmental effects include changes in the distribution of pathogens, their hosts, and vectors caused by changes in habitat; the effects of changes in temperature and seasonality on disease resistance in fish, reptiles, and amphibians; increases in contaminant loads and pathogen abundance; changes in the number and severity of extreme weather events; and increases in windborne contaminant and pathogen exposure pathways. The varied impacts of global change will also influence the susceptibility of aquatic and terrestrial organisms to other environmental stresses, making those impacts an essential consideration in the multiple stressors that could be affecting the health of the environment. Knowledge of the environmental effects of climate and land use change gained by implementation of the Global Change Science Strategy will be essential for comprehensive environmental 


\section{Sensitivity of Freshwater Mussels to Ammonia Results in Lower Water-Quality Criteria}

Approximately 10 percent of native North American freshwater mussels and snails have become extinct in historical times, and about one-half of the remaining 900 species are of conservation concern. One hundred freshwater mollusk species are listed by the U.S. Fish and Wildlife Service as threatened or endangered. Factors that contributed to these declines include habitat alteration, invasive species, over-utilization, disease, predation, and contaminants. USGS toxicologists helped develop a new standard method for conducting toxicity testing on freshwater mussels and found that mussels are frequently more sensitive to ammonia than standard test organisms. This is noteworthy because ammonia is the most ubiquitous toxic chemical in our Nation's surface waters. Consequently, U.S. EPA is using mussel toxicity data to update the National WaterQuality Criteria for ammonia, lowering the acute criterion

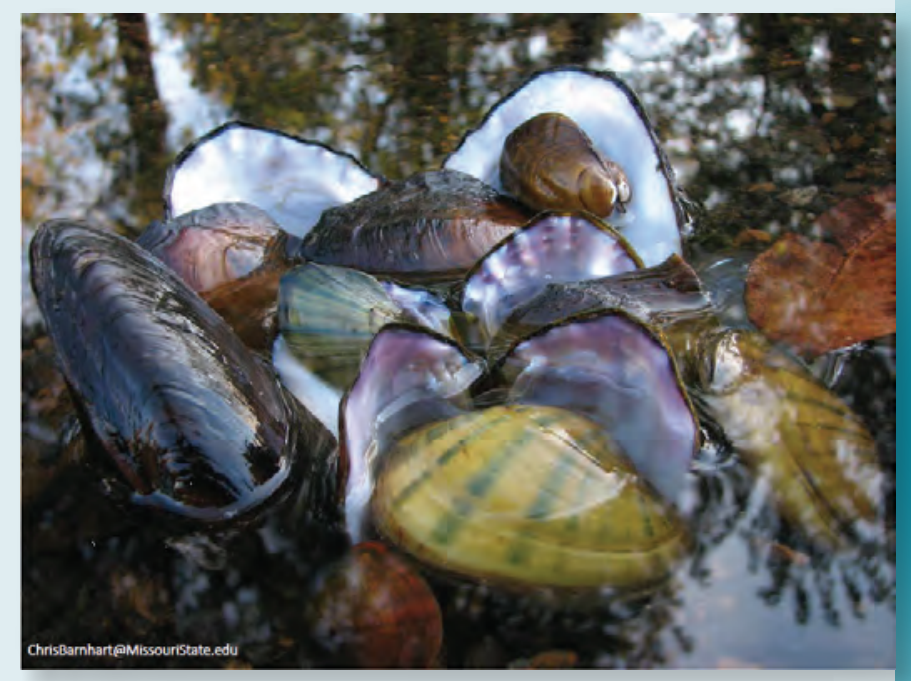
by about three-fold and chronic criterion by about five-fold.

Photograph, courtesy of Chris Barnhart, shows an assemblage of mussels from the Pomme de Terre River, Hickory County, Missouri, including black sandshell, white heelsplitter, fatmucket, pink heelsplitter, three-ridge, deertoe, and pocketbook. More information is available online at $h t t p: / / w w w . c e r c . u s g s . g o v / P r o j e c t s$. aspx?Projectld $=5$.

health assessments. The Environmental Health research activities and efforts to establish linkages with the public health community will assist global change assessments, particularly in regard to the human-health implications of global change.

Core Science Systems - Data on the geographic, geomorphologic, and geologic characteristics of the earth and the human infrastructure across the landscape are essential for any evaluation of the factors that affect the environment and associated impacts on the health of the environment. Determination of the cause of current environmental impacts and forecasts of potential future environmental impacts will require core science information on past trends, and will require projections of future changes in human activities on the landscape. Activities under the Core Science Systems Science Strategy will be a valuable source of this information, as well as a source of innovative tools for relating spatial data to environmental health outcomes, such as data on sources and distribution of environmental contamination and distribution of disease occurrence. Furthermore, the Core Science Systems Science Strategy will fulfill valuable supporting activities for the Environmental Health and other science strategies by providing tools for geospatial analysis of large datasets and providing innovative approaches to increase accessibility to a wide range of natural science information from all other USGS science strategies.
Ecosystems - The improved understanding of fundamental ecosystem processes and functions that will be developed by the Ecosystems Science Strategy is essential to characterizing and responding to the impacts of environmental contaminants and pathogens. The effects of ecosystem changes will alter organisms' exposure to chemical contaminants, vectors, and pathogens. Changing habitats and biodiversity will affect the resilience of ecosystems to environmentally driven disease. The degradation of ecosystem processes ultimately may lead to adverse effects on human health. Invasive species can serve as a source of exotic pathogens. A broad range of ecological stressors will contribute to cumulative ecological impacts. Knowledge of the effects of ecological factors as well as alternative resource management actions will be essential in preventing and mitigating the effects of environmentally driven disease. An understanding of the linkages between changes in ecosystem function and health risks is necessary to identify and predict emerging health risks, and to develop adaptive management strategies.

Energy and Mineral Resources - All actions to extract and use energy and mineral resources have some implication for the environment. Mineral and coal mining, generation and disposal of produced waters, burning of fossil fuels, spills and leaks of energy and mineral industry chemicals, hydraulic fracturing, and development of alternative energy sources such 
as biofuels, new battery technology, and geothermal and wind energy all can impact the environment. Actions of this strategy and the Energy and Mineral Resources Science Strategy will be coordinated to evaluate the environmental impacts and resulting public health implications of energy and mineral resource production and use. Energy and Mineral Resources research activities will help characterize the mineralogic and geochemical properties of energy and mineral resource deposits, baseline geochemical conditions in soil and sediment, and the mobilization of naturally occurring contaminants by resource extraction activities. Environmental Health research activities will provide expertise in the factors that affect contaminant transport, exposure pathways to aquatic and terrestrial organisms, and ecological effects.

Natural Hazards-Beyond the immediate threats posed by floods, hurricanes, wildfires, volcanic eruptions, and earthquakes, these disasters can leave lingering environmental health concerns. Natural hazards often cause environmental disturbances that have an impact on the sources of, and exposures to contaminants and pathogens. The long-term environmental health consequences of natural disasters, which are often less understood, can warrant significant concern. Strategic activities under the Environmental Health Science Strategy will be coordinated with the Natural Hazards Science Strategy to help characterize the environmental health effects of hazards by: (1) building upon their actions in immediate response to such disasters with assessments of potential longterm environmental health implications, including changes in contaminant sources and exposure pathways and changes in the habitat of pathogens and vectors, (2) improving preparedness by helping to identify measures that will prevent or mitigate potential environmental health problems, and (3) defining rapid-response actions that can be taken to quickly define environmental health risks in the immediate aftermath of disasters.

Water-The hydrologic cycle plays an essential role in the distribution of natural and anthropogenic contaminants, vectors, and pathogens in aquatic and terrestrial environments, and in determining ecological and human exposure to these contaminants. Knowledge gained from implementation of the USGS Water Science Strategy will be essential for effective implementation of this strategy. A fundamental understanding of the natural and human factors that affect water quantity, movement, and quality is required to define various sources of contaminants and pathogens, to determine their relative importance, and to characterize environmental settings that may be more vulnerable to various environmental health concerns. Many hydrologic factors influence the health of the environment and must be considered when determining the specific causes of adverse environmental health outcomes and identifying best management practices. The Environmental Health Science Strategy will coordinate closely with large USGS water quantity and quality assessment programs to make added use of their national monitoring networks, infrastructure for surveillance, and the associated datasets in interpretations of environmental health issues. Furthermore, a priority of the Environmental Health Science Strategy is to develop new tools and methodologies to identify and address emerging environmental health concerns. This includes developing methods to measure contaminants and pathogens of emerging concern in the environment, and using those methods to make initial assessments of the relative priorities. These new methods and the information they provide will be made available to Water programs for design and implementation of their systematic national monitoring and assessment activities.

\section{Environmental Health and Hazards}

Earthquakes, hurricanes, volcanic eruptions, and other natural disasters are well known for the threats they pose to human safety. USGS has helped describe the less publicized but potentially significant threats these disasters can pose to environmental health, such as the Valley Fever outbreak associated with the 1994 Northridge California earthquake and health implications of exposure to volcanic ash. More recently, USGS expertise from across the Bureau is being called upon to help assess the environmental, ecological, and human-health impacts of hurricanes, dust storms, flooding, wildfires, and other extreme events as they affect the United States. The USGS also is integrating environmental health considerations into its disaster scenarios that model and help prepare for plausible impacts of future disasters, such as the Southern California ShakeOut earthquake and ARkStorm extreme winter storm scenarios. More information is available in the article titled "Geoscientists Aid in the Aftermath of Disasters", in the magazine Earth (Plumlee, 2009).

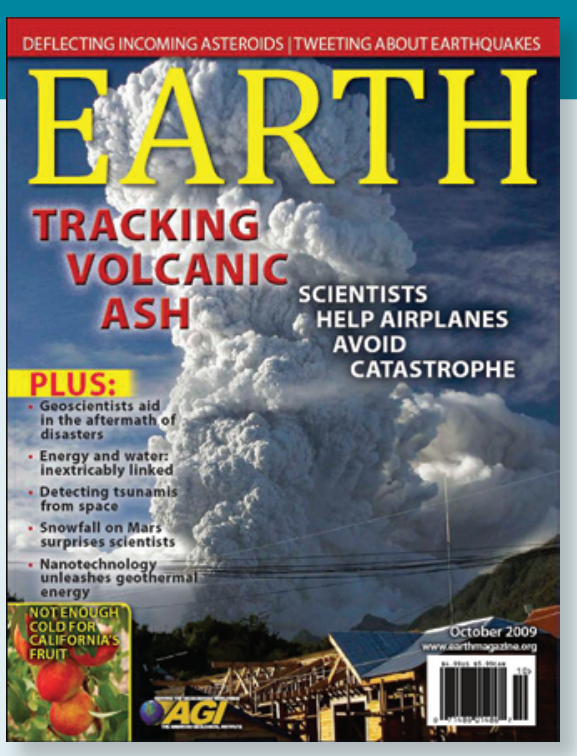




\section{Summary of Intended Outcomes}

This strategy describes how USGS will address the highest priority environmental health issues facing the Nation. The ultimate intended outcome of this science strategy is prevention and reduction of adverse impacts to the quality of the environment, the health of our living resources, and human health by providing high-quality objective environmental health science information and tools that are used by managers, regulators, other scientists, industry, and the public to make improved decisions that directly affect health outcomes. It is the responsibility of USGS to reach broadly across its scientific expertise and bring the fullest extent of its capabilities and scientific contributions to fulfill this role. It is incumbent on USGS to reach out to scientific partners to ensure that our efforts are integrated with and take full advantage of the activities of others across the broader environmental health science community. Finally it is incumbent on USGS to reach out to all stakeholders to ensure that USGS efforts are focused on the highest priority environmental health issues and that products are provided in the most timely and usable form to all those who can use them.

Although prevention is not always feasible, science to support prevention is a high priority of this strategy. The strategic science actions proposed herein will provide new tools and fundamental knowledge for managing the release, mitigation, management, and remediation of the most significant environmental contamination problems facing the Nation in the next decade. These strategic science actions also will characterize the factors that affect transmission of diseases with the goal of informing decisions to reduce the spread and adverse health outcomes of disease among free-ranging populations of aquatic and terrestrial animals, domesticated animals, and humans. Strategic science actions to enhance the understanding of the effects of exposure to combinations of contaminants and pathogens will help explain heretofore poorly understood diseases, and help to more accurately quantify the individual impacts of different disease agents on the health of aquatic and terrestrial organisms. Finally, strategic science actions to implement a coordinated Bureau-wide capability for rapidresponse to characterize the environmental impacts of disasters are intended to integrate USGS expertise in environment and wildlife health with USGS capabilities in preparation for and response to disasters, and provide that expertise to agencies with the primary responsibility for disaster response.

The actions proposed in this strategy will draw on science activities from across the Bureau including activities conducted as part of other science strategies. Similarly, the activities conducted as part of this strategy will support the activities of the other six science strategies. Collectively, these seven USGS science strategies will allow the coordination of research activities and the sharing of expertise and information, while providing a point of direct access to USGS products and expertise in environmental health science.

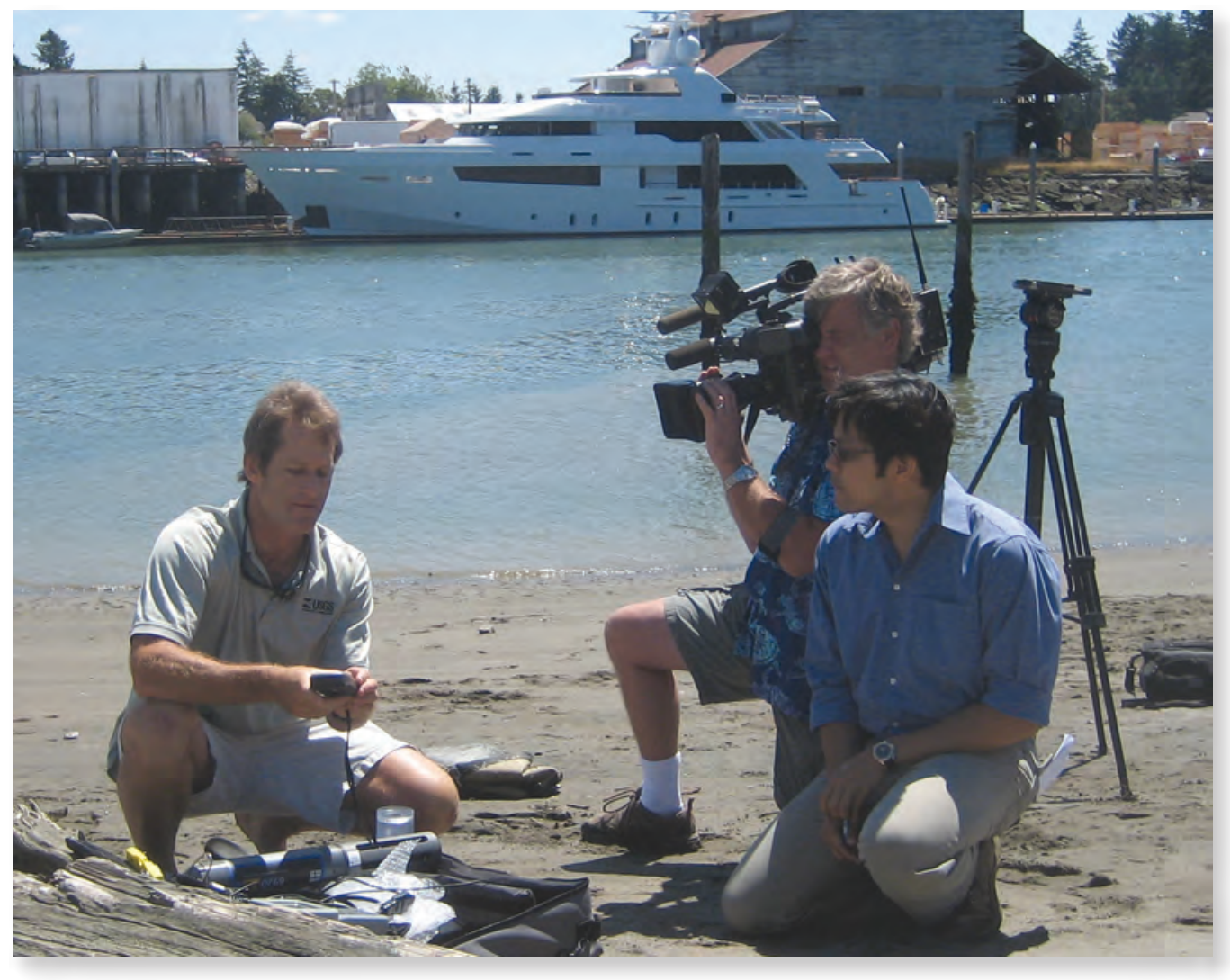

USGS scientist is interviewed by KOMO-TV (ABC, Seattle) at the Swinomish Tribal Community Center on July 21, 2008, near La Conner, Washington. The Coast Salish Nation and Swinomish Indian Tribal Community, in partnership with the U.S. Geological Survey. has examined the coastal waters of the Salish Sea providing a new strategy that blends western science and Coast Salish culture to study water-quality and its effects on environmental health. Photograph by John Clemens, USGS. 


\section{Acknowledgments}

The authors would like to recognize John Lamoreux for his work as executive secretary of the Science Strategy Planning Team responsible for preparing this strategy, and Eric A. Morrissey for the preparation of illustrations in this report. The report was improved by reviews from the following USGS scientists, Collin A. Eagles-Smith, James F. Fairchild, Milton Friend, Denis R. LeBlanc, William H. Orem, Frank Panek, John M. Pearce, Barnett A. Rattner, Roger Sayre, and William G. Wilber.

We also would like to thank the scientists from many Federal agencies who provided input to this strategy for their agencies.

USGS scientist installing ocean chemistry monitoring equipment on Sombrero Reef, Florida Keys, July 9, 2009. Photograph by Ilsa B. Kuffner, USGS. 


\section{References Cited}

American Veterinary Medical Association, 2008, One healthA new professional imperative: Schaumburg, Illinois, Final Report, One Health Initiative Task Force, 71 p.

Animal and Plant Health Inspection Service and Centers for Disease Control and Prevention, 2011, National Select Agent Registry, accessed June 26, 2011, at http://www. selectagents.gov/select $\% 20$ agents $\% 20$ and $\% 20$ Toxins $\% 20$ list.html.

Birnbaum, L.S., 2012, Environmental chemicals-Evaluating low-dose effects: Environmental Health Perspectives, v. 120 , no. 4 , p. A143-A144.

Blazer, V.S., Iwanowicz, L.R., Starliper, C.E., Iwanowicz, D.D., Barbash, P., Hedrick, J.D., Reeser, S.J., Mullican, J.E., Zaugg, S.D., Burkhardt, M.R., and Kelble, J., 2010, Mortality of centrarchid fishes in the Potomac drainage-Survey results and overview of potential contributing factors: Journal of Aquatic Animal Health, v. 22, no. 3, p. 190-218.

Boyles, J.G., Cryan, P.M., McCracken, G.F., and Kunz, T.H., 2011, Economic importance of bats in agriculture: Science, v. 332 , no. 6025 , p. $41-42$.

Brian, J.V., Harris, C.A., Scholze, Martin, Backhaus, Thomas, Booy, Petra, Lamoree, Marja, Pojana, Giulio, Jonkers, Niels, Runnalls, Tamsin, Bonfà, Angela, Marcomini, Antonio, and Sumpter, J.P., 2005, Accurate prediction of the response of freshwater fish to a mixture of estrogenic chemicals: Environmental Health Perspectives, v. 113, no. 6, p. 721-728.

Buxton, H.T., Griffin, D.W., Pierce, B.S., 2008, Earth science and public health-Proceedings of the second national conference on USGS health-related research: U.S. Geological Survey Scientific Investigations Report 2008-5022, 47 p. (Also available at http://pubs.usgs.gov/sir/2008/5022/pdf/ sir2008-5022.pdf.)

Diamanti-Kandarakis, Evanthia, Bourguignon, Jean-Pierre, Giudice, L.C., Hauser, Russ, Prins, G.S., Soto, A.M., Zoeller, R.T., and Gore, A.C., 2009, Endocrine-disrupting chemicals-An Endocrine Society scientific statement: Endocrine Reviews, v. 30, no. 4, p. 293-342.

Feingold, B.J., Vogosen, Leora, Davis, Meghan, Leibler, Jessica, Peterson, Amy, Silbergeld, E.K. 2010, A niche for infectious disease in environmental health-Rethinking the toxicological paradigm: Environmental Health Perspectives, v. 118 , no. 8 , p. 1165-1172.

Friend, Milton, 2006, Disease emergence and resurgence-The wildlife-human connection: U.S. Geological Survey Circular 1285, 108 p. (Also available at http://137.227.242.129/publications/disease_emergence/.)
Government Accountability Office, 2011, Antibiotic resistance-Data gaps will remain despite HHS taking steps to improve monitoring: Washington D.C., Government Accountability Office report GAO-11-406, 66 p.

Hinck, J.E., Blazer, V.S., Schmitt, C.J., Papoulias, D.M., and Tillitt, D.E., 2009, Widespread occurrence of intersex in black basses (Micropterus spp.) from U.S. rivers, 19952004: Aquatic Toxicology, v. 95, no. 1, p. 60-70.

Institute of Medicine, 2011, Roundtable on Environment, Health Sciences, Research, and Medicine, accessed June 15, 2011, at http://www.iom.edu/Activities/Environment/ EnvironmentalHealthRT.aspx.

Jerolmack, Colin, 2012, Who's worried about turkeys? How 'organisational silos' impede zoonotic disease surveillance: Sociology of Health and Illness, doi: 10.1111/j.1467-9566.2012.01501.x, accessed October 1, 2012, at http://onlinelibrary.wiley.com/doi/10.1111/j.14679566.2012.01501.x/abstract.

Johnson, P.T.J., Chase, J.M., Dosch, K.L., Hartson, R.B., Gross, J.A., Larson, D.J., Sutherland, D.R., and Carpenter, S.R., 2007, Aquatic eutrophication promotes pathogenic infection in amphibians: Proceedings of the National Academy of Sciences, U.S.A., v. 104, no. 40, p. 15781-15786.

Jones, K.E., Patel, N.G., Levy, M.A., Storeygard, Adam, Balk, Deborah, Gittleman, J.L., and Daszak, Peter, 2008, Global trends in emerging infectious diseases: Nature, v. 451, no. 7181, p. 990-993.

Kidd, K.A., Blanchfield, P.J., Mills, K.H., Palace, V.P., Evans, R.E., Lazorchak, J.M., and Flick, R.W., 2007, Collapse of a fish population after exposure to a synthetic estrogen: Proceedings of the National Academy of Sciences, U.S.A., v. 104, no. 21, p. 8897-8901.

Kolpin, D.W., Furlong, E.T., Meyer, M.T., Thurman, E.M., Zaugg, S.D., Barber, L.B., and Buxton, H.T., 2002, Pharmaceuticals, hormones, and other organic wastewater contaminants in U.S. streams 1999-2000 - A national reconnaissance: Environmental Science and Technology, v. 36, no. 6, p. $1202-1211$.

Lederberg, Joshua, Shope, R.E., and Oaks, S.C., Jr., eds., 1992, Emerging infections-Microbial threats to health in the United States: Washington, D.C., Institute of Medicine, National Academy of Sciences, 294 p.

McKinney, C.W., Loftin, K.A., Meyer, M.T., Davis, J.G., Pruden, A., 2010, tet and sul antibiotic resistance genes in livestock lagoons of various operation type, configuration, and antibiotic occurrence: Environmental Science and Technology, v. 44, no. 16, p. 6102-6109. 
McNutt, M.K., 2010, Strategic science planning and high-level budget development - Charge to Science Strategy Planning Team (SSPT): Director's memorandum to USGS staff, January 26, 2010. (Also available at http://www.usgs.gov/ start_with_science/docs/ss_charter.pdf.)

Morens, D.M., Folkers, G.K., and Fauci, A.S., 2008, Emerging infections-A perpetual challenge: Lancet Infectious Diseases, v. 8, no. 11, p. 710-719.

National Institute of Environmental Health Sciences, 2006, NIEHS 2006-2011 Strategic Plan-New frontiers in environmental sciences and human health: U.S. Department of Health and Human Services, NIH Publication 2006-218, $24 \mathrm{p}$.

National Science and Technology Council, 2008, National nanotechnology initiative - Strategy for nanotechnologyrelated environmental, health, and safety research: Washington, D.C., Subcommittee on Nanoscale Science, Engineering, and Technology, Committee on Technology, 90 p.

National Research Council, 2007, Earth materials and health, research priorities for earth science and public health: Washington, D.C., National Academies Press, 176 p.

Office of Science and Technology Policy, 2011, National Science and Technology Council Committee on Environment, Natural Resources, and Sustainability, accessed June 15, 2011, at http://www.whitehouse.gov/administration/eop/ ostp/nstc/committees/cenrs.

Paine, R.T., Tegner, M.J., and Johnson, E.A., 1998, Compounded perturbations yield ecological surprises: Ecosystems, v. 1 , no. 6 , p. 535-545.

Phillips, P.J., Smith, S.G., Kolpin, D.W., Zaugg, S.D., Buxton, H.T., Furlong, E.T., Esposito, Kathleen, and Stinson, Beverley, 2010, Pharmaceutical formulation facilities as sources of opioids and other pharmaceuticals to wastewater treatment plant effluents: Environmental Science and Technology, v. 44, no. 13, p. 4910-4916.

Plumlee, G.S., 2009, Report from ground zero-How geoscientists aid in the aftermath of environmental disasters: Earth, v. 54, no. 10, p. 38-47.

President's Cancer Panel, 2010, Reducing environmental cancer risk-What we can do now: 2008-2009 Annual Report of the President's Cancer Panel, U.S. Department of Health and Human Services, National Institutes of Health, National Cancer Institute, 147 p. plus appendixes, accessed August 8, 2011, at http://deainfo.nci.nih.gov/advisory/pcp/ annualReports/pcp08-09rpt/PCP_Report_08-09_508.pdf.
Prüss-Ütün, A., and Corvalán, C., 2006, Preventing disease through healthy environments - Towards an estimate of the environmental burden of disease: Geneva, Switzerland, World Health Organization, 104 p.

Stahl, R.G., Hooper, M.J., Balbus, J.M., Clements, W., Fritz, A., Gouin, T., Helm, R., Hickey, C., Landis, W., and Moe, J.S., 2013, The influence of global climate change on the scientific foundations and applications of environmental toxicology and chemistry-Introduction to a SETAC international workshop: Environmental Toxicology and Chemistry, v. 32, no. 1, p. 13-19. (Also available at http:// onlinelibrary.wiley.com/doi/10.1002/etc.2037/abstract.)

Stone, W.W., Gilliom, R.J., and Crawford, C.G. 2008, Watershed Regressions for Pesticides (WARP) for predicting annual maximum and maximum moving-average concentrations of atrazine in streams: U.S. Geological Survey OpenFile Report 2008-1186, 19 p. (Also available at http://pubs. usgs.gov/of/2008/1186/pdf/ofr2008-1186.pdf.)

Tillitt, D.E., Papoulias, D.M., Whyte, J.J., and Richter, C.A., 2010, Atrazine reduces reproduction in fathead minnow (Pimephales promelas): Aquatic Toxicology, v. 99, no. 2, p. 149-159.

U.S. Department of Agriculture, 2003, Economic impact of West Nile Virus on the Colorado and Nebraska equine industries: 2002. Info Sheet \#N394.0403, April 2003, accessed March 22, 2012, at http://www.aphis.usda.gov/ animal_health/nahms/equine/downloads/wnv2002_CO_ NB.pdf.

U.S. Department of Agriculture, 2010, Colony collapse disorder progress report: Washington, D.C., U.S. Department of Agriculture, Agricultural Research Service, 7 p.

U.S. Department of Health and Human Services, 2009, National health security strategy of the United States of America: Washington, D.C., U.S. Department of Health and Human Services, 43 p., accessed July 29, 2011 at http://www.phe.gov/Preparedness/planning/authority/nhss/ strategy/Documents/nhss-final.pdf.

U.S. Department of Homeland Security, 2008, National response framework: Washington, D.C., U.S. Department of Homeland Security [FEMA publication P-682], 82 p., accessed July 29, 2011, at http://www.fema.gov/pdf/ emergency/nrf/nrf-core.pdf.

U.S. Department of the Interior, 2010, Strategic Plan for Fiscal Years 2011-2016: Washington, D.C., U.S. Department of the Interior, 44 p., accessed August 8, 2011, at http://www. doi.gov/pmb/ppp/strategic-planning.cfm. 
U.S. Environmental Protection Agency, 2008, 2008 report on the environment: Washington, D.C., U.S. Environmental Protection Agency, National Center for Environmental Assessment, EPA/600/R-07/045F, 366 p., accessed August 8, 2011, at $h$ ttp://www.epa.gov/roe/.

U.S. Environmental Protection Agency, 2010, Drinking water strategy: World Wide Web accessed July 29, 2011, at http:// water.epa.gov/lawsregs/rulesregs/sdwa/dwstrategy/index. cfm.

U.S. Geological Survey, 2007, Facing tomorrow's challenges-U.S. Geological Survey science in the decade 2007-2017: U.S. Geological Survey Circular 1309, 69 p. (Also available at http://pubs.usgs.gov/circ/2007/1309/.)

U.S. Geological Survey, 2012a, USGS oil spill response: Accessed July 12, 2012, at http://www.usgs.gov/oilspill/.

U.S. Geological Survey, 2012b, USGS Multi-Hazards Demonstration Project: Accessed August 15, 2012, at http:// urbanearth.gps.caltech.edu/about/.

U.S. Geological Survey, 2012c, GeoHealth Newsletter-The U.S. Geological Survey's environmental health newsletter, accessed May 16, 2012, at http://health.usgs.gov/geohealth/.
U.S. Geological Survey, 2011, USGS CoreCast-It's natural science from the inside out: Accessed June 15, 2011, at http://www.usgs.gov/corecast/.

The White House, 2010, National security strategy: Washington, D.C., The White House, 52 p., accessed July 25, 2011, at http://www.whitehouse.gov/sites/default/files/rss_viewer/ national_security_strategy.pdf.

Vandenberg, L.N., Colborn, T., Hayes, T.B., Heindel, J.J., Jacobs, D.R., Lee, D., Shioda, T., Soto, A.M., vom Saal, F.S., Welshons, W.V., Zoeller, R.T., and Myers, J.P., 2012, Hormones and endocrine-disrupting chemicalsLow-dose effects and nonmonotonic dose responses: Endocrine Reviews, v. 33, no. 3, p. 378-455.

Woolhouse, M.E.J., and Gowtage-Sequeria, Sonya, 2005, Host range and emerging and reemerging pathogens: Emerging Infectious Diseases, v. 11, no. 12, p. 1842-1847.

World Health Organization, 2011, About the One Health Initiative: accessed September 15, 2011, at http://www. onehealthinitiative.com/about.php.

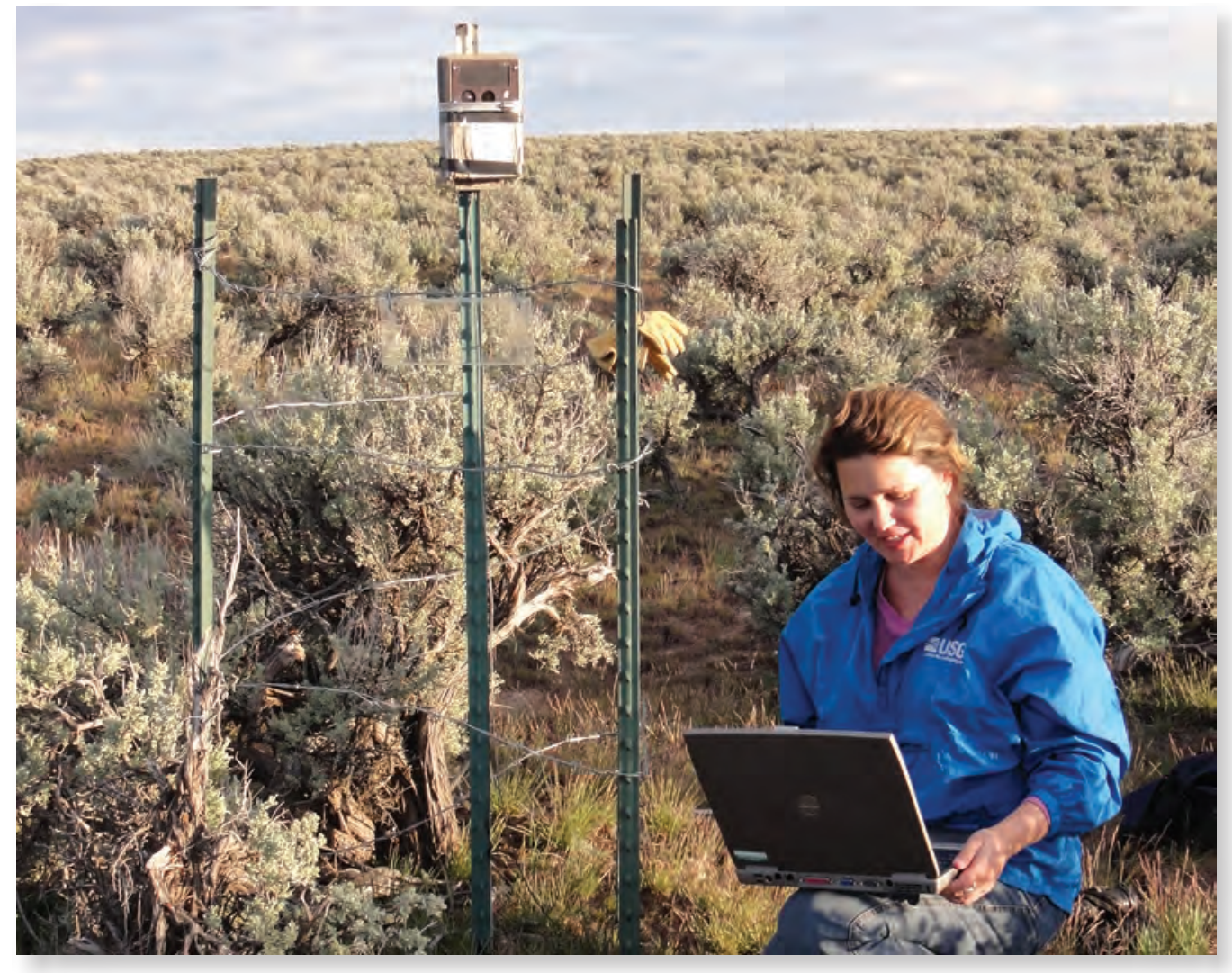

USGS scientist downloads data from phenocam located in Idaho. The phenocam takes a picture daily and that data is used to help track phenological changes (the timing and vigor of seasonal biological events). The data from the phenocam is used (with other data) to gain a better understanding of vegetation changes over the entire ecoregion. Photograph by USGS. 


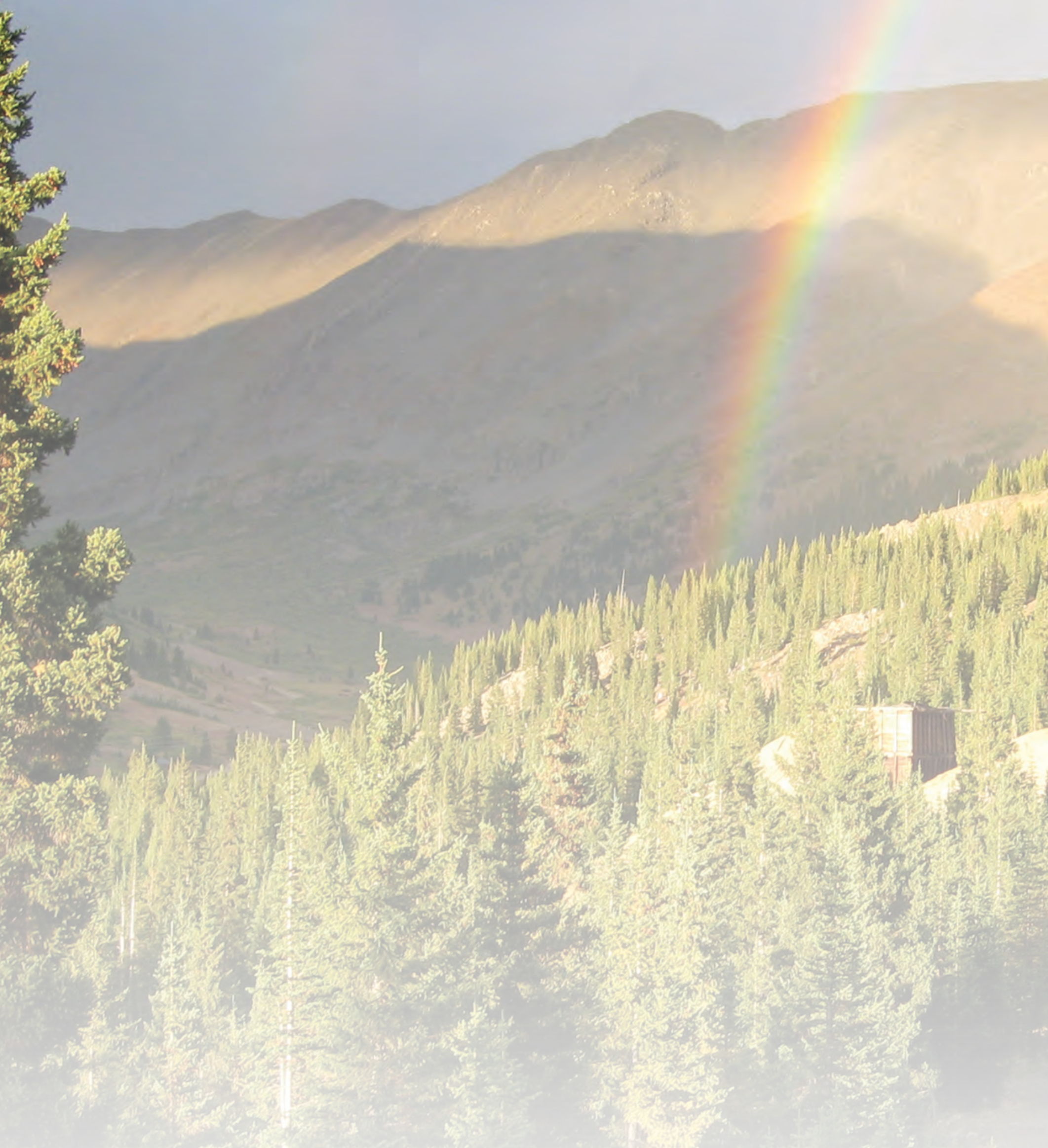




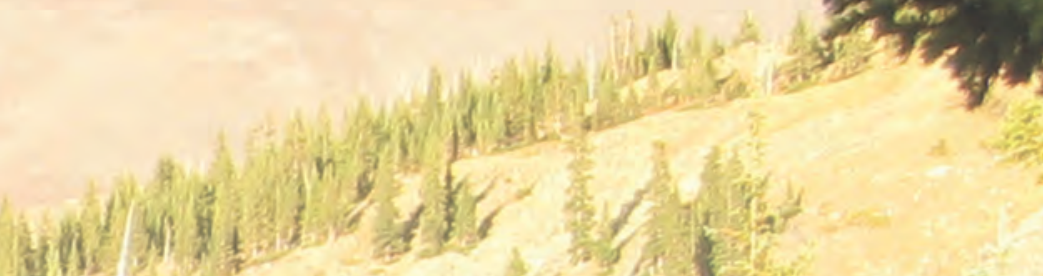

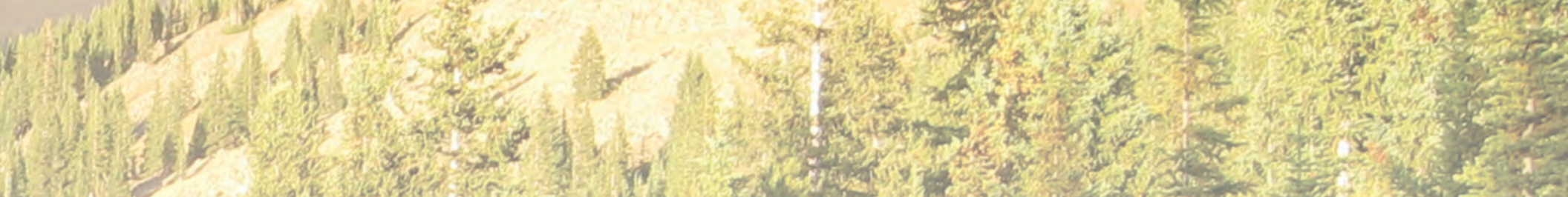
15.

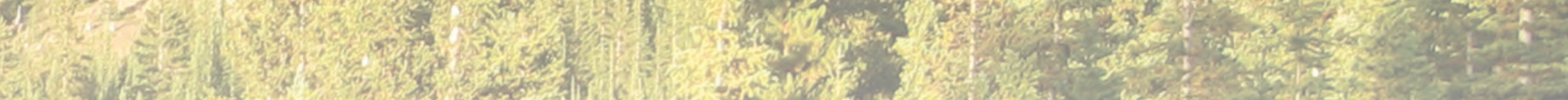

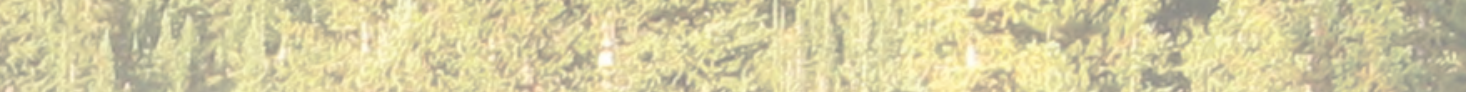
S27.

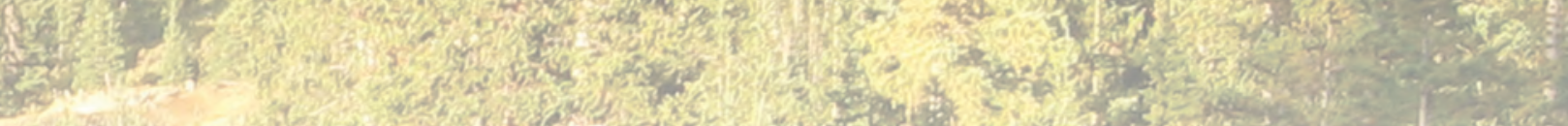
(2) (1) 2.

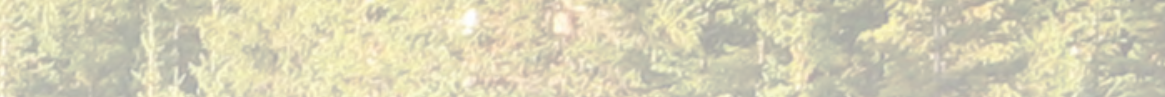

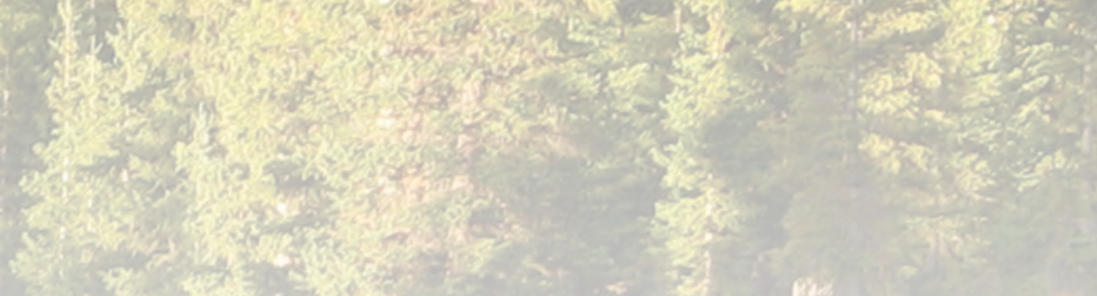



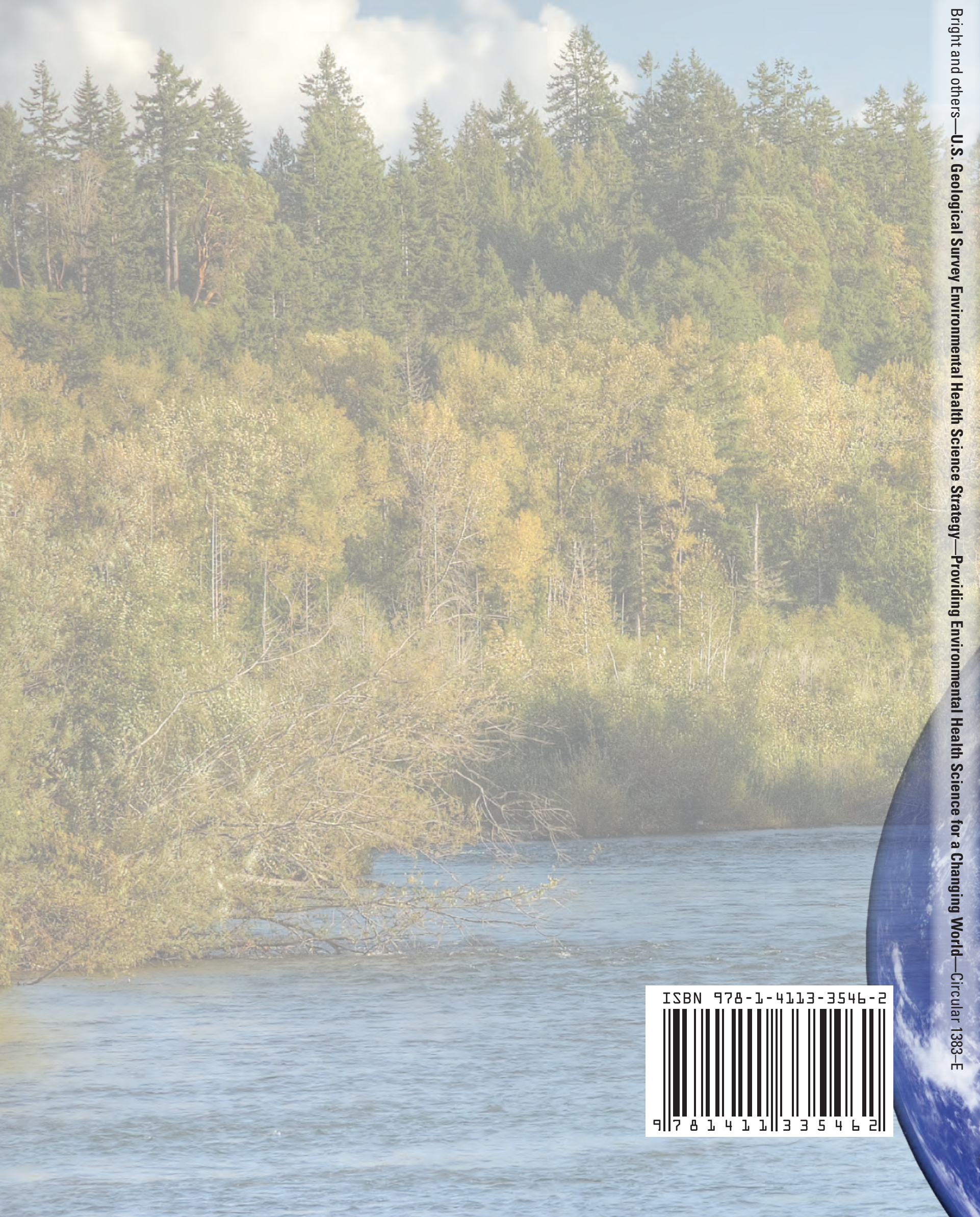